\title{
Adriano Marques de Almeida
}

Avaliação da função aeróbia em atletas profissionais de futebol de campo submetidos a reconstrução do ligamento cruzado anterior

Tese apresentada à Faculdade de Medicina da Universidade de São Paulo para obtenção do título de Doutor em Ciências

Programa de Ortopedia e Traumatologia

Orientador: Dr. André Pedrinelli

São Paulo 
Dados Internacionais de Catalogação na Publicação (CIP)

Preparada pela Biblioteca da

Faculdade de Medicina da Universidade de São Paulo

Creprodução autorizada pelo autor

Almeida, Adriano Marques de

Avaliação da função aeróbia em atletas profissionais de futebol de campo submetidos a reconstrução do ligamento cruzado anterior / Adriano

Marques Almeida -- São Paulo, 2017.

Tese(doutorado)--Faculdade de Medicina da Universidade de São Paulo.

Programa de Ortopedia e Traumatologia.

Orientador: André Pedrinelli.

Descritores: 1.Ligamento cruzado anterior 2.Reconstrução do ligamento cruzado anterior 3.Joelho 4.Ferimentos e Lesões 5.Volta ao esporte 6.Reabilitação 7.Consumo de oxigênio

USP/FM/DBD-156/17 
Dedicatória 
À minha querida esposa, Leila, por seu apoio e compreensão.

À minha mãe, Elizete (in memoriam), e ao meu pai, Adiel. 
Agradecimentos 


\section{AGRADECIMENTOS}

Aos Profs. Drs. Gilberto Luís Camanho, Olavo Pires de Camargo e Tarcísio E. P. De Barros Filho, pela oportunidade de realizar este trabalho no Instituto de Ortopedia e Traumatologia do Hospital das Clínicas da Faculdade de Medicina da Universidade de São Paulo.

Ao Prof. Dr. Arnaldo José Hernandez, pelos valiosos ensinamentos neste trabalho e na minha carreira.

Ao Dr. André Pedrinelli, orientador desta tese, pelas valiosas contribuições a este trabalho.

Ao Dr. Paulo Roberto Santos-Silva, por sua inestimável contribuição, sem a qual esta tese não teria sido possível.

À Profa. Dra. Júlia Maria D’Andrea Greve, pelo apoio e contribuições a este projeto.

Aos Drs. Marco Antônio Ambrósio, Júlio César C. Nardelli, Tiago Lazaretti Fernandes, pela amizade e colaboração nas diferentes etapas deste projeto.

Aos fisioterapeutas Felix Andrusaitis e Rachel Luz Soares pela reabilitação dos pacientes.

Aos Srs. e Sras. Marcelo Pedro, André de Oliveira Silva, Marcus Vinicius Grecco, Mara Silvia Afonso, Sara Novak, José Bussamra Filho e Adriana da Silva Cerqueira pelo excelente trabalho no Laboratório de Estudos do Movimento, local onde foi realizado este trabalho.

Às Sras. Tânia Borges e Rosana Moreno da Costa pela dedicação à secretaria do programa de pós-graduação e auxílio neste projeto. 
A todos os pacientes que participaram deste projeto, pela colaboração com a ciência médica. 
“Aquilo que não pode ser medido, não pode ser melhorado"

Sir William Thomsom (Lord Kelvin) 
Normalização Adotada 


\section{NORMALIZAÇÃO ADOTADA}

Esta tese está de acordo com as seguintes normas, em vigor no momento desta publicação:

Referências: adaptado de International Committee of Medical Journals Editors (Vancouver).

Universidade de São Paulo. Faculdade de Medicina. Divisão de Biblioteca e Documentação. Guia de apresentação de dissertações, teses e monografias. Elaborado por Anneliese Carneiro da Cunha, Maria Julia de A. L. Freddi, Maria F. Crestana, Marinalva de Souza Aragão, Suely Campos Cardoso, Valéria Vilhena. 3a ed. São Paulo: Divisão de Biblioteca e Documentação; 2011.

Abreviaturas dos títulos dos periódicos de acordo com List of Journals Indexed in Index Medicus.

Resolução $n^{\circ} 466$ do Conselho Nacional de Saúde do Brasil, de 12 de dezembro de 2012, que regulamenta a pesquisa envolvendo seres humanos no Brasil.

Nomes das estruturas anatômicas baseados na Terminologia Anatômica: Terminologia Anatômica Internacional, Editora Manole, $1^{\text {a }}$ ed. São Paulo, 2001.

Vocabulário ortográfico da língua portuguesa, $5^{a}$ edição, 2009, elaborado pela Academia Brasileira de Letras, em consonância com o Acordo Ortográfico da Língua Portuguesa, promulgado pelo decreto n 6583/2008.

A análise estatística foi realizada com a colaboração de Henry Dan Kiyomoto. 
Sumário 


\section{SUMÁRIO}

Lista de abreviaturas, símbolos e siglas

Lista de figuras

Lista de tabelas

Lista de gráficos

Resumo

Abstract

1 INTRODUÇÃO .................................................................................. 2

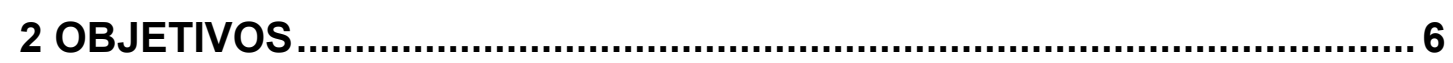

3 REVISÃO DA LITERATURA ............................................................. 8

3.1 Reconstrução do LCA em jogadores de futebol ............................. 8

3.2 Retorno ao esporte após a reconstrução do LCA ......................... 11

$3.3 \mathrm{VO}_{2 \max }$ no futebol de alto rendimento ................................... 13

3.4 Destreinamento em jogadores de futebol ................................ 18

3.5 Economia de corrida................................................... 19

3.6 Teste isocinético computadorizado...................................... 20

3.7 Análise da composição corporal por bioimpedância ..................... 22

3.8 Questionários de função do joelho ...................................... 24

3.9 Relação entre fadiga e risco de lesão ligamentar do joelho ............ 25

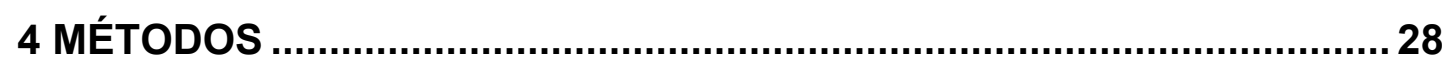

4.1 Aprovação da comissão de ética e consentimento informado.........28

4.2 Casuística ................................................................... 29

4.2.1 Critérios de inclusão.................................................. 29

4.2.2 Critérios de exclusão............................................ 30

4.3 Técnica cirúrgica para reconstrução do LCA .............................. 31

4.4 Programa de intervenção fisioterápica ................................... 38

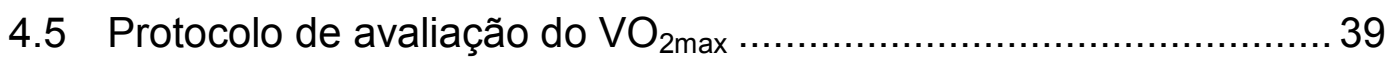

4.6 Análise de gases expirados (ergoespirometria) ......................... 41

4.7 Parâmetros avaliados .................................................... 44

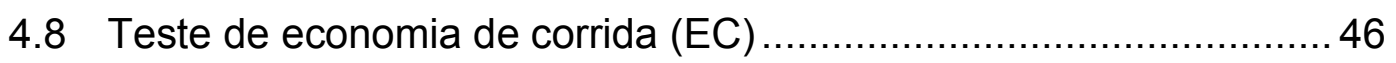

4.9 Teste isocinético computadorizado.................................... 47

4.10 Avaliação da composição corporal por bioimpedância .................. 50

4.11 Questionários de função do joelho ....................................... 52 
4.12 Cálculo da amostra ............................................................... 53

4.13 Análise estatística............................................................. 54

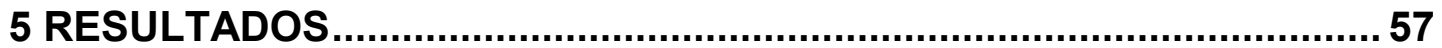

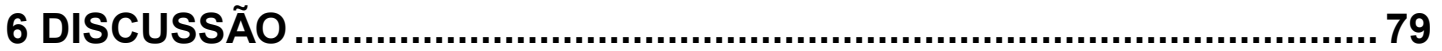

6.1 Consumo máximo de oxigênio $\left(\mathrm{VO}_{2 \max }\right)$ após $\mathrm{RLCA} \ldots \ldots \ldots \ldots \ldots \ldots . . . \ldots 79$

6.2 Pico de velocidade de corrida no $\mathrm{VO}_{2} \max \left(\mathrm{VVO}_{2 \max }\right) \ldots \ldots \ldots \ldots \ldots . . . . . . . . .82$

6.3 Limiares ventilatórios um (LV1) e dois (LV2) ............................... 83

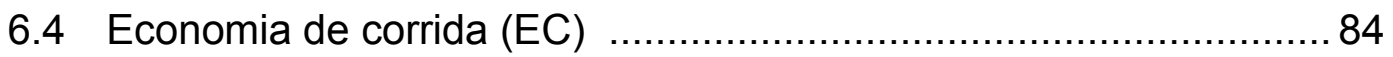

6.5 Questionários Lysholm e IKDC ............................................ 86

6.6 Avaliação isocinética computadorizada dos músculos flexores e

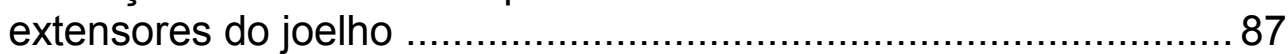

6.7 Avaliação da composição corporal por bioimpedância ................... 89

6.8 Fadiga e risco de lesão do LCA ........................................... 90

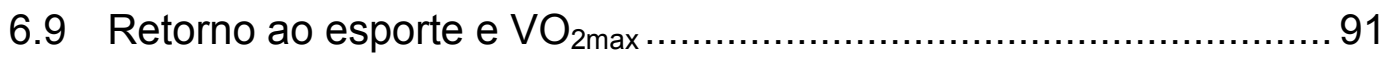

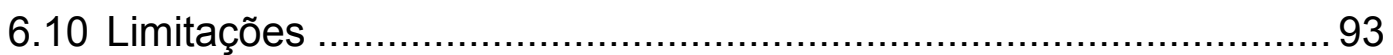

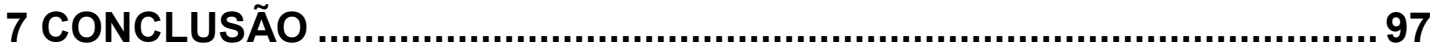

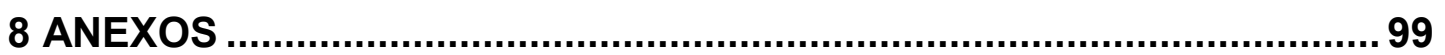

9 REFERÊNCIAS .............................................................................. 115

Apêndice 
Listas 


\section{ABREVIATURAS, SÍMBOLOS E SIGLAS}

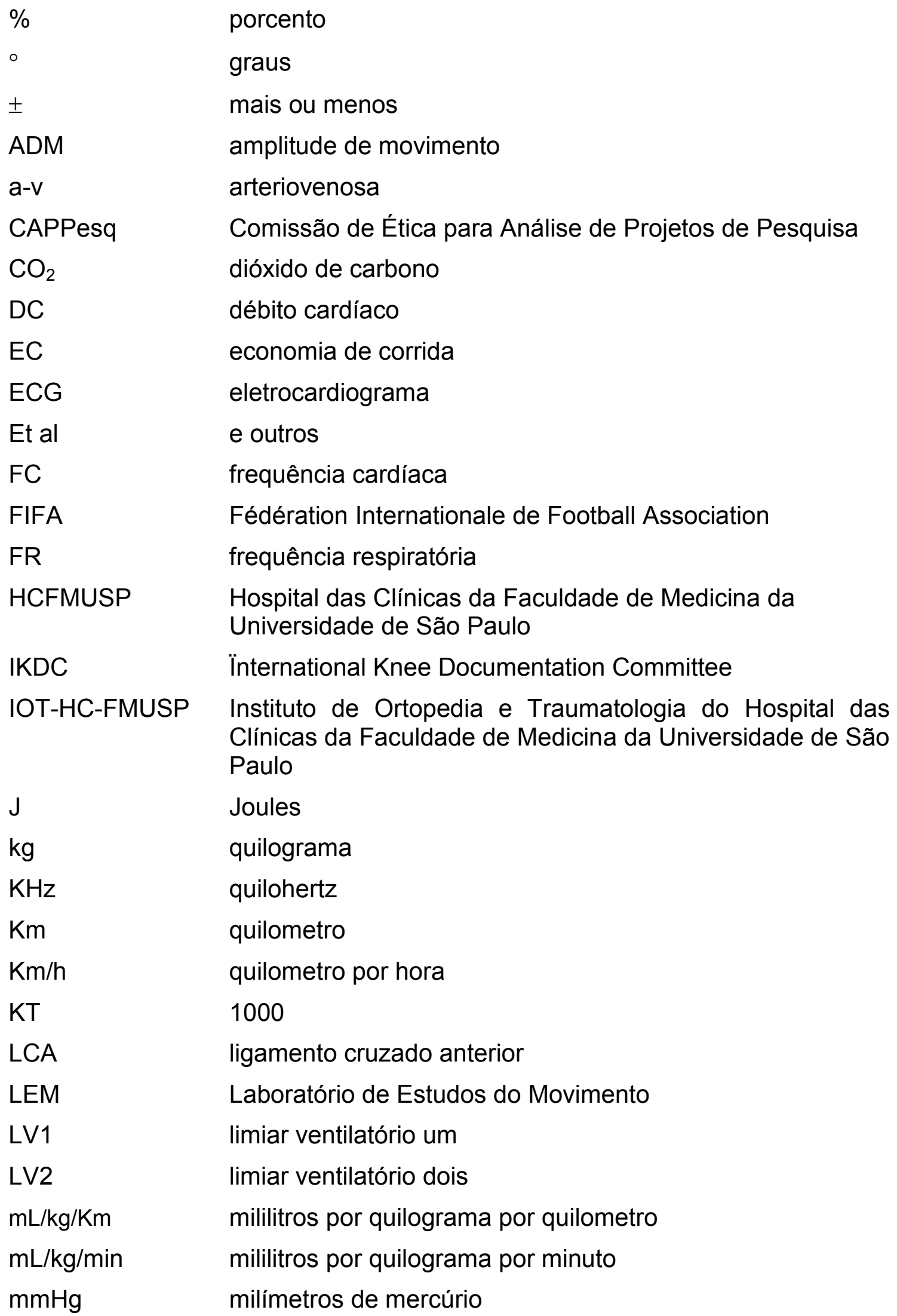




\begin{tabular}{|c|c|}
\hline N.m & Newton metro \\
\hline $\mathrm{N}_{2}$ & nitrogênio \\
\hline$n^{\circ}$ & número \\
\hline$\%$ & graus por segundo \\
\hline $\mathrm{O}_{2}$ & oxigênio \\
\hline$P$ & valor de $p$ \\
\hline PA & pressão arterial \\
\hline $\mathrm{PETCO}_{2}$ & pressão expirada final de dióxido de carbono \\
\hline $\mathrm{PETO}_{2}$ & pressão expirada final de oxigênio \\
\hline $\mathrm{PO}_{2}$ & pulso de oxigênio \\
\hline QR & quociente respiratório \\
\hline RLCA & reconstrução do ligamento cruzado anterior \\
\hline RSSA & repeated-shuttle sprint ability \\
\hline STG & semitendinoso e gracilis \\
\hline SUS & Sistema Único de Saúde \\
\hline US\$ & dólares norteamericanos \\
\hline USP & Universidade de São Paulo \\
\hline VC & volume corrente \\
\hline $\mathrm{VCO}_{2}$ & comumo de dióxido de carbono \\
\hline$V_{E}$ & ventilação pulmonar \\
\hline $\mathrm{V}_{\mathrm{E}} / \mathrm{NCO}_{2}$ & equivalente ventilatório de dióxido de carbono \\
\hline $\mathrm{V}_{\mathrm{E}} / \mathrm{VO}_{2}$ & equivalente ventilatório de oxigênio \\
\hline vLV1 & velocidade no limiar ventilatório um \\
\hline vLV2 & velocidade no limiar ventilatório dois \\
\hline $\mathrm{VO}_{2}$ & consumo de oxigênio \\
\hline $\mathrm{VO}_{2 \max }$ & consumo máximo de oxigênio \\
\hline VS & volume sistólico \\
\hline $\mathrm{vVO}_{2 \max }$ & velocidade durante o consumo máximo de oxigênio \\
\hline W & Watts \\
\hline
\end{tabular}




\section{LISTAS DE FIGURAS}

Figura 1 - Preparação do enxerto com tendões semitendíneo e grácil ...33

Figura 2 - Imagem de artroscopia do joelho para reconstrução do LCA . 35

Figura 3 - Imagem de artroscopia do joelho demonstrando passagem do enxerto para reconstrução do LCA

Figura 4 - Radiografias de joelho em posição anteroposterior e perfil após reconstrução do LCA

Figura 5 - Fotografia da esteira $h / p / \operatorname{cosmos}{ }^{\circledR}$ utilizada para os testes e equipamento de análise de troca gasosa

Figura 6 - Fotografia de atleta durante o teste ergoespirométrico

Figura 7 - Imagem obtida da tela do monitor ao final do teste de ergoespirometria na esteira......

Figura 8 - Dinamômetro isocinético Biodex System 3 Pro® utilizado no estudo

Figura 9 - $\quad$ Analisador de composição corporal InBody ${ }^{\circledR} 230$ utilizado no estudo 


\section{LISTAS DE TABELAS}

Tabela 1 - Análise da composição corporal dos atletas com lesão do LCA nos momentos pré-operatório e pós-operatório e nos atletas do grupo controle

Tabela 2 - Resultados do consumo máximo de oxigênio $\left(\mathrm{VO}_{2 \mathrm{max}}\right)$ e limiares ventilatórios um (LV1) e dois (LV2) obtidos no teste ergoespirométrico em esteira

Tabela 3 - Resultados dos questionários Lysholm e IKDC no préoperatório, após reconstrução e no grupo controle (média \pm desvio padrão) 68

Tabela 4 - Resultados de dinamometria isocinética para os músculos extensores do joelho a $60 \%$ s.

Tabela 5 - Resultados de dinamometria isocinética para os músculos flexores do joelho a $60 \%$

Tabela 6 - Resultados de dinamometria isocinética para os músculos extensores do joelho a $240 \%$ s.

Tabela 7 - Resultados de dinamometria isocinética para os músculos flexores do joelho a $240 \%$ s

Tabela 8 - Correlação entre os resultados dos escores funcionais e dos questionários Lysholm e IKDC 


\section{LISTA DE GRÁFICOS}

Gráfico 1 - Consumo máximo de oxigênio $\left(\mathrm{VO}_{2 \max }\right)$ nos grupos avaliados

Gráfico 2 - Velocidade no $\mathrm{VO}_{2 \max }\left(\mathrm{VVO}_{2 \max }\right)$ nos grupos avaliados. 61

Gráfico 3 - Limiar ventilatório dois (LV2), ou ponto de compensação respiratória, nos grupos avaliados

Gráfico 4 - Velocidade no LV2 (vLV2) nos grupos avaliados 64

Gráfico 5 - Limiar ventilatório um (LV1), ou limiar anaeróbio, nos grupos avaliados

Gráfico 6 - Velocidade no LV1 (vLV1) nos grupos avaliados 65

Gráfico 7 - Composição do $\mathrm{VO}_{2 \max }$ nos diferentes grupos 65

Gráfico 8 - Economia de corrida (EC) nos grupos avaliados 67

Gráfico 9 - Resultados do questionário IKDC nos grupos avaliados. 67

Gráfico 10 - Resultados do questionário Lysholm nos grupos avaliados 69

Gráfico 11 - Distribuição dos resultados categorizados do questionário Lysholm nos grupos avaliados (em número de indivíduos).....69 
Almeida AM. Avaliação da função aeróbia em atletas profissionais de futebol de campo submetidos a reconstrução do ligamento cruzado anterior [tese]. São Paulo: Faculdade de Medicina, Universidade de São Paulo; 2017.

INTRODUÇÃO: A lesão do ligamento cruzado anterior (LCA) é considerada uma lesão grave e pode afetar a carreira de um jogador de futebol profissional. O tratamento cirúrgico é frequentemente necessário para o tratamento da instabilidade. Embora a reconstrução do LCA seja considerada um procedimento eficaz em restaurar a estabilidade articular, a literatura mostra que apenas $55 \%$ dos atletas retornam à prática de esportes competitivos após a cirurgia. Jogadores de futebol profissional dependem de habilidades técnicas, táticas e físicas, como boa função do joelho e capacidade aeróbia. O objetivo deste trabalho é avaliar a capacidade aeróbia em jogadores profissionais de futebol de campo com lesão do LCA e após seis meses de reabilitação pósoperatória. MÉTODOS: Vinte jogadores profissionais de futebol de campo com lesão do LCA foram submetidos a reconstrução do LCA com tendões flexores autólogos e foram comparados com 20 jogadores profissionais de futebol de campo em atividade, sem histórico de lesão no joelho. Avaliamos a capacidade aeróbia máxima pelo consumo máximo de oxigênio $\left(\mathrm{VO}_{2 \max }\right)$ e submáxima pelos limiares ventilatórios (LV1 e LV2), avaliados por ergoespirometria em esteira utilizando o protocolo de Heck modificado. Os testes foram realizados no pré-operatório e aos seis meses de pós-operatório e os resultados comparados ao grupo controle de jogadores profissionais em plena atividade. Também realizamos questionários de função subjetiva do joelho (Lysholm e IKDC), dinamometria isocinética computadorizada e avaliação da composição corporal por bioimpedância. RESULTADOS: No grupo com lesão do LCA a média da idade foi de 21,7 anos, enquanto no grupo controle foi de 22,1 anos $(p=0,99)$. O intervalo de tempo a lesão e a cirurgia foi, em média, cinco meses. No pré-operatório, o $\mathrm{VO}_{2 \max }$, em $\mathrm{mL} / \mathrm{kg} / \mathrm{min}$, foi em média \pm desvio padrão de $45,2 \pm 4,3$, aos seis meses de pós-operatório 48,9 $\pm 3,8$ ( $p<0,001)$ e no grupo controle 56,9 $\pm 4,2$ ( $p<0,001$ comparado ao pré-operatório e pós-operatório). A porcentagem de gordura corporal, em média \pm desvio padrão, no pré-operatório foi de $14,7 \pm 3,7$, no pós-operatório $14,9 \pm 5,4$ e no grupo controle $12,8 \pm 4$, sem diferença estatisticamente significativa entre os grupos. Os resultados do questionário Lysholm no pré-operatório, pós-operatório e no grupo controle foram, em média, $77,25,94,12$ e 97,5 ( $p<0,05$ em todas as comparações) e do questionário IKDC subjetivo foram 59,46, 87,75 e 97,28 ( $p<0,001$ em todas as comparações). $O$ déficit de pico de torque de extensão do joelho a $60 \%$, foi de 
$21,5 \%$ no pré-operatório, $15,7 \%$ no pós-operatório $(p=0,63)$ e $3,1 \%$ no grupo controle ( $p<0,001$ com relação ao pré-operatório e pós-operatório). CONCLUSÃO: Os jogadores profissionais de futebol de campo avaliados seis meses após a reconstrução do LCA apresentaram $\mathrm{VO}_{2 \max }$ significativamente inferior aos resultados do grupo controle, embora os resultados pós-operatórios tenham sido significativamente superiores aos observados no pré-operatório. Houve uma melhora significativa nos scores de função do joelho no pósoperatório com relação ao pré-operatório e a composição corporal dos indivíduos não apresentou diferenças estatisticamente significativas.

Descritores: Ligamento cruzado anterior; Reconstrução do ligamento cruzado anterior; Joelho; Ferimentos e lesões; Volta ao esporte; Reabilitação; Consumo de oxigênio. 
Abstract 
Almeida AM. Aerobic capacity in professional football players with anterior cruciate ligament reconstruction [thesis]. São Paulo: "Faculdade de Medicina, Universidade de São Paulo"; 2017.

INTRODUCTION: Anterior cruciate ligament $(A C L)$ injury is a severe injury and may impact a professional football player's career. Surgical treatment is often indicated due to knee instability. Although ACL reconstruction (ACLR) is considered a successful procedure in restoring knee stability in athletes, it has been shown that only $55 \%$ return to competitive sports after surgery. Professional football players need technical, tactical and physical skills to succeed, including adequate knee function and aerobic capacity. Our purpose is to evaluate aerobic capacity in professional football players with $A C L$ injury and six months after ACL reconstruction. METHODS: Twenty professional football players underwent $A C L$ reconstruction with autologous hamstring grafts and were compared to 20 active, uninjured professional football players. We assessed maximal aerobic capacity with maximal oxygen consumption $\left(\mathrm{VO}_{2 \max }\right)$ and submaximal with ventilatory thresholds, measured by ergoespirometric test performed in a treadmill with a modified Heck protocol. The tests were performed pre-operatively and six months after ACLR, and compared to the control group. We also performed knee function questionnaires (Lysholm and IKDC), isokinetic strength test and body composition evaluation with electric bioimpedance. RESULTS: ACL group average age was 21.7 y.o., and control group 22.1 y.o. $(p=.99)$. Time span between injury and surgery was 5 months, in average. Pre-operative $\mathrm{VO}_{2 \max }$ was $45.2 \pm 4.3 \mathrm{~mL} / \mathrm{kg} / \mathrm{min}$, post-operative was $48.9 \pm 3.8(p>.001)$ and control group was $56.9 \pm 4.2(p<.001$ in both comparisons). Pre-op body fat percentage was $14.7 \pm 3.7$, post-op was $14.9 \pm$ 5.4 and control $12.8 \pm 4$ (n.s.). Lysholm questionnaire results were $77.25,94.12$, and 97.5 (pre-op, post-op and control, respectively, $p<.05$ in all comparisons). IKDC results were 59.46, 87.75 and 97.28 (pre-op, post-op and control, respectively, $\mathrm{p}<.001$ in all comparisons). Preop peak torque isokinetic knee extension deficit at $60 \%$ was $21.5 \%$, postop $15.7 \%(p=.63)$ and control $3.1 \%$ $(p<.001)$. CONCLUSION: Professional football players had significantly lower $\mathrm{VO}_{2 \max }$ six months after ACLR compared to controls, although their results were significantly higher than observed pre-operatively. There was a significant improvement in knee function scores after ACLR. Body composition evaluation was not significant different among the groups evaluated. 
Descriptors: Anterior cruciate ligament; Anterior cruciate ligament reconstruction; Knee; Wounds and injuries; Return to sport; Rehabilitation; Oxygen consumption. 


\section{Introdução}




\section{INTRODUÇÃO}

O futebol é um dos esportes mais praticados no mundo. Segundo dados da "Fédération Internationale de Football Association" (FIFA) estima-se que 265 milhões de pessoas pratiquem futebol em todo o mundo, sendo 38 milhões de atletas registrados, dos quais 110 mil atletas profissionais ${ }^{1}$. No Brasil, são registrados mais de 2 milhões de atletas, 16.200 como profissionais ${ }^{1}$. Para a prática de futebol em nível competitivo, o jogador deve possuir qualidades técnicas, táticas, físicas e fisiológicas bem desenvolvidas como resistência, velocidade, agilidade, força, e também uma elevada capacidade funcional cardiopulmonar para produção de energia prolongada ${ }^{2-4}$.

O futebol é um dos esportes que apresenta o maior risco de lesão do ligamento cruzado anterior (LCA) ${ }^{5}$. Do total de lesões graves, definidas como lesões que provocam o afastamento do atleta de suas atividades por quatro semanas ou mais, 30 a $45 \%$ ocorrem no joelho, correspondendo a lesões do LCA ou lesões meniscais ${ }^{6,7}$. A incidência de lesão do LCA no futebol varia entre $0,15 \%$ a $3,67 \%$ por indivíduo por ano e 0,07 a 1,08 por mil horas de exposição ${ }^{8,9}$. $O$ tratamento cirúrgico é o procedimento de escolha em atletas com lesão do LCA, objetivando reconstruir o ligamento para estabilizar a articulação. Essas lesões têm provocado grande impacto econômico. As estimativas norte-americanas são de 200 mil casos por ano, gerando um custo anual de US\$ 4 bilhões ${ }^{9}$.

Os avanços na técnica cirúrgica têm obtido bons ou excelentes resultados em mais de $90 \%$ dos casos $^{10-13}$ e aumentado o potencial para o retorno do atleta ao esporte competitivo ${ }^{11,14-16}$, em um prazo estimado de seis meses ${ }^{13,15-}$ 19. Entretanto, outros estudos mostram que, um ano após a cirurgia, até dois terços dos atletas operados não retornaram ao mesmo nível de atividade esportiva, e apenas $55 \%$ destes indivíduos retornaram a atividades competitivas $^{20,21}$. Portanto, a instabilidade articular residual ou a relesão do ligamento, embora ocorram em até $10 \%$ dos casos, não são as únicas causas 
responsáveis pela maior parte dos indivíduos que não conseguem retornar plenamente ao esporte.

Diversos critérios têm sido propostos para avaliar a função articular e permitir o retorno seguro ao esporte após reconstrução do $\operatorname{LCA}^{19,22}$. Questionários específicos e validados podem ser utilizados para avaliar a função do joelho. Testes de força muscular por dinamometria isocinética avaliam o déficit de força muscular, sendo que um déficit superior a $10 \%$ é considerado significativo. Outros testes bastante utilizados são os "hop tests", que comparam a distância de salto unipodálico entre o membro operado e não operado. Estes critérios avaliam a função articular, força muscular e propriocepção. A atividade esportiva envolve não apenas a função articular, o gesto esportivo e a coordenação motora. Há necessidade de capacidade física que permita a execução do esforço físico necessário para o gesto esportivo. Portanto, o retorno ao esporte, principalmente competitivo, não depende apenas da função do ligamento, ou do joelho, ou da perna operada. Depende, entre outros fatores, do condicionamento físico do atleta. Entretanto, não encontramos na literatura dados a respeito da condição cardiorrespiratória e da capacidade aeróbia do atleta no retorno ao esporte após reconstrução do LCA.

Durante uma partida de futebol de campo de 90 minutos de duração, um jogador corre cerca de $10 \mathrm{~km}$, alternando períodos de alta e baixa intensidade, em uma intensidade média próxima ao limiar anaeróbio, ou seja, intensidade do exercício em que a produção e remoção do lactato estão equilibradas ${ }^{23}$. Devido à duração de uma partida, o componente aeróbio predomina na maior parte do tempo. Entretanto durante uma partida ocorrem cerca de 150 a 250 períodos curtos de alta intensidade, principalmente nos lances decisivos, que dependem do metabolismo anaeróbio. Portanto, é uma modalidade esportiva de resistência mista ${ }^{3,23}$. O método mais utilizado para avaliar a capacidade cardiorrespiratória máxima de um indivíduo é a medida do consumo máximo de oxigênio $\left(\mathrm{VO}_{2 \max }\right)$ por ergoespirometria ${ }^{24,25}$. Vários estudos têm demonstrado que entre jogadores profissionais de futebol de campo $\circ \mathrm{VO}_{2 \max }$ situa-se em torno de $60 \mathrm{~mL} / \mathrm{kg} / \mathrm{min}^{23}$. A ergoespirometria também permite quantificar, por 
alterações ventilatórias, os limiares fisiológicos de esforço submáximo, como o limiar anaeróbio e ponto de compensação respiratória ${ }^{24,26-27}$.

Tendo em vista que o futebol profissional é praticado em alta intensidade, precisamos conhecer as condições de desempenho do jogador frente às demandas funcionais desse esporte antes do retorno ao esporte e competição após cirurgia de reconstrução do LCA. Para essa finalidade devemos utilizar critérios de desempenho que avaliem não apenas o joelho operado, mas também as condições cardiorrespiratórias e metabólicas necessárias para suportar as exigências de uma partida de futebol com mínimo risco.

O retorno do atleta às atividades competitivas após uma cirurgia de reconstrução do LCA deve levar em conta força, potência, e resistência, assim como equilíbrio, propriocepção, momento apropriado e desempenho cardiovascular $^{14}$. Os critérios e parâmetros de retorno ao esporte devem ser mais exigentes para o retorno ao esporte competitivo em atletas profissionais ${ }^{22}$, comparados à população geral. O programa de reabilitação deve ser individualizado de forma a atender as necessidades individuais de cada atleta. Entretanto, percebemos a falta de estudos que levem em consideração não apenas a função articular, mas o condicionamento físico dos atletas no momento de retorno ao esporte.

Dessa forma, propusemos a avaliação da função aeróbia em jogadores profissionais de futebol de campo após reconstrução do LCA. A capacidade aeróbia em nível adequado é fundamental para a prática do futebol profissional. Sendo assim, as avaliações do $\mathrm{VO}_{2 \max }$, dos limiares ventilatórios um e dois (LV1 e LV2) e da economia de corrida (EC) permitirão um entendimento mais acurado da capacidade de desempenho do atleta no momento de retorno ao esporte após a reconstrução do LCA, principalmente no atleta profissional, com o objetivo de retornar ao esporte competitivo ${ }^{28,29}$. 
2 Objetivos 


\section{OBJETIVOS}

O objetivo do presente estudo é avaliar a função aeróbia de jogadores profissionais de futebol de campo submetidos a reconstrução do LCA aos seis meses de pós-operatório, utilizando $0 \mathrm{VO}_{2 \max }$ e limiares ventilatórios. $\mathrm{O}$ desfecho primário é o consumo máximo de oxigênio $\left(\mathrm{VO}_{2 \max }\right)$ aos seis meses de pós-operatório, comparado ao $\mathrm{VO}_{2 \max }$ pré-operatório desses atletas e comparado ao resultado de jogadores profissionais de futebol de campo em atividade, sem histórico de lesão.

Os desfechos secundários são os limiares ventilatórios submáximos: o limiar ventilatório um (LV1), que corresponde ao limiar anaeróbio, e o limiar ventilatório dois (LV2) que corresponde ao ponto de compensação respiratória, assim como as velocidades de corrida em que $\mathrm{o} \mathrm{VO}_{2 \max }$ e os limiares ventilatórios são atingidos e as porcentagens do $\mathrm{VO}_{2 \max }$ que correspondem aos limiares ventilatórios. Como desfecho secundário também avaliamos a economia de corrida, ou seja, o consumo de oxigênio para a realização de esforço submáximo na esteira.

Avaliamos também a composição corporal por bioimpedância, a força muscular dos músculos extensores e flexores do joelho por dinamometria isocinética computadorizada, e os escores funcionais do joelho por questionários específicos, nos períodos pré-operatório e pós-operatório e nos atletas do grupo controle, uma vez que esses resultados podem influenciar o desempenho dos atletas e também os resultados do desfecho primário. 
3 Revisão da Literatura 


\section{REVISÃO DA LITERATURA}

\subsection{Reconstrução do LCA em jogadores de futebol}

Segundo a literatura, uma lesão relacionada ao futebol pode ser classificada como grave quando causa afastamento do futebol por mais de quatro semanas, ou sérias lesões no sistema musculoesquelético ou visceral ${ }^{7}$. Portanto, baseados nesta definição, podemos dizer que a lesão do LCA no jogador de futebol é uma lesão grave.

A lesão do ligamento cruzado anterior do joelho é um dos assuntos mais estudados da literatura científica em ortopedia. Uma pesquisa rápida na base de dados PubMed com os termos "anterior cruciate ligament" ou "anterior cruciate ligament reconstruction", realizada em 16 de janeiro de 2016, resultou em 15.762 artigos. Não é o escopo desta revisão esgotar este assunto, e sim focar especificamente nos aspectos relacionados à lesão de LCA em jogadores de futebol.

A escolha entre enxerto de tendões isquiotibiais ou ligamento patelar é um dos fatores mais controversos relacionados à cirurgia de reconstrução do LCA. Em uma pesquisa com 94 cirurgiões ortopédicos responsáveis pelo tratamento de atletas de elite, Erickson et al. ${ }^{15}$ (2015) relatam que $70,2 \%$ afirmaram optar pelo uso de enxerto de ligamento patelar. Farber et al. ${ }^{16}$, em 2014, relatam que $68 \%$ dos cirurgiões ortopédicos responsáveis por times de futebol profissionais de elite norte-americanos preferiram utilizar enxerto do ligamento patelar.

Apesar das opiniões de especialistas, ensaios clínicos randomizados não são conclusivos quanto à superioridade de uma das técnicas. Aune et al. ${ }^{30}$, em 2001, publicaram um estudo randomizado comparando os resultados de reconstrução do LCA com enxerto de ligamento patelar ou tendões 
isquiotibiais. Setenta e dois pacientes foram operados e avaliados por dois anos. Os autores observaram melhores resultados subjetivos, maior força do quadríceps e melhor resultado funcional aos seis meses nos casos operados com tendões isquiotibiais, sem diferenças significativas aos dois anos de seguimento.

Beynnon et al. ${ }^{31}$, em 2002, realizaram um estudo randomizado com 56 pacientes comparando os resultados de reconstrução do LCA com enxerto de ligamento patelar ou tendões isquiotibiais e observaram melhor estabilidade do joelho aos três anos de seguimento com o uso de ligamento patelar.

Um estudo prospectivo e randomizado com 96 pacientes foi publicado por Maletis et al. ${ }^{10} \mathrm{em} 2007$. Nesse estudo o desfecho primário foi a anteriorização da tíbia medida por artrômetro KT-1000. Observaram anteriorização da tíbia de $2 \mathrm{~mm}$ nos casos operados com ligamento patelar, comparada com 2,9 mm no grupo operado com tendões isquiotibiais aos três meses de seguimento, diferença estatisticamente significativa. Esta diferença não foi observada nas avaliações subsequentes. Não observaram diferenças nos resultados dos questionários funcionais.

Em 2016, Webster et al. $^{32}$ publicaram um estudo prospectivo randomizado com 15 anos de seguimento comparando os resultados de reconstrução do LCA com enxerto de ligamento patelar ou tendões isquiotibiais. Observaram que aos três anos de pós-operatório estavam presentes maiores déficits de força de extensão do joelho e maior dor para ajoelhar nos pacientes operados com ligamento patelar, mas sem diferenças significativas aos quinze anos. Da mesma forma, até o terceiro ano de seguimento observaram maior anteriorização da tíbia nos pacientes operados com tendões isquiotibiais, mas sem diferenças significativas aos quinze anos. Os resultados a longo prazo foram similares em ambos os grupos.

Especificamente em jogadores de futebol, Walden et al. ${ }^{13}$ (2011) em um estudo de coorte realizado na Suécia com jogadores de futebol profissional incluindo 78 casos, relatam que nestes casos foi utilizado o enxerto de isquiotibiais com maior frequência ( $67 \%$ dos casos), e não houve diferença 
significativa no retorno ao esporte comparando ambos os enxertos, com uma taxa de retorno ao esporte de $94 \%$. Brophy et al. ${ }^{33}$, em 2012, publicaram os resultados de uma coorte avaliando cem praticantes de futebol não profissionais com seguimento médio de sete anos. Observaram que $72 \%$ retornaram ao futebol em um período médio de 12 meses, e não houve diferença quanto ao tempo e taxa de retorno ao esporte comparando os tipos de enxerto. Zaffagnini et al. ${ }^{19}$, em 2014, realizaram a reconstrução do LCA com enxerto de isquiotibiais em 21 jogadores profissionais de futebol, sendo que $95 \%$ dos casos retornaram ao mesmo nível de atividade esportiva em até um ano.

Estes dados mais recentes apresentam resultados bastante diferentes dos publicados por Roos et al. ${ }^{34}$, em 1995, sobre a cirurgia de reconstrução do LCA em jogadores de futebol. Nesta casuística retrospectiva, iniciada em 1986, observaram que apenas $20 \%$ dos jogadores operados retornaram ao mesmo nível de atividade pré-operatório. Neste caso, a grande maioria dos procedimentos foi realizada com enxerto de ligamento patelar. De acordo com Ekstrand $^{11}$, em 2011, as diferenças dos resultados apresentados por estes estudos, com quase 20 anos de intervalo, decorrem do aperfeiçoamento do diagnóstico, das técnicas cirúrgicas e do processo de reabilitação. A assistência recebida pelos atletas de elite representa na maior parte das vezes a situação próxima do ideal, com equipes altamente especializadas e empenhadas no seu tratamento e recuperação.

Fernandes et al. ${ }^{35}$, em 2014, correlacionaram os parâmetros radiográficos de posicionamento do túnel femoral com o retorno a atividade esportiva em 86 atletas. Observaram maior taxa de retorno ao esporte e melhor resultado funcional nos atletas em que o túnel femoral foi posicionado na região anteromedial.

Utilizando o enxerto de isquiotibiais na reconstrução do LCA, Tudisco et al. ${ }^{18}$, em 2015, compararam os resultados das técnicas transtibial e anteromedial para o túnel femoral em jogadores de futebol não profissionais. Observaram que nos pacientes em que o túnel femoral foi perfurado pelo portal 
anteromedial foram obtidos melhores resultados funcionais e de pivot shift. Achados semelhantes foram relatados por Franceschi et al. ${ }^{36}$, em 2013, que observaram melhor estabilidade rotacional e menor translação anterior perfurando o túnel femoral pelo portal anteromedial.

\subsection{Retorno ao esporte após a reconstrução do LCA}

O objetivo principal da reconstrução do LCA é eliminar a instabilidade do joelho permitindo inclusive a prática de esportes. Segundo Myer et al. ${ }^{14}$, em 2006, o retorno ao esporte é determinado pela estabilidade do joelho, confiança do paciente, tempo de pós-operatório, e opinião da equipe médica. Segundo os autores, a utilização de testes objetivos que avaliem quantitativamente a capacidade funcional pode otimizar a reabilitação para o retorno pleno e seguro ao esporte. Citam, entre estes testes, amplitude de movimento, questionários, teste isocinético, posturografia, mas não citam a avaliação da capacidade aeróbia destes pacientes como um critério a ser avaliado objetivamente. Segundo os autores, entre os critérios objetivos estão um resultado mínimo de 70 no escore IKDC e déficit de força inferior a $15 \%$ comparado com o membro colateral medido por dinamômetro isocinético.

Em 2011, Barber-Westin e Noyes $^{37}$ avaliaram em uma revisão sistemática os critérios utilizados para permitir o retorno sem restrição às atividades esportivas após reconstrução do LCA. Observaram que não há uma padronização nestes critérios, e que os critérios mais utilizados e recomendados envolvem força muscular, função articular, estabilidade e controle neuromuscular.

Em uma metanálise sobre retorno ao esporte após reconstrução do LCA, Ardern et al. ${ }^{21}$, em 2014, avaliaram 69 artigos incluindo 7.556 participantes. Observaram que $81 \%$ retornaram à prática de esportes, $65 \%$ 
retornaram ao nível de atividade esportiva anterior à lesão e apenas 55\% retornaram ao esporte competitivo. Segundo os autores, pacientes jovens, sexo masculino, atletas de elite, escores de função do joelho classificados como normal e enxerto de tendões isquiotibiais foram fatores que favoreceram o retorno ao esporte competitivo.

Cada esporte apresenta peculiaridades relacionadas ao movimento, gesto esportivo e capacidades. Portanto, a reabilitação avançada e os critérios de retorno devem ser direcionados ao esporte específico. No futebol profissional, Zaffagnini et al. ${ }^{19}$, em 2014, definiram os seguintes critérios para permitir o retorno às atividades em campo após a reconstrução do LCA: ausência de instabilidade ou falseios durante a atividade, dor e derrame mínimos ou ausentes, ADM completa, déficit de pico de torque isocinético inferior a $20 \%$ e capacidade de correr em uma esteira por $8 \mathrm{~km} / \mathrm{h}$ por mais de 10 minutos. Seguindo estes critérios, os autores avaliaram prospectivamente um grupo de 21 jogadores de futebol profissional, e relatam um tempo médio de retorno a partidas oficiais de $186 \pm 52$ dias.

Outros autores, entretanto, relatam um tempo maior para retorno ao esporte competitivo. Em um estudo de coorte realizado na Suécia com 71 casos de reconstrução do LCA em jogadores de futebol, Waldén et al. ${ }^{13}$, em 2011, relataram que 69 pacientes (94\% dos casos) retornaram ao esporte competitivo com um tempo médio de $237,5 \pm 76,1$ dias. Por sua vez, em um estudo de coorte incluindo 100 jogadores de futebol, Brophy et al. ${ }^{33}$, em 2012, observaram que $72 \%$ dos atletas retornaram ao esporte com um tempo médio de retorno de 12,2 \pm 14,3 meses. Segundo os autores, pacientes mais jovens e do sexo masculino tiveram maior probabilidade de retorno ao esporte, e o tipo de autoenxerto utilizado não apresentou influência.

Segundo Bizzini et al. ${ }^{38}$, em 2012, integrar elementos específicos do esporte na reabilitação do jogador de futebol é um desafio, pois este esporte requer gestos específicos, coordenação, agilidade, potência e velocidade. Segundo o autor, os critérios utilizados para o retorno ao esporte, como sinais e sintomas no joelho, testes de salto ("hop tests"), e medida objetiva da força 
muscular por teste isocinético, fornecem informações importantes sobre a condição do joelho operado, mas não são suficientes para retornar ao futebol competitivo após a reconstrução do LCA. Bizzini e Silvers ${ }^{39}$, em 2014, propõe que para retornar à competição o atleta apresente força muscular igual ou superior aos níveis anteriores à lesão ou ao membro contralateral e testes de performance como RSSA (repeated-shuttle sprint ability) e Yo-yo semelhantes aos níveis anteriores à lesão.

Em 2016, Kyritsis et al. ${ }^{22}$ definem seis critérios clínicos para liberação de atletas profissionais para retorno ao esporte. Os critérios definidos são déficit do quadríceps a $60 \%$ inferior a $10 \%$ comparado à outra perna, índice de simetria superior a $90 \%$ nos testes de salto único, salto triplo e salto cruzado triplo (single hop, triple hop e triple crossover hop), teste de corrida em T em menos de $11 \mathrm{~s}$ e reabilitação específica no campo completa. Observaram que os atletas que não preenchiam todos os critérios apresentaram um risco 4,1 vezes maior de relesão.

\section{3 $\mathrm{VO}_{2 \max }$ no futebol de alto rendimento}

$\mathrm{O}$ conceito de $\mathrm{VO}_{2 \max }$ iniciou-se com as pesquisas de Hill e Lupton, em $1923^{40}$. Segundo esse trabalho clássico, os fatores que determinam o consumo máximo de oxigênio são: o débito cardíaco; o grau de saturação de oxigênio do sangue arterial; o grau de saturação de oxigênio do sangue venoso (cuja diferença indica a extração tecidual de oxigênio); e a capacidade do sangue em transportar oxigênio. Postularam que: há um limite máximo para consumo de oxigênio; este limite apresenta variações entre indivíduos; um alto $\mathrm{VO}_{2 \max }$ é fundamental para atividades de resistência; é limitado pela capacidade do sistema cardiorrespiratório em transportar oxigênio para os músculos. 
A fórmula estabelecida por Fick apud Albouaini ${ }^{41}$ ilustra os fatores que interferem no $\mathrm{VO}_{2 \max }$ :

$$
\mathrm{VO}_{2 \max }=\mathrm{FC}_{\max } \times \mathrm{VS}_{\max } \times \text { diferença }(\mathrm{a}-\mathrm{v}) \mathrm{O}_{2 \max }
$$

Onde: $\mathrm{FC}_{\max }$ (frequência cardíaca máxima), VS $\mathrm{S}_{\max }$ (volume sistólico máximo) e diferença (a-v) $\mathrm{O}_{2 \max }$ (diferença arteriovenosa de oxigênio máxima). $\mathrm{O}$ produto entre $\mathrm{FC}_{\max } \mathrm{x} V \mathrm{~S}_{\max }$ equivale ao débito cardíaco (DC). Alterações em qualquer um destes fatores pode influenciar o $\mathrm{VO}_{2 \max }$.

Em 1996, Billat e Koraslztein ${ }^{42}$ publicaram uma revisão sobre a importância da velocidade no $\mathrm{VO}_{2 \max }\left(\mathrm{VVO}_{2 \max }\right)$. Nesta velocidade, o sistema cardiovascular, pulmonar, e a difusão de $\mathrm{O}_{2}$ para os músculos atingiram o nível máximo. Portanto, o organismo não tem como satisfazer as necessidades de $\mathrm{O}_{2}$ para velocidades maiores. $\mathrm{O} \mathrm{VVO}_{2 \max }$ integra o $\mathrm{VO}_{2 \max }$ e a economia de corrida em um único fator, o que ajuda a explicar diferenças em performance que apenas o $\mathrm{VO}_{2 \max }$ ou a $\mathrm{EC}$ não esclarecem isoladamente.

Segundo Bassett e Howley ${ }^{25}$, em 2000, o $\mathrm{VO}_{2 \max }$ é limitado principalmente pela capacidade do sistema cardiorrespiratório em transportar oxigênio, e não pela capacidades dos músculos em utilizá-lo. Esta afirmação é corroborada pelas medidas de $\mathrm{VO}_{2 \max }$ em um mesmo indivíduo destreinado ou treinado, cujas diferenças ocorrem principalmente devido a um aumento do débito cardíaco ${ }^{43,44}$. Entretanto, o $\mathrm{VO}_{2 \max }$ não é o único preditor de performance em exercícios de resistência. O desempenho é muito influenciado pela eficiência com que o sistema musculoesquelético utiliza o oxigênio para produzir trabalho ${ }^{25}$.

Helgerud et al. ${ }^{45}$, em 2001, analisaram a relação entre a capacidade aeróbia e o desempenho no futebol. Um grupo de 19 jogadores foi dividido de forma aleatória em um grupo de treinamento com nove atletas e um grupo controle com dez atletas. Os atletas do grupo treinamento foram submetidos a 
um treinamento de 8 semanas. Os autores observaram que neste grupo 0 $\mathrm{VO}_{2 \max }$ aumentou de $58,1 \pm 4,5$ para $64,3 \pm 3,9 \mathrm{~mL} / \mathrm{kg} / \mathrm{min}$, a economia de corrida melhorou em $6,7 \%$, a distância percorrida durante as partidas aumentou em $20 \%$, o número de corridas em velocidade aumentou em $100 \%$, e o número de envolvimentos com a bola aumentou em $24 \%$. Concluem que o aumento da capacidade aeróbia em jogadores de futebol melhora o seu desempenho em campo.

De acordo com Stølen et al. ${ }^{23}$, em 2005, o metabolismo aeróbio predomina durante a prática do futebol. Entretanto, as ações mais decisivas, como ataques, defesas e saltos, utilizam o metabolismo anaeróbio. Para obter um desempenho superior técnico, tático e individual, o jogador de futebol necessita de alta capacidade física. Segundo os autores, o consumo máximo de oxigênio $\left(\mathrm{VO}_{2 \max }\right)$ em jogadores de linha adultos do gênero masculino varia entre 50 a $75 \mathrm{~mL} / \mathrm{kg} / \mathrm{min}$, sendo maior em atacantes do que em jogadores de defesa, enquanto goleiros apresentam $\mathrm{VO}_{2 \max }$ entre 50 a $55 \mathrm{~mL} / \mathrm{kg} / \mathrm{min}$. Durante uma partida, a intensidade média de exercício é cerca de $75 \%$ do $\mathrm{VO}_{2 \max }$.

Segundo Albouaini et al. ${ }^{41} \circ \mathrm{VO}_{2 \max }$ é a principal medida laboratorial de capacidade física cardiorrespiratória e é a medida mais importante durante o teste de exercício. $\mathrm{O} \mathrm{VO}_{2 \max }$ integra os sistemas cardiovascular, pulmonar e musculoesquelético, e, portanto, representa o nível máximo de metabolismo oxidativo envolvendo grandes grupos musculares. Os limiares ventilatórios são indicadores submáximos, porém menos dependentes da motivação do indivíduo durante o teste.

Olivier et al. ${ }^{44}$, em 2007, estudaram o efeito da cirurgia do joelho na função cardíaca em jogadores de futebol. Avaliaram dez jogadores de futebol com lesão do LCA submetidos a cirurgia, submetidos a avaliação ecocardiográfica antes e sete dias após a cirurgia. Avaliaram o volume sistólico, a fração de ejeção e o débito cardíaco destes pacientes. O volume sistólico é calculado como a diferença entre o volume sistólico final do ventrículo esquerdo e o volume diastólico final do ventrículo esquerdo. A fração 
de ejeção é calculada como o quociente da diferença entre o volume sistólico final do ventrículo esquerdo e o volume diastólico final do ventrículo esquerdo e o volume diastólico final do ventrículo esquerdo. O débito cardíaco é calculado como o volume sistólico multiplicado pela frequência cardíaca. Observaram uma redução significativa do volume diastólico final do ventrículo esquerdo, do volume sistólico, da fração de ejeção e do débito cardíaco, mesmo com um aumento compensatório significativo da frequência cardíaca.

Em um estudo realizado por Boone et al..$^{28}$ em 2012, foi avaliada a economia de corrida e $\mathrm{VO}_{2 \max }$ em jogadores de futebol de elite. Nestes atletas, a média de economia de corrida variou de acordo com a posição em campo, sendo de $231,4 \pm 8,8$ para os zagueiros, $218,4 \pm 10,3$ para os laterais, $214,4 \pm$ 11,1 para os meio-campistas, e $223,3 \pm 9,7$ para os atacantes. $O \mathrm{VO}_{2 \max }$ também apresentou variação, sendo $56,3 \pm 2,9$ para os zagueiros, $61,0 \pm 3,3$ para os laterais, $60,9 \pm 2,7$ para os meio-campistas, e $58,2 \pm 3,1$ para os atacantes. Observaram que os laterais e meio-campistas apresentam significativamente melhor $\mathrm{VO}_{2 \max }$ e economia de corrida do que os zagueiros.

Em 2013, Tonnessen et al. ${ }^{46}$ avaliaram o $\mathrm{VO}_{2 \max }$ de 1.545 jogadores profissionais de futebol noruegueses e encontraram um $\mathrm{VO}_{2 \max }$ médio entre 62 a $64 \mathrm{~mL} / \mathrm{kg} / \mathrm{min}$ em todas as categorias, com exceção da terceira a quinta divisão que apresentaram $\mathrm{VO}_{2 \max }$ em média $2 \mathrm{~mL} / \mathrm{kg} / \mathrm{min}$ inferior.

As variações da capacidade física durante a pré-temporada foram avaliadas por Castagna et al. ${ }^{47}$ em 2013, que observaram em 19 atletas profissionais uma variação do $\mathrm{VO}_{2 \max }$ de $58,2 \pm 4,4$ para $61,4 \pm 4,1 \mathrm{~mL} / \mathrm{kg} / \mathrm{min}$ entre o início da pré-temporada e após um período de treinamento de oito semanas. $O$ efeito do destreinamento na capacidade física de jogadores de futebol foi estudado por Koundourakis et al. ${ }^{48}$ em 2014, que avaliaram 55 jogadores profissionais, e observaram que um período de seis semanas de destreinamento levou a uma redução significativa do $\mathrm{VO}_{2 \max }$, de $60,31 \pm 2,52$ para $57,67 \pm 2,54 \mathrm{~mL} / \mathrm{kg} / \mathrm{min}$. Como regra geral, é sugerido que a capacidade física exigida para um bom desempenho no futebol profissional requer um $\mathrm{VO}_{2 \max }$ próximo de $60 \mathrm{~mL} / \mathrm{kg} / \mathrm{min}^{23,47}$. 
$\mathrm{O}$ efeito da prática de futebol recreativo sobre $\circ \mathrm{VO}_{2 \max }$ foi avaliado por Milanović et al. ${ }^{49}$, em 2015, em uma revisão sistemática com metanálise, incluindo 17 estudos. Os autores concluíram que a prática recreativa do futebol duas vezes por semana por 12 semanas aumentou o $\mathrm{VO}_{2 \max }$ em média 3,51 $\mathrm{mL} / \mathrm{kg} / \mathrm{min}$, o que significou um aumento de 8 a $13 \%$. Comparados com indivíduos sedentários o efeito foi amplamente benéfico, e moderadamente benéfico quando comparado a corrida ou musculação.

Em 2016, Ross et al. ${ }^{50}$ publicaram um consenso da "American Heart Association" sobre a importância da avaliação do condicionamento cardiorrespiratório na prática clínica. Segundo este consenso, esta avaliação proporciona dados importantes de morbidade e mortalidade em conjunto com fatores de risco tradicionais, como obesidade, diabetes, hipertensão arterial e dislipidemia. Este consenso defende $\circ$ uso rotineiro da avaliação do condicionamento cardiorrespiratório, como um sinal vital, sendo a medida do consumo de oxigênio $\left(\mathrm{VO}_{2}\right)$ o método mais objetivo e preciso, embora outros métodos de estimativa possam ser utilizados na prática clínica. O consenso afirma já haver dados suficientes para demonstrar os benefícios do condicionamento cardiorrespiratório na redução da mortalidade, principalmente por causas cardiovasculares. Segundo os autores, os maiores benefícios ocorrem quando o indivíduo migra do grupo menos condicionado $\left(\mathrm{VO}_{2 \max }\right.$ abaixo de $30 \mathrm{~mL} / \mathrm{kg} / \mathrm{min}$ ) para o grupo seguinte. Aumentos adicionais em indivíduos bem condicionados $\left(\mathrm{VO}_{2 \max }\right.$ acima de $45 \mathrm{~mL} / \mathrm{kg} / \mathrm{min}$ ) estão mais relacionados à performance do que a benefícios à saúde. 


\subsection{Destreinamento em jogadores de futebol}

Segundo Mujika e Padilla ${ }^{51,52}$, em 2000, o destreinamento é um fenômeno comum em esportes competitivo, causado pela perda parcial ou completa de adaptação fisiológica por estímulo insuficiente como ocorre nas situações de lesão. Portanto, o desempenho no futebol competitivo depende de componentes de força, potência, resistência e habilidades para compensar a demanda física em campo.

Em 2013, Castagna et al. ${ }^{47}$ avaliaram a variação do $\mathrm{VO}_{2 \max }$ entre o início e o término da pré-temporada em jogadores de futebol profissional, e observaram um aumento significativo de 58,2 para $61,4 \mathrm{~mL} / \mathrm{kg} / \mathrm{min}$ durante a pré-temporada, equivalente a 5,5\%. Koundourakis et al. ${ }^{48}$, em 2014, demonstraram uma reduçao de 4,4\% no $\mathrm{VO}_{2 \max }$ em 6 semanas de destreinamento. Entretanto Martin et al. ${ }^{53}$, em 1986, avaliando seis atletas corredores ou ciclistas observou uma redução de até $20 \%$ no $\mathrm{VO}_{2 \max }$ em três meses de destreinamento.

De acordo com Ostojic ${ }^{54}$, em 2003, três semanas de destreinamento foram associadas a diminuição significativa no tempo de corrida nos $50 \mathrm{~m}$ em jogadores de futebol sérvios. Caldwell e Peters ${ }^{55}$, em 2009, demonstraram que oito semanas sem treinamento antes de iniciar a pré-temporada no futebol inglês levou a uma redução significativa do $\mathrm{VO}_{2 \max }$, aumentou significativamente o tempo de corrida de $15 \mathrm{~m}$ e do teste de agilidade, reduziu a capacidade de salto em altura, reduziu a flexibilidade na região lombar e nos isquiotibiais, e levou a aumento no percentual de gordura corporal.

Bangsbo et al. ${ }^{4}$, em 2006, demonstram que três semanas de destreinamento, seguidas por quatro semanas de treinamento foram suficientes para manter o nível de $\mathrm{VO}_{2 \max }$ em jogadores profissionais de futebol. Clark et al. ${ }^{56}$, em 2008 , demonstraram que o limiar anaeróbio também foi modificado em diferentes momentos da temporada em jogadores 
profissionais de futebol. Os valores na pré-temporada foram os mais baixos, seguidos do final da temporada. Os valores mais altos foram observados no meio da temporada, por três anos consecutivos.

Por outro lado, Helgerud et al. ${ }^{57}$ em 2011, demonstraram um aumento de $8,6 \%$ no $\mathrm{VO}_{2 \max }$ de jogadores de futebol profissional, de 60,5 para 65,7 $\mathrm{mL} / \mathrm{kg} / \mathrm{min}$, com um treino intervalado a $90-95 \%$ da frequência cardíaca máxima duas vezes por semana por oito semanas.

McMaster et al. ${ }^{58}$, em 2013, demonstraram que houve uma redução de $14,5 \%$ da força em atletas de rugby e futebol americano após um período de destreinamento de 7,2 semanas. Amigó et al. ${ }^{59}$, em 1998, realizaram biópsias musculares nas férias de quatro a oito semanas de jogadores espanhóis. Os resultados mostraram diminuição na área de secção transversal das fibras musculares do tipo 1 e 2 e nas enzimas importantes para a resistência aeróbia e anaeróbia. Cormie et al. ${ }^{60}$, em 2011, sugeriram que os atletas de elite podem ser capazes de manter os ganhos de força máxima por até quatro semanas.

Em 2013, Djokić ${ }^{61}$ relatou um caso de uma jogadora de handeball profissional com lesão do LCA em que descreveu um programa de reabilitação entre o terceiro e o sexto mês pós-operatório, avaliando o $\mathrm{VO}_{2 \max }$ no início e no témino deste programa de reabilitação. Nesta atleta observou uma evolução no $\mathrm{VO}_{2 \max }$ de 51,33 para $55,07 \mathrm{~mL} / \mathrm{kg} / \mathrm{min}$.

\subsection{Economia de corrida}

De acordo com Foster e Lucia ${ }^{62}$, em 2007, a economia de corrida (EC) é a quantidade de energia necessária para manter uma velocidade submáxima de corrida. É medida pelo custo de oxigênio por unidade de massa corporal por distância percorrida em $\left(\mathrm{mLO}_{2} / \mathrm{kg} / \mathrm{km}\right)$. De acordo com Bangsbo et al. ${ }^{63}$, em 
2007, a distância atingida por um jogador de futebol ao final de uma partida depende da agilidade e da capacidade de executar repetidamente trabalho aeróbio de alta intensidade o que é influenciado pela EC.

Segundo Morgan et al. ${ }^{64}$, em 1989, o consumo de oxigênio para uma determinada atividade pode variar consideravelmente entre indivíduos com $\mathrm{VO}_{2 \max }$ similar. A economia de corrida é definida como a relação entre intensidade do exercício e o consumo de oxigênio, e medida em consumo de oxigênio relacionado ao tempo ou distância percorrida $(\mathrm{mL} / \mathrm{kg} / \mathrm{km})$. Segundo os autores a variação do consumo de oxigênio durante a atividade pode estar relacionada a fatores anatômicos, mecânicos e neuromusculares.

Boone et al. ${ }^{28}$, em 2014, avaliaram a $\mathrm{EC}$ e $\circ \mathrm{VO}_{2 \max }$ em jogadores de futebol de elite. Nestes atletas, a média de $\mathrm{EC}$ em $\mathrm{mLO}_{2} / \mathrm{kg} / \mathrm{km}$ variou de acordo com a posição em campo, sendo de $231,4 \pm 8,8$ para os zagueiros, 218 , $4 \pm 10,3$ para os laterais, $214,4 \pm 11,1$ para os meio-campistas, e $223,3 \pm 9,7$ para os atacantes. $O \mathrm{VO}_{2 \max } \mathrm{em} \mathrm{mLO} / \mathrm{kg} / \mathrm{min}$ também apresentou variação, sendo $56,3 \pm 2,9$ para os zagueiros, $61,0 \pm 3,3$ para os laterais, $60,9 \pm 2,7$ para os meio-campistas, e 58,2 $\pm 3,1$ para os atacantes. Observaram que os laterais e meio-campistas apresentaram significativamente melhor $\mathrm{VO}_{2 \max }$ e $\mathrm{EC}$ do que os zagueiros.

\subsection{Teste isocinético computadorizado}

Os principais esforços envolvidos no futebol, como correr, chutar, saltar, girar, levantar, envolvem os membros inferiores. Segundo Cometti et al. ${ }^{65}$, em 2001, a força máxima que pode ser exercida durante uma contração muscular voluntária é um importante fator envolvido no desempenho. 
Oberg et al. ${ }^{66}$, em 1986, avaliaram 240 atletas de diferentes categorias, desde elite até amadores, observando diferenças significativas nos picos de torque entre atletas de diferentes categorias. Em 2015, Ruas et al. ${ }^{67}$ avaliaram 102 atletas de diferentes posições, observando que há diferenças significativas no pico de torque do quadríceps e flexores de acordo com a posição em campo. Os goleiros apresentaram significativamente maior força muscular do que os demais jogadores. Considerando apenas os jogadores de linha, o pico de torque do quadríceps teve uma média de 258 N.m, enquanto o pico de torque dos isquiotibiais teve uma média de 158 N.m.

De acordo com Pua et al. $^{68}$, em 2008, os testes isocinéticos não reproduzem perfeitamente os movimentos e contrações musculares das atividades cotidianas. Porém, estes testes são úteis por permitirem quantificar déficits musculares, possibilitarem distinguir os pacientes aptos a retornar de forma mais segura às atividades esportivas, e correlacionarem-se, ao menos de forma moderada, a avaliações subjetivas de função do joelho.

Dauty et al. ${ }^{69}$ em 2005, publicaram uma revisão sistemática sobre os resultados de testes isocinéticos após reconstrução do LCA. Analisando as publicações que avaliaram os déficits de força muscular para extensão do joelho após seis meses da reconstrução, observaram um déficit de $28 \%$ a $34 \%$ na avaliação a velocidade angular de $60 \%$ e de $18 \%$ a $31 \%$ a velocidade angular de $180 \%$ s.

Em 2010, Xergia et al. ${ }^{70}$ realizaram uma metanálise incluindo estudos randomizados e não randomizados sobre a influência do tipo de enxerto utilizado para reconstrução do LCA na força muscular medida por teste isocinético. Observaram que nos pacientes em que foram utilizados tendões isquiotibiais houve uma tendência de maior força dos músculos extensores e menor força de músculos flexores comparado ao uso do ligamento patelar.

Em 2011, Barber-Westin e Noyes ${ }^{37}$ realizaram uma revisão sistemática sobre critérios de retorno ao esporte após reconstrução do LCA e sugerem uma força muscular do quadríceps e isquiotibiais maior do que $80 \%$ a $90 \%$ comparada à perna contralateral para permitir o retorno ao esporte. 
Em 2015, Czaplicki et al. ${ }^{71}$ avaliaram a evolução dos resultados de dinamometria isocinética em pacientes submetidos a reconstrução do LCA com tendões flexores. Observaram aos seis meses de pós-operatório um déficit de força de extensão de $22 \%$ comparado à perna contralateral aos 12 meses o déficit observado foi de $15 \%$. Com relação à força de flexão o déficit observado foi de $8 \%$ aos seis meses e $4 \%$ aos 12 meses de pós-operatório.

Em 2015, Undheim et al. ${ }^{72}$ avaliaram 39 estudos em revisão sistemática sobre a associação entre retorno ao esporte após reconstrução do LCA e a força muscular avaliada por dinamometria isocinética. Observam que não há um padrão de avaliação, e tampouco um consenso sobre o critério para retorno ao esporte. Sugerem que seja utilizado um protocolo de cinco repetições concêntricas de flexão e extensão do joelho a uma velocidade angular de $60 \%$, com arco de movimento entre 0 a $100^{\circ}$, com correção da gravidade, avaliando o pico de torque.

\subsection{Análise da composição corporal por bioimpedância}

A análise da composição corporal é utilizada em atletas para avaliar condições de treinamento e desempenho destes atletas ${ }^{73,74}$. Vários métodos podem ser utilizados para avaliação da composição como a pesagem hidrostática, dual-energy X-ray absorptiometry (DXA), pletismografia, medidas de dobra cutânea, bioimpedância ${ }^{74}$.

De acordo com Jaffrin ${ }^{75}$, em 2009, a bioimpedância é um método não invasivo e relativamente barato para avaliação de parâmetros de composição corporal, como água corporal total, água extracelular, percentual de gordura corporal e massa livre de gordura. Por sua praticidade, este tipo de avaliação tem sido cada vez mais utilizado na área de nutrição e medicina esportiva. 
Segundo os autores, a bioimpedância apresenta boa correlação quando comparada a métodos mais sofisticados, como DXA.

De acordo com Moon ${ }^{74}$, em 2013, a avaliação por bioimpedância é bastante conveniente quando comparada a métodos como DXA, pletismografia, e modelos laboratoriais de múltiplos compartimentos ${ }^{73}$. Entretanto, este método utiliza equações específicas para predizer o conteúdo de gordura a partir da resistência elétrica medida pelo aparelho. Estas equações são desenvolvidas a partir de uma amostra de indivíduos, e podem gerar erros quando utilizadas em indivíduos com morfologia não usual. A bioimpedância pode ser utilizada para avaliar alterações da composição corporal em atletas ao longo do tempo, e segundo os autores apresentou boa correlação com métodos como DXA.

Melchiorri et al. ${ }^{76}$, em 2007, apresentaram dados da composição corporal de 32 jogadores profissionais de futebol italianos, avaliados por bioimpedância. Relatam que a porcentagem de gordura corporal dos atletas foi em média e desvio padrão $12,7 \pm 4$, a massa livre de gordura foi de $67,9 \pm 6,5$ $\mathrm{kg}$, a massa de gordura foi de $9,8 \pm 3$, e a massa celular corporal foi de $34,7 \pm$ 3,6 .

Em 2014, Micheli at al. ${ }^{77}$ avaliaram os resultados de bioimpedância de 893 jogadores de futebol italianos de diferentes níveis de performance. Observaram que a massa livre de gordura variou de $62,1 \mathrm{~kg}$ a $66,3 \mathrm{~kg}$, e a porcentagem de gordura corporal variou de $15,2 \%$ a $16,1 \%$. Observam que os resultados são bastante diferentes dos observados na população geral, refletindo uma composição corporal específica, relacionada à atividade esportiva. 


\subsection{Questionários de função do joelho}

Para avaliação da função e sintomas da articulação do joelho existem questionários específicos, com a função de padronizar a análise dos resultados, tentando excluir a subjetividade do pesquisador e do paciente. $O$ questionário IKDC subjetivo (International Knee Documentation Committee Subjective Knee Form), publicado por Irrgang et al. ${ }^{78}$, em 2001, foi desenvolvido como uma medida de avaliação para detectar sintomas, atividades habituais e esportivas em pacientes com uma variedade de condições do joelho. Em 2006, Anderson et al. ${ }^{79}$ publicaram dados normativos deste questionário para a população norte-americana. Segundo os autores, o resultado médio para este questionário, incluindo todas as faixas etárias, foi de 82 pontos. Apenas 26\% dos entrevistados tiveram 100 pontos. Em 2010, Metsavaht et al. $^{80}$ publicaram a tradução e adaptação cultural deste questionário para o Brasil.

O questionário proposto por Lysholm ${ }^{81}$, em 1982, foi desenvolvido para avaliar o seguimento de cirurgias para lesões ligamentares do joelho e enfatiza os sintomas de instabilidade. É constituído de oito questões, com alternativas de respostas fechadas. O resultado final é expresso ordinalmente e nominalmente. Um resultado de 95 a 100 pontos é classificado como excelente, 84 a 94 como bom, 65 a 83 regular e abaixo de 64 como ruim. Este questionário foi validado para o português por Peccin et al. ${ }^{82}$ em 2006. 


\subsection{Relação entre fadiga e risco de lesão ligamentar do joelho}

Tem sido demonstrada a influência da fadiga, principalmente da fadiga periférica, na biomecânica do joelho ${ }^{83,84}$. Estas alterações biomecânicas estão relacionadas à lesão do $\mathrm{LCA}^{83}$. Os atuais programas de prevenção de lesão do LCA, como o proposto por Sugimoto et al. ${ }^{85}$, em 2015 , enfatizam a fadiga como um fator de risco para lesão do LCA.

Chappell et al. $^{84}$, em 2005 , estudaram o efeito da fadiga sobre a cinemática do joelho em vinte atletas. Neste estudo o protocolo de fadiga consistiu em cinco saltos seguidos por uma corrida de 30 metros. Os dados foram coletados com câmeras e sensores. Os parâmetros avaliados foram o pico de força de cisalhamento da tíbia proximal, a altura do salto, o momento de extensão do joelho, o momento em varo e valgo do joelho, e o ângulo de flexão do joelho. Concluíram que a fadiga muscular dos membros inferiores alterou a biomecânica e o controle motor, provocando um aumento da força de cisalhamento da tíbia proximal, associada a aumento do ângulo em valgo e redução do ângulo de flexão do joelho de cerca de $12 \%$, principalmente em mulheres.

Em 2009, Tsai et al. ${ }^{86}$ avaliaram o efeito da fadiga e recuperação na mecânica do joelho em mulheres durante mudança lateral de direção, e utilizaram um protocolo de fadiga similar ao utilizado por Chappell et al. ${ }^{84}$, citado acima. Utilizaram câmeras e sensores para coletar os dados de pico de angulação do joelho, e os momentos internos da articulação do joelho nos planos sagital, coronal e axial. Concluíram que após a indução de fadiga houve um aumento do momento adutor e de rotação interna, que persistiram mesmo após 40 minutos de repouso.

Em 2012, Quammen et al. ${ }^{87}$ avaliaram dois diferentes protocolos de fadiga, de curta e longa duração. O objetivo foi utilizar um modelo que estivesse mais próximo da prática de futebol, para analisar as alterações 
neuromusculares que ocorrem durante o estado de fadiga neste esporte específico. O protocolo de longa duração, denominado slow linear oxidative fatigue protocol (SLO-FP) tem como objetivo estimular a fadiga cardiovascular, mimetizando as demandas de uma partida de futebol. O protocolo de curta duração, denominado functional agility short-term fatigue protocol (FAST-FP) consistiu de saltos verticais repetidos e mudanças rápidas de direção, em um período de cinco minutos. O protocolo de longa duração consistiu de um teste ergoespirométrico com medida do $\mathrm{VO}_{2 \max }$, com duração de cerca de 15 minutos, seguida de uma corrida em esteira com duração de 30 minutos, completando os 45 minutos de duração de um tempo de uma partida. Em seguida realizaram atividades de correr, parar e saltar, definidos aleatoriamente e projetados em uma tela na frente dos atletas, monitorados por câmaras e sensores para avaliar medidas cinéticas e cinemáticas. Os autores observaram uma redução no grau de flexão do joelho e quadril após a fadiga de cerca de $7 \%$. Comparando os protocolos, observaram resultados similares quanto às alterações pré e pós-fadiga. Concluíram que a fadiga, em conjunto com movimentos inesperados, provoca alterações biomecânicas que aumentam o risco de lesão do LCA.

Em 2014, Gokeler et al. ${ }^{88}$ avaliaram o efeito da fadiga na performance de aterrissagem em doze pacientes após a reconstrução do LCA, comparando com um grupo controle. Neste estudo o protocolo de fadiga consistiu em saltos sucessivos até que altura do salto não atingiu $70 \%$ do salto inicial. Utilizando um escore que avalia o erro na técnica do salto, observaram maiores escores (ou seja, pior técnica no salto) em pacientes com reconstrução do LCA, e piora nos escores em ambos os grupos após fadiga.

Em 2016, Watson et al. ${ }^{89}$ avaliaram a incidência de lesão em jogadores de futebol e observaram que os jogadores que sofreram lesão apresentavam menor $\mathrm{VO}_{2 \max }$ na pré-temporada, comparados aos jogadores que não sofreram lesão $(57,5 \mathrm{mLkg} / \mathrm{min}$ versus $63,4 \mathrm{~mL} / \mathrm{kg} / \mathrm{min}, \mathrm{p}=, 014)$. Concluíram também que $\circ \mathrm{VO}_{2 \max }$ foi um preditor independente de risco de lesão. 
4 Métodos 


\section{MÉTODOS}

\subsection{Aprovação da comissão de ética e consentimento informado}

A pesquisa foi proposta e realizada de acordo com os padrões éticos internacionais propostos pela declaração de Helsinki, em 1964, e suas subsequentes atualizações, e em conformidade com a resolução número 466 do Conselho Nacional de Saúde do Brasil, de 12 de dezembro de 2012, que regulamenta a pesquisa envolvendo seres humanos no Brasil.

O presente estudo foi aprovado pela Comissão de Ética para Análise de Projetos de Pesquisa (CAPPesq) do Hospital das Clínicas da Faculdade de Medicina da Universidade de São Paulo (HCFMUSP) como protocolo de pesquisa IOT 983, número do parecer 368.105, em 21 de agosto de 2013 (Anexo 1). O estudo foi registrado e aprovado na Plataforma Brasil, sob o número 14440613.9.0000.0068 e registrado na plataforma Clinical Trials, registro NCT02674282.

Todos os pacientes envolvidos no projeto receberam orientações pessoalmente e assinaram Termo de Consentimento Livre e Esclarecido, detalhando todas as etapas da pesquisa. O termo assegurava ao paciente, entre outras, a prerrogativa de participar ou não da pesquisa, bem como deixar de participar a qualquer momento, sem qualquer prejuízo ao seu tratamento (Anexo 2).

O autor declara não haver qualquer conflito de interesse com o tema estudado e apresentado nesta tese.

A pesquisa foi realizada no Instituto de Ortopedia e Traumatologia do HCFMUSP, com recursos próprios da instituição. 


\subsection{Casuística}

Os pacientes participantes do estudo foram provenientes do ambulatório do grupo de medicina do esporte do IOTHCFMUSP, atendidos pelo Sistema Único de Saúde (SUS) e procuraram espontaneamente o serviço para tratamento. Todos os pacientes avaliados eram jogadores profissionais de futebol de campo, devidamente registrados na respectiva federação. As avaliações foram realizadas no Laboratório de Estudos do Movimento do Instituto de Ortopedia e Traumatologia (LEM - IOT). Foram realizadas avaliações antes da cirurgia e seis meses após a cirurgia de reconstrução nos pacientes com lesão LCA, e uma avaliação no grupo controle. O grupo controle consistiu de jogadores de futebol em atividade, sem histórico de lesão no joelho.

Antes de se submeterem aos procedimentos, os indivíduos foram esclarecidos sobre os procedimentos de avaliação, objetivos do estudo e os possíveis benefícios e riscos de um estudo desta natureza. Aqueles que concordaram assinaram um termo de consentimento livre e esclarecido (resolução específica 196/96 do Conselho Nacional de Saúde) aprovado de acordo com o Comitê de Ética da Instituição.

\subsubsection{Critérios de inclusão}

- Lesão do LCA;

- Jogador profissional de futebol de campo, devidamente registrado na respectiva federação;

- Maturidade esquelética; 
- Sexo masculino.

\subsubsection{Critérios de exclusão}

- Incapacidade de realização do teste ergoespirométrico;

- Incapacidade de correr em esteira;

- Derrame articular no joelho;

- Cirurgias prévias no joelho;

- Complicações pós-operatórias (infecção, artrofibrose, ciclope);

- Falha da cirurgia de reconstrução do LCA;

- Lesão associada de ligamentos colaterais e/ou LCP;

- Segmento inadequado;

- Goleiros.

Os critérios de inclusão para o grupo controle eram os mesmos, exceto a lesão do LCA.

Após o estudo piloto, foram selecionados consecutivamente 31 pacientes, que preencheram os critérios de participação no estudo. Destes pacientes, seis recusaram-se a participar da pesquisa. Do total de 25 pacientes, três não retornaram para seguimento. Um paciente não completou o teste ergoespirométrico no pré-operatório devido a sintomas no joelho, pois apresentava uma lesão em alça de balde. Um paciente foi excluído pois foi 
reoperado aos três meses de pós-operatório devido a um ciclope. Desta forma, vinte pacientes completaram as avaliações.

Recrutamos um grupo de jogadores de futebol profissional saudáveis e em atividade, sem histórico de lesões, para realizar os mesmos testes, cujos resultados foram utilizados como controle para comparação.

\subsection{Técnica cirúrgica para reconstrução do LCA}

Os casos foram operados por um único cirurgião, o autor desta tese. Com o paciente em decúbito dorsal horizontal sob raquianestesia, realizamos inicialmente um exame físico sob anestesia confirmando a instabilidade do joelho com os testes de Lachman, gaveta anterior e pivot-shift. Utilizamos torniquete pneumático posicionado na coxa proximal e calibrado em 350 $\mathrm{mmHg}$. Utilizamos cefazolina, $1 \mathrm{~g}$ por via endovenosa para profilaxia de infecção.

Realizamos a reconstrução do LCA com enxerto de tendões semitendíneo e grácil (STG) por artroscopia. O enxerto foi retirado por uma via de acesso na região crural anterior e medial ipsilateral de cerca de 3 a 4 centímetros, cerca de 2 a 3 centímetros medial à tuberosidade da tíbia e 2 a 3 centímetros distal à face articular superior da tíbia.

Realizamos a dissecção por planos até a fáscia do tendão do músculo sartório, que era aberta longitudinalmente para exposição dos tendões dos músculos semitendíneo e grácil. Os mesmos tendões eram dissecados e liberados de suas aderências e vínculos tendíneos, liberados na sua inserção distal na tíbia e retirados com auxílio de um stripper de tendão (Stryker, MI, USA), em sua totalidade. 
O enxerto era preparado em uma mesa auxiliar, em que os remanescentes de tecido muscular eram retirados e os tendões limpos de aderências remanescentes. As extremidades dos tendões eram preparadas com uma sutura contínua ancorada com fio de Vicryl ${ }^{\circledR} \mathrm{n}^{\circ} 1$ (Ethicon Inc. NJ, EUA). Os tendões eram dobrados em dois, formando um enxerto quádruplo, cujo diâmetro era medido (Figura 1).

Realizamos artroscopia do joelho pelos portais anterolateral e anteromedial. Inserimos a ótica pelo portal anterolateral. Realizamos uma inspeção articular, avaliando as superfícies de cartilagem, meniscos e ligamentos, para visualização de lesões condrais ou meniscais. As lesões meniscais foram tratadas apropriadamente, por meniscectomia parcial, total, ou sutura meniscal, conforme indicado. 

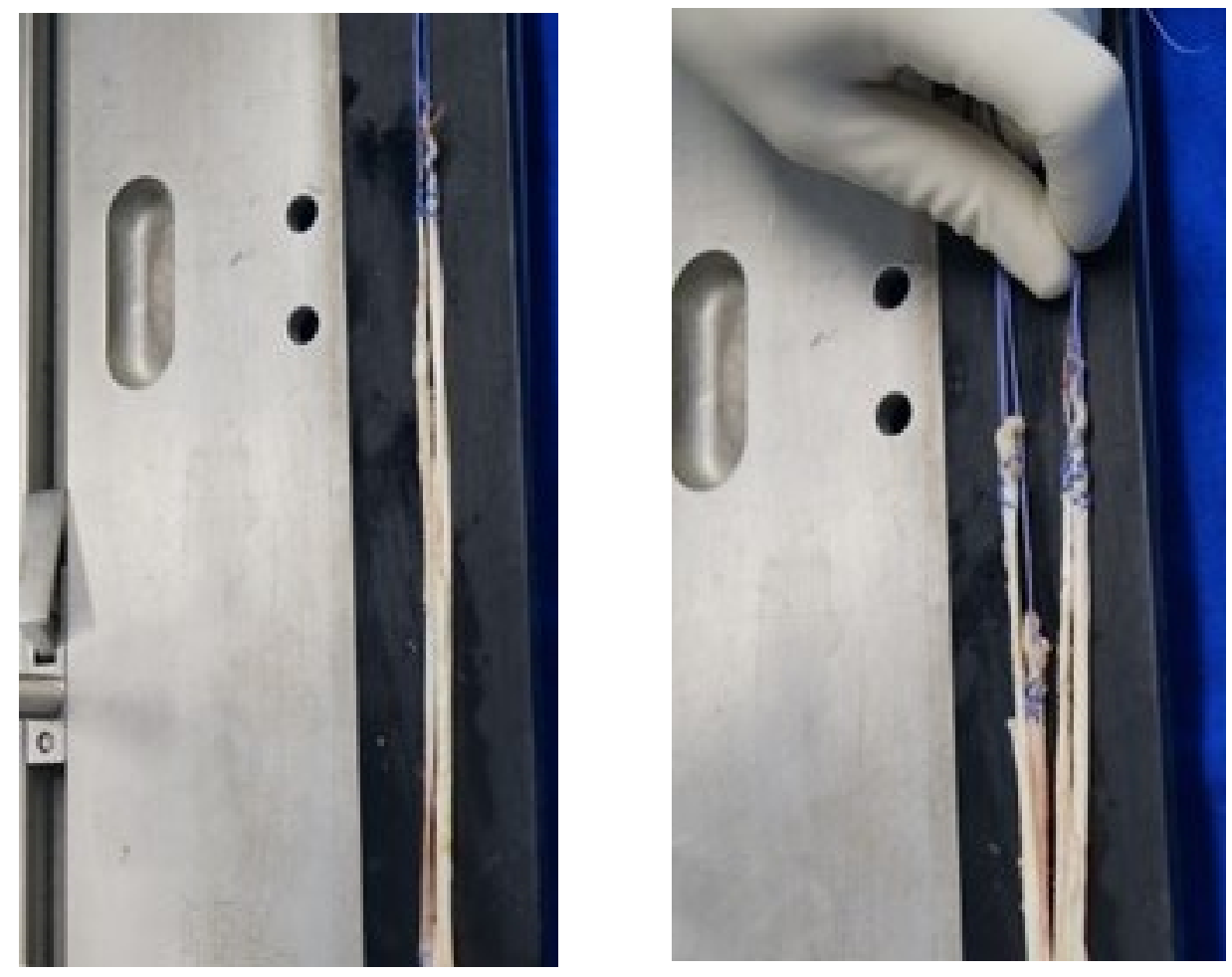

Figura 1 - Preparação do enxerto com tendões semitendíneo e grácil FONTE: Arquivo do autor 
A técnica utilizada para reconstrução do LCA foi a técnica anatômica. Iniciamos pelo túnel femoral com acesso pelo portal medial. Com o joelho em cerca de $120^{\circ}$ de flexão, posicionamos um fio guia no ponto de inserção original do LCA, entre os feixes anteromedial e posterolateral. Realizamos a perfuração do côndilo lateral de dentro para fora com broca de $5 \mathrm{~mm}$, e medimos o comprimento total do túnel, entre a entrada e a cortical do côndilo lateral. A seguir realizamos a perfuração com uma broca de diâmetro correspondente ao diâmetro do enxerto, em uma profundidade 5 a $10 \mathrm{~mm}$ menor do que o comprimento total do túnel do côndilo lateral, sempre preservando a cortical lateral nesta perfuração.

Em seguida o trajeto do túnel era reparado com um fio de Ethibond ${ }^{\circledR} n^{\circ} 5$ (Ethicon Inc. NJ, EUA), com trajeto entre a face lateral da coxa, passando pelo túnel e saindo pelo portal medial. Com o joelho em $90^{\circ}$ de flexão, utilizamos um guia tibial (Stryker, MI, USA) com angulação de $55^{\circ}$ para perfuração do túnel tibial. O fio guia era inserido na região anteromedial da tíbia, pela mesma incisão utilizada para retirada do enxerto, e posicionado no local de inserção original do LCA (Figura 2). Confirmado o posicionamento adequado, realizamos a perfuração do túnel com broca correspondente ao diâmetro do enxerto.

Em seguida o fio de Ethibond ${ }^{\circledR}$ era tracionado pelo túnel tibial e usado para direcionar o enxerto para o interior da articulação e dos túneis (Figura 3). A fixação femoral foi realizada com dispositivo metálico de fixação cortical com laço de comprimento fixo do tipo endobutton (Engimplan, Rio Claro, SP, Brasil). Avaliamos a existência ou não de impacto intercondilar e a isometricidade do enxerto. A fixação tibial foi realizada com parafuso de interferência metálico para tecidos moles (Engimplan, Rio Claro, SP, Brasil) (Figura 4).

Os pacientes receberam alta no mesmo dia da cirurgia, com orientação de retorno ambulatorial em uma semana. Orientamos o uso de muletas por três semanas e carga parcial, sem imobilização. 


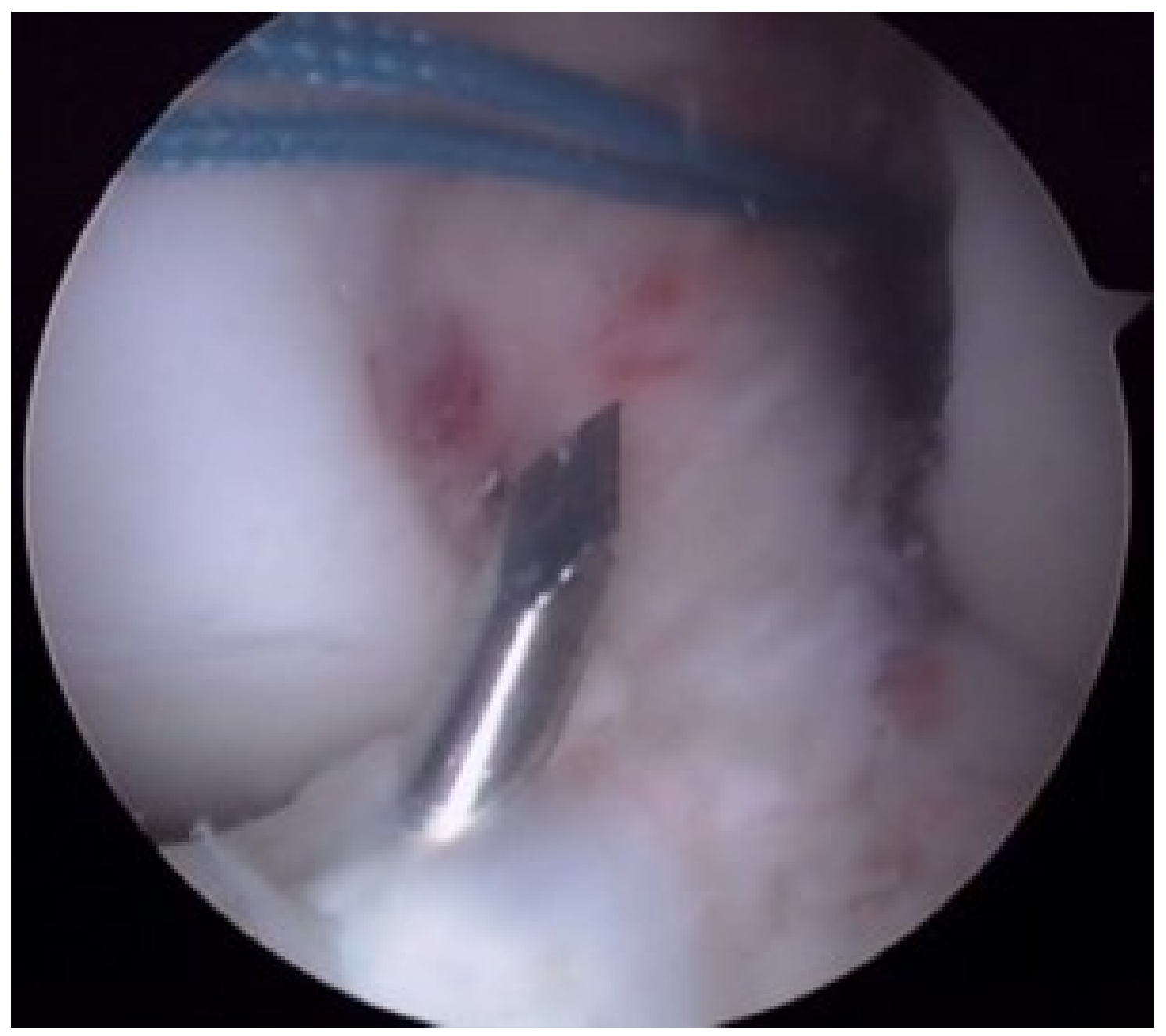

Figura 2 - Imagem de artroscopia do joelho para reconstrução do LCA. Observamos fio metálico posicionado na região de inserção tibial do $L C A$ e fio de Ethibond $\AA n^{\circ} 5$ reparando o trajeto do túnel femoral e saindo da articulação pelo portal medial

FONTE: Arquivo do autor 


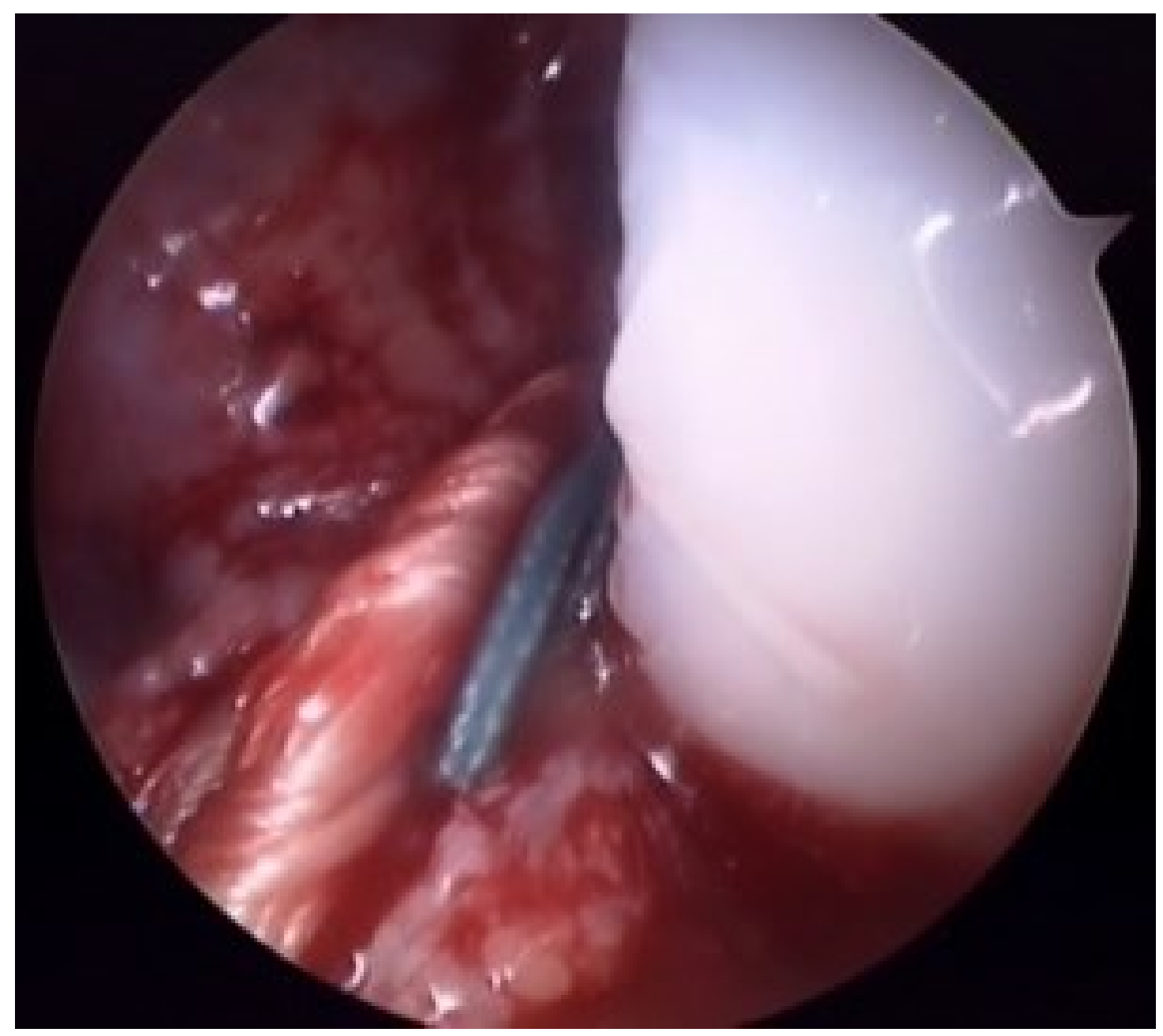

Figura 3 - Imagem de artroscopia do joelho demonstrando passagem do enxerto para reconstrução do LCA. Observamos o enxerto sendo tracionado para o interior da articulação pelo fio de Ethibond $\AA$ (verde)

FONTE: Arquivo do autor 

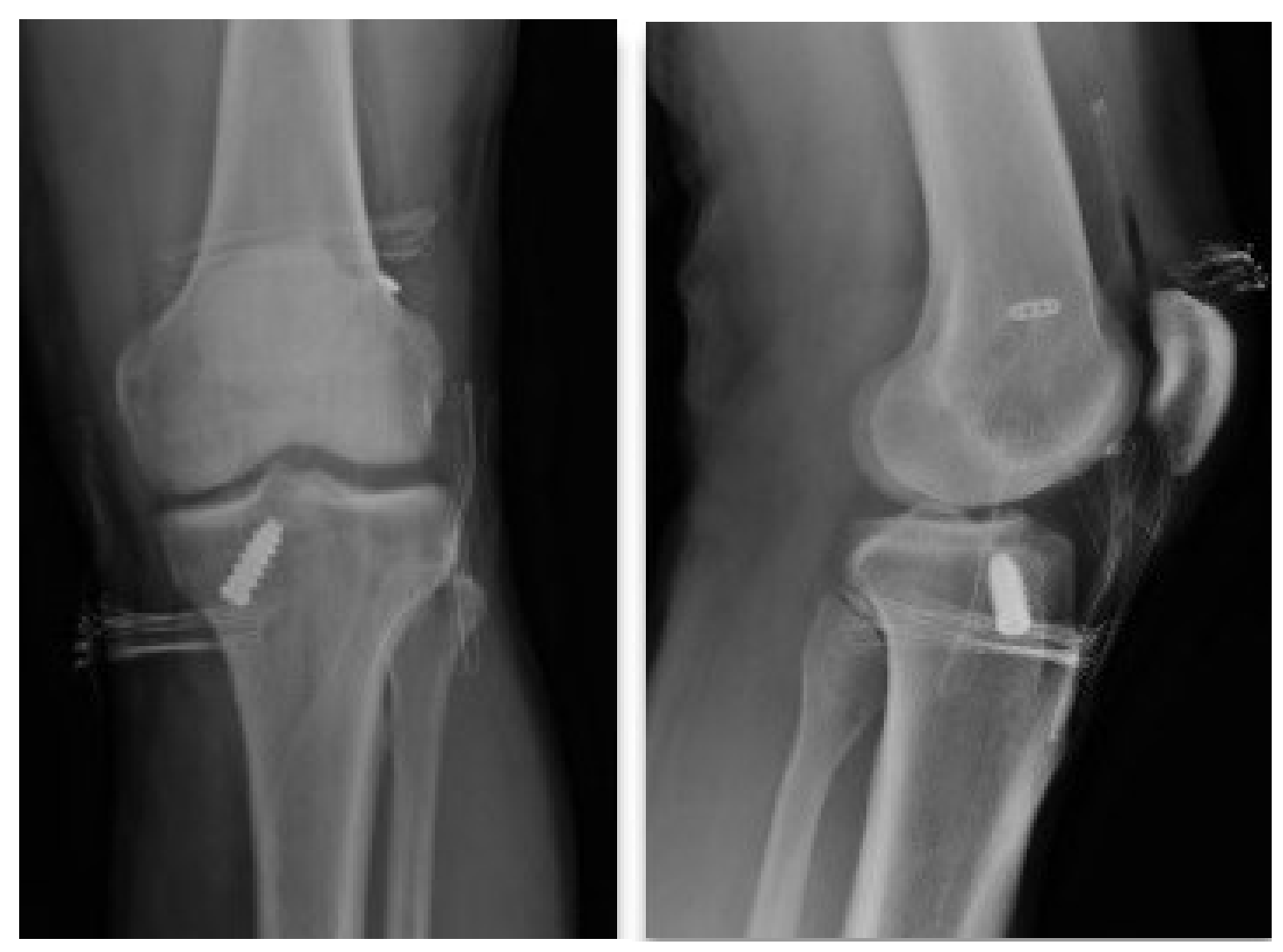

Figura 4 - Radiografias de joelho em posição anteroposterior e perfil após reconstrução do LCA. Observamos o dispositivo metálico de fixação cortical com laço de comprimento fixo do tipo endobutton junto à cortical lateral do fêmur e o parafuso de interferência metálico na tíbia

FONTE: Arquivo do autor 


\subsection{Programa de intervenção fisioterápica}

O programa de reabilitação foi o mesmo em todos os indivíduos operados e seguiu o protocolo de reabilitação do Grupo de Medicina do Esporte do IOTHC-FMUSP (Anexo 3). A fase de reabilitação iniciou-se durante a internação, com exercícios para recuperação da amplitude de movimento articular e contração isométrica do quadríceps. Permitimos a marcha com auxílio de muletas, com apoio progressivo no membro operado, durante três semanas. Os pacientes retornaram ao ambulatório na primeira e segunda semanas para avaliar o aspecto do curativo, presença de derrame articular e sinais flogísticos. A seguir orientamos o retorno após duas semanas, completando o primeiro mês, e a seguir mensalmente. Enfatizamos a recuperação do arco de movimento articular e da força muscular. A partir do primeiro mês permitimos exercícios com bicicleta ergométrica. Exercícios de propriocepção unipodálica foram recomendados após o terceiro mês de pós-operatório. Permitimos iniciar corrida em linha reta após o quarto mês de pós-operatório. 


\subsection{Protocolo de avaliação do $\mathrm{VO}_{2 \max }$}

Utilizamos eletrocardiograma (ECG) computadorizado (HeartWere $®$, Ergo 13, Belo Horizonte, Brasil) de 13 derivações para avaliar a resposta eletrocardiográfica e frequência cardíaca (FC) no repouso, durante o esforço e na fase de recuperação do teste de esforço. A pressão arterial (PA) foi medida indiretamente pelo método auscultatório antes do início do teste, durante o esforço e na fase de recuperação, utilizando-se esfigmomanômetro com leitura aneroide em $\mathrm{mmHg}$ (Tycos, EUA).

Os jogadores realizaram um teste de esforço em esteira rolante $\mathrm{h} / \mathrm{p} / \operatorname{cosmos} \AA$ (Pulsar, Alemanha) de velocidade $(\mathrm{km} / \mathrm{h})$ e inclinação (\%) variável (Figura 5). Utilizamos o protocolo de Heck modificado escalonado com incremento de $1,2 \mathrm{~km} / \mathrm{h}(20 \mathrm{~m} / \mathrm{min})$ a cada dois minutos e inclinação fixa de $2 \%{ }^{24}$. Neste protocolo, os jogadores permaneceram um minuto em repouso e foram aquecidos por três minutos nas velocidades de 4,8, 6,0 e 7,2 km/h com duração de um minuto cada. Logo em seguida os jogadores começaram a correr com a velocidade de $8,4 \mathrm{~km} / \mathrm{h}$ e incrementos de $1,2 \mathrm{~km} / \mathrm{h}$ a cada dois minutos $^{24}$ (Anexo 3).

Durante o transcorrer do teste e com o objetivo de aumentar a motivação, os indivíduos receberam encorajamento verbal. A percepção subjetiva do esforço foi quantificada, em cada estágio do teste de exercício cardiopulmonar, pela escala linear gradual de 15 pontos (6 a 20) de Borg, fixada próxima à esteira. O teste foi interrompido por exaustão voluntária, com 18 pontos ou mais na escala de Borg. O protocolo atendeu a expectativa de duração do teste para avaliação da capacidade física de cada atleta, de tal forma que o tempo total de exercício ficasse entre 8 e 17 minutos, conforme previamente descrito na literatura ${ }^{90}$. A fase de recuperação foi ativa, com duração de três minutos, iniciada imediatamente, com velocidades decrescentes com duração de um minuto. 


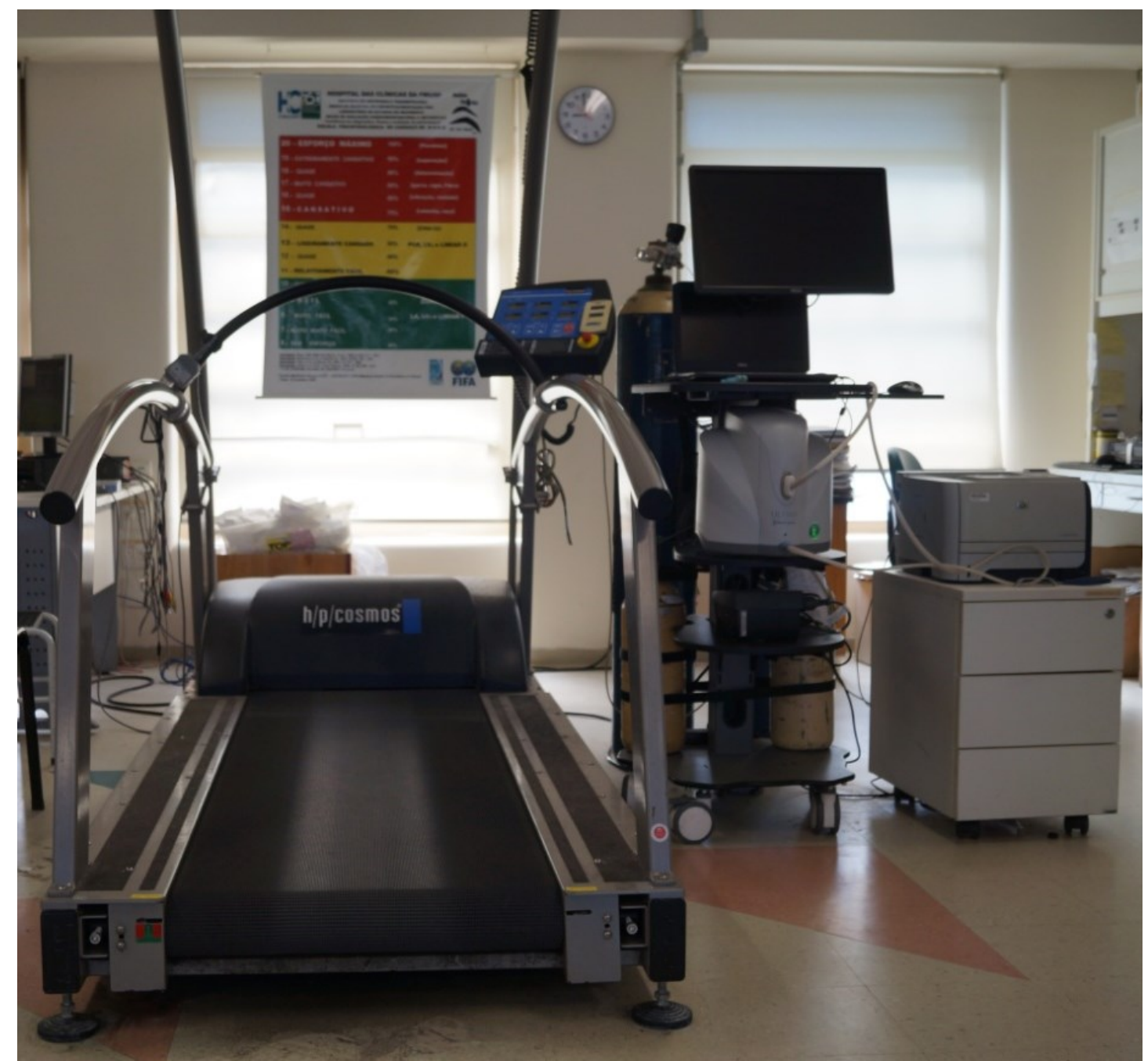

Figura 5 - Fotografia da esteira $h / p / \operatorname{cosmos}{ }^{\circledR}$ utilizada para os testes e equipamento de análise de troca gasosa. Obtida no Laboratório de Estudos do Movimento, IOTHCFMUSP

FONTE: Arquivo do autor 


\subsection{Análise de gases expirados (ergoespirometria)}

Os modernos sistemas de análise metabólica por meio dos gases expirados permitem a análise das trocas gasosas em repouso, durante 0 exercício e na fase de recuperação e produzem medidas respiração a respiração do consumo de oxigênio $\left(\mathrm{VO}_{2}\right)$, produção de dióxido de carbono $\left(\mathrm{VCO}_{2}\right)$ e ventilação (VE). É um método reprodutível e de alta confiabilidade e tem sido considerado padrão ouro na avaliação das trocas gasosas e utilizado por diversos autores tanto em indivíduos saudáveis quanto em indivíduos com doenças $^{91-93}$.

Todos os testes foram realizados pelo fisiologista Dr. Paulo Roberto dos Santos-Silva no Laboratório de Estudos do Movimento do IOTHCFMUSP. No presente estudo utilizamos um sistema computadorizado de análise de troca gasosa (CPX/ULTIMA, Medgraphics $\AA$, Saint Paul, MN, EUA) utilizando o software Breeze Suíte 6.4.1 (MGC Diagnostics ${ }^{\circledR}$, Saint Paul, MN, EUA) para captação dos dados respiração-a-respiração, armazenamento e processamento das variáveis cardiorrespiratórias e metabólicas (Figura 5).

A análise dos fluxos e volumes foi realizada por um pneumotacômetro bidirecional de pressão diferencial de alta precisão e espaço morto de $39 \mathrm{ml}$. O pneumotacômetro foi calibrado, antes da realização de cada teste, com uma seringa (5530, Hans Rudolph®, Kansas City, MO, EUA) por meio de dez movimentos (cinco expirações e cinco inspirações) com capacidade para três litros e espaço morto de $100 \mathrm{ml}$, empregado como fator de correção que determinou a leitura do volume respiratório. Foram medidas as pressões expiradas de oxigênio $\left(\mathrm{PETO}_{2}\right)$ por meio de uma célula do tipo zircônia de resposta rápida e elevada precisão $\left( \pm 0,03 \%\right.$ de $\left.\mathrm{O}_{2}\right)$, enquanto as pressões expiradas de dióxido de carbono $\left(\mathrm{PETCO}_{2}\right)$, pelo princípio infravermelho com precisão de $\pm 0,05 \%$ de $\mathrm{CO}_{2}$ e resposta $<130 \mathrm{~ms}$. Os analisadores de $\mathrm{O}_{2}$ e de $\mathrm{CO}_{2}$ foram calibrados, antes e imediatamente após a realização de cada teste, com mistura gasosa conhecida, em dois cilindros contendo as seguintes 
concentrações: $\mathrm{O}_{2}=11,9 \%$ e $20,9 \%$ e $\mathrm{CO}_{2}=5,09 \%$, e balanceada com nitrogênio $\left(\mathrm{N}_{2}\right)$, com a utilização da própria composição do ar atmosférico. As variáveis ventilatórias foram registradas respiração a respiração e depois calculadas para o tempo médio de 30 segundos. Os indivíduos foram posicionados na esteira com um capacete no qual se acoplou um bocal esterilizado. O nariz foi vedado com um prendedor, com o objetivo de captar o ar atmosférico para a análise dos gases expirados pelos sensores de $\mathrm{O}_{2}$ e $\mathrm{CO}_{2}$ (Figura 6).

A técnica de amostragem respiração a respiração avalia a quantidade de $\mathrm{O}_{2}$ consumida, resultante da diferença entre $\mathrm{O} \mathrm{O}_{2}$ inspirado, constante na atmosfera, e a quantidade de $\mathrm{O}_{2}$ expirado, além da produção de $\mathrm{CO}_{2}{ }^{41}$. Durante todo o protocolo de teste, os gases expirados foram coletados e analisados a cada ciclo respiratório. 


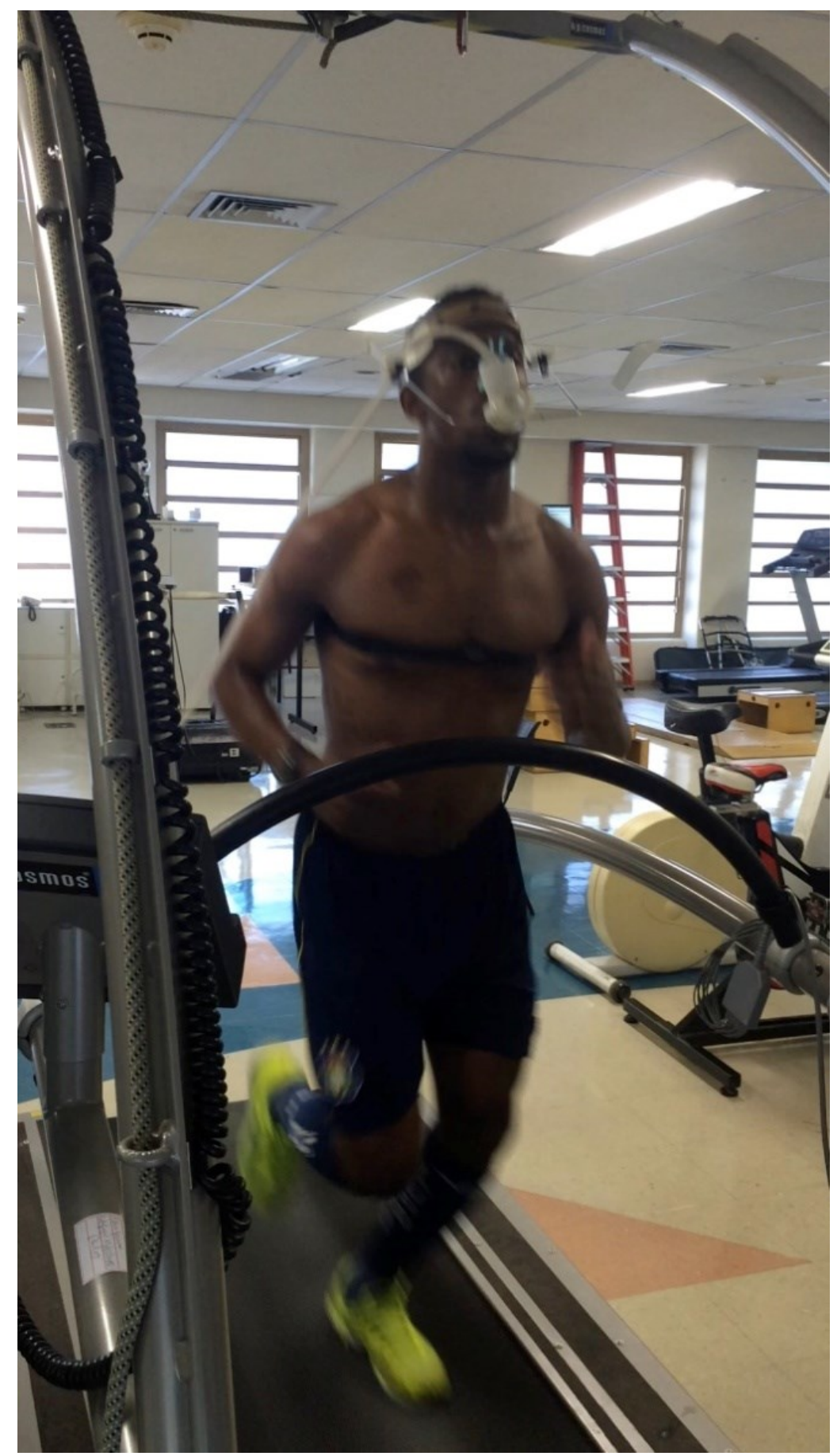

Figura 6 - Fotografia de atleta durante 0 teste ergoespirométrico. Fotografia obtida no Laboratório de Estudos do Movimento, IOTHCFMUSP

FONTE: Arquivo do autor 


\subsection{Parâmetros avaliados}

Foram avaliados, em repouso e no esforço, a ventilação pulmonar $\left(V_{E}\right)$, a frequência respiratória (FR), o volume corrente (VC), o consumo de oxigênio $\left(\mathrm{VO}_{2}\right)$, a produção de dióxido de carbono $\left(\mathrm{VCO}_{2}\right)$, a pressão expirada final de oxigênio $\left(\mathrm{PETO}_{2}\right)$, a pressão expirada final de dióxido de carbono $(\mathrm{PETCO} 2)$ e o pulso de oxigênio $\left(\mathrm{PO}_{2}\right)$. Foram calculados pelo software o quociente respiratório $\left(\mathrm{QR}=\mathrm{VCO}_{2} / \mathrm{VO}_{2}\right)$, o equivalente ventilatório de oxigênio $\left(\mathrm{V}_{\mathrm{E}} / \mathrm{VO}_{2}\right)$, e o equivalente ventilatório de dióxido de carbono $\left(\mathrm{V}_{\mathrm{E}} / \mathrm{VCO}_{2}\right)$.

Determinamos, no decorrer do teste, o limiar ventilatório um $\left(L_{1}\right)$, correspondente ao limiar anaeróbio, o limiar ventilatório dois $\left(L_{2}\right)$, correspondente ao ponto de compensação respiratória, e o consumo máximo de oxigênio $\left(\mathrm{VO}_{2 \max }\right)$ de acordo com a combinação de vários critérios de determinação, definidos a seguir (Figura 7) ${ }^{94}$.

$\mathrm{O} \mathrm{VO}_{2 \max }$ foi verificado quando os avaliados atingiram pelo menos três dos seguintes critérios de validação fisiológica: (a) platô do $\mathrm{VO}_{2}$, quando não foi verificado aumento no $\mathrm{VO}_{2}$ maior que $2,0 \mathrm{~mL} / \mathrm{kg} / \mathrm{min}$ para incremento de velocidade entre o penúltimo e o último estágio do teste; (b) quociente respiratório (QR) máximo, igual ou superior a 1.10 $10^{95,96}$; (c) frequência cardíaca (FC) máxima, igual ou superior a $95 \%$ da resposta cronotrópica máxima predita para a idade, de acordo com a equação de Tanaka [208 - (0,7 x idade $)]^{97}$; (d) valor igual ou superior a 18 na escala de percepção subjetiva de cansaço de Borg e (e) sinais de cansaço extremo como: intensa hiperpnéia, suor excessivo, rubor facial ou dificuldade de manter coordenação motora adequada com o incremento de velocidade da esteira rolante. A escala de Borg de percepção de cansaço foi utilizada em todos os testes para complementar a monitoração da intensidade do exercício. 


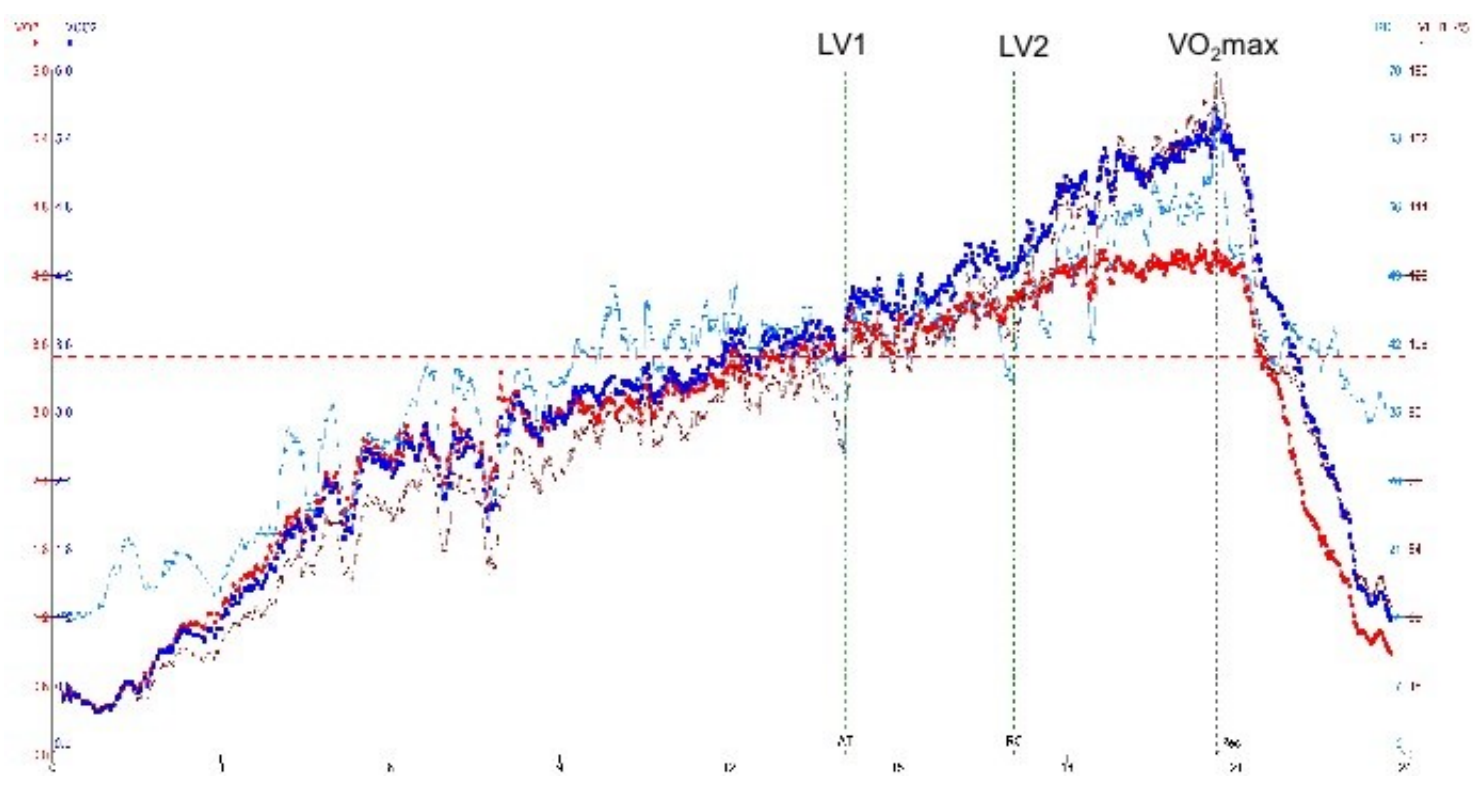

Figura 7 - Imagem obtida da tela do monitor ao final do teste de ergoespirometria na esteira. A linha vermelha representa o $\mathrm{VO}_{2}$; a linha azul representa o $\mathrm{VCO}_{2}$; a linha azul clara representa a frequência respiratória; a linha marrom representa a ventilação pulmonar. As linhas verticais paralelas determinam o limiar ventilatório um (LV1), limiar ventilatório dois (LV2) e consumo máximo de oxigênio $\left(\mathrm{VO}_{2 \max }\right)$. Explicação detalhada no texto

FONTE: $\quad$ Arquivo do autor 
$\mathrm{O} \mathrm{LV}_{2}$ foi determinado seguindo os seguintes critérios: (a) perda da linearidade da relação entre ventilação pulmonar $\left(V_{E}\right)$ e a produção de dióxido de carbono $\left(\mathrm{VCO}_{2}\right)$, verificada a partir do menor equivalente ventilatório de dióxido de carbono $\left(\mathrm{V}_{E} / \mathrm{VCO}_{2}\right)$, quando foi atingido o valor mais baixo de $\mathrm{V}_{\mathrm{E}} / \mathrm{VCO}_{2}$ antes de começar a aumentar; (b) verificação do maior valor da pressão expirada de dióxido de carbono $\left(\mathrm{PETCO}_{2}\right)$, precedendo sua queda abrupta, ou seja, valor mais alto de $\mathrm{PETCO}_{2}$ antes de começar a sua diminuição; (c) abrupto aumento da frequência respiratória $[F R]^{98}$; (12) (d) platô do volume corrente $[\mathrm{VC}]$ e (v) incremento abrupto da ventilação pulmonar $\left[\mathrm{V}_{\mathrm{E}}\right]^{99}$.

O LV 1 foi determinado seguindo os seguintes critérios: (a) perda da linearidade da relação entre ventilação pulmonar $\left(V_{E}\right)$ e o consumo de oxigênio $\left(\mathrm{VO}_{2}\right)$, verificada a partir do menor equivalente ventilatório de oxigênio $\left(V_{E} / V_{2}\right)$, quando foi atingido o valor mais baixo de $V_{E} / V_{2}$ antes de começar a aumentar ${ }^{100}$; (b) verificação do menor valor de pressão expirada de oxigênio $\left(\mathrm{PETO}_{2}\right)$; (c) ascensão do quociente respiratório (QR); (d) aumento abrupto da frequência respiratória (FR); e) platô do volume corrente (VC) e (f) incremento abrupto da ventilação pulmonar $\left(V_{E}\right)$.

\subsection{Teste de economia de corrida (EC)}

A economia de corrida $(E C)$ é definida como a demanda de energia para uma dada velocidade de corrida submáxima e é determinada medindo o consumo de oxigênio durante a corrida a essa velocidade estável. É medida pelo custo de oxigênio por unidade de massa corporal por distância percorrida $(\mathrm{mL} / \mathrm{kg} / \mathrm{km})^{62}$. Para o teste é necessária uma velocidade de corrida entre $70 \%$ e $85 \%$ do $\mathrm{VO}_{2 \max }$. Os atletas capazes de consumir menos oxigênio durante a 
execução do exercício em uma determinada velocidade têm, portanto, uma melhor EC.

O atleta realizava aquecimento por três minutos nas velocidades de 6 $\mathrm{km} / \mathrm{h}$ e $7,5 \mathrm{~km} / \mathrm{h}$, respectivamente. Posteriormente, corriam por mais dez minutos na velocidade fixa de $9,0 \mathrm{~km} / \mathrm{h}$ e esteira com inclinação de $2 \%$. Utilizamos a média do $\mathrm{VO}_{2}$ medido entre o $8^{\circ}, 9^{\circ}$ e $10^{\circ} \mathrm{min}$ a $9,0 \mathrm{~km} / \mathrm{h}$ como referência para o cálculo da $\mathrm{EC}$, que foi definida como a relação entre o $\mathrm{VO}_{2} \mathrm{e}$ a velocidade de corrida por km, segundo a fórmula e exemplo abaixo:

$$
\mathrm{EC}=\mathrm{VO}_{2}\left(\mathrm{mLO}_{2} / \mathrm{kg} / \mathrm{km}\right)=\mathrm{VO}_{2}(\mathrm{mLO} / \mathrm{kg} / \mathrm{min}) \div(\mathrm{vel}[\mathrm{km} / \mathrm{h}]) \times 60
$$

\section{Exemplo:}

$\mathrm{EC}=\mathrm{VO}_{2} 8^{\circ}=35 \mathrm{ml} / \mathrm{kg} / \mathrm{min}+9^{\circ}=33 \mathrm{ml} / \mathrm{kg} / \mathrm{min}+10^{\circ}=34 \mathrm{ml} / \mathrm{kg} / \mathrm{min}=102 / 3$

$E C=34 \mathrm{ml} / \mathrm{kg} / \mathrm{min} \div 9 \mathrm{~km} / \mathrm{h}=3,77$

$\mathrm{EC}=3,77 \times 60=226 \mathrm{mLO}_{2} / \mathrm{kg} / \mathrm{KM}$

\subsection{Teste isocinético computadorizado}

Realizamos teste isocinético para musculatura extensora e flexora do joelho no pré-operatório e aos seis meses de pós-operatório dos indivíduos com lesão de LCA e uma vez nos indivíduos do grupo controle. O teste isocinético foi realizado no aparelho Biodex System 3 Pro (Biodex Medical Systems, Inc. NY, EUA), no Laboratório de Medicina do Esporte do IOT (Figura 
8). O teste isocinético foi realizado pelo mesmo avaliador em todos os participantes da pesquisa objetivando manter a consistência do procedimento.

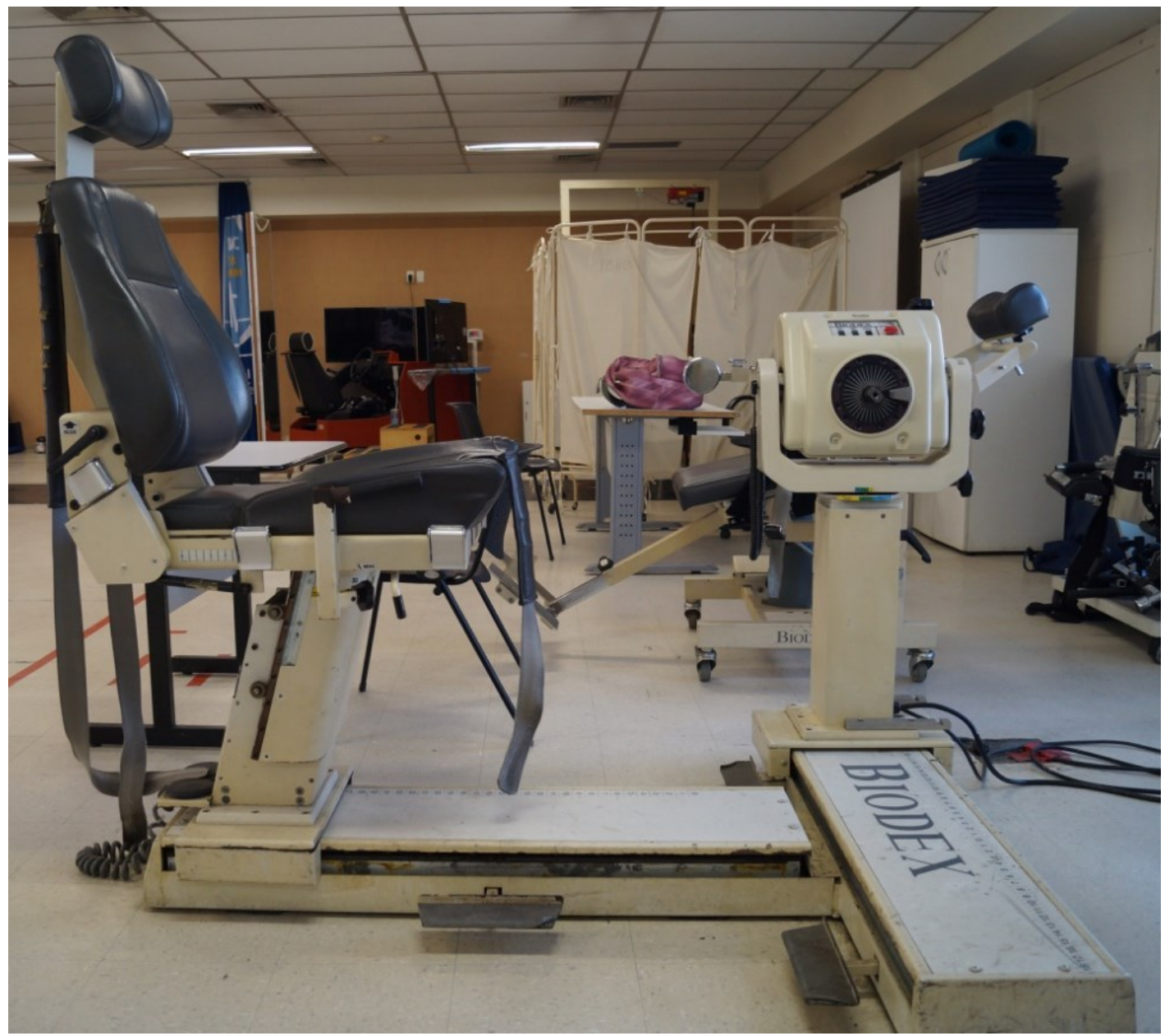

Figura 8 - Dinamômetro isocinético Biodex System 3 Pro® utilizado no estudo. Fotografia obtida no Laboratório de Estudos do Movimento, IOTHCFMUSP

FONTE: Arquivo do autor 
O paciente realizou um aquecimento de cinco minutos em bicicleta ergométrica, seguido de alongamento. $O$ experimento foi iniciado com 0 indivíduo posicionado de acordo com as referências e orientações do fabricante do equipamento, orientando o dinamômetro a $90^{\circ}$, com uma inclinação do mesmo de $0^{\circ}$, com o assento orientado a $90^{\circ}$ e inclinação do encosto de $85^{\circ}$. Para uma maior estabilidade do tronco foi utilizado um par de cintos de ombro e um cinto pélvico. A coxa e o tornozelo do membro a ser testado também foram presos com cintos. $O$ eixo de rotação do dinamômetro foi alinhado com o eixo da articulação do joelho (côndilo lateral do fêmur).

Foram realizados testes para avaliação da musculatura extensora e flexora do joelho nas velocidades angulares de $60 \%$ s e $240 \%$ s respectivamente no modo concêntrico. $O$ aparelho corrigia a ação da gravidade com a pesagem do membro avaliado relaxado, em flexão do joelho de $45^{\circ}$. Através deste dado os valores das variáveis isocinéticas foram automaticamente ajustados para gravidade pelo programa do equipamento. $O$ paciente foi orientado quanto ao teste, e realizou três repetições para aprendizado, com a perna não lesionada. O teste foi iniciado na velocidade angular de $60 \%$, com quatro repetições sucessivas com a perna não lesionada, e a seguir com a perna lesionada. Após descanso de oito segundos foram feitas 20 repetições na velocidade angular de $240 \%$, na mesma sequência. Os parâmetros avaliados foram o pico de torque, trabalho total e potência média, em termos absolutos e relativos à perna não lesionada (déficit percentual), e a relação entre o pico de torque dos músculos flexores e extensores da mesma perna (Anexo 4). 


\subsection{Avaliação da composição corporal por bioimpedância}

Os indicadores de composição corporal foram determinados por meio do método de bioimpedância tetrapolar, utilizando-se o aparelho multifrequência InBody 230 (Seul, Coréia do Sul) (Figura 9), segundo os procedimentos contidos no manual do próprio equipamento.

Os pacientes e os atletas do grupo controle foram orientados a estar em abstinência alcoólica nas últimas 24 horas, urinar até trinta minutos antes da avaliação e permanecer em repouso durante cinco minutos antes de iniciar a avaliação. Todas as avaliações foram realizadas às oito horas da manhã por um único e experiente profissional. Foram avaliados os parâmetros de massa corpórea, estatura, índice de massa corpórea, massa muscular, massa de gordura e porcentagem de gordura (Anexo 5). 


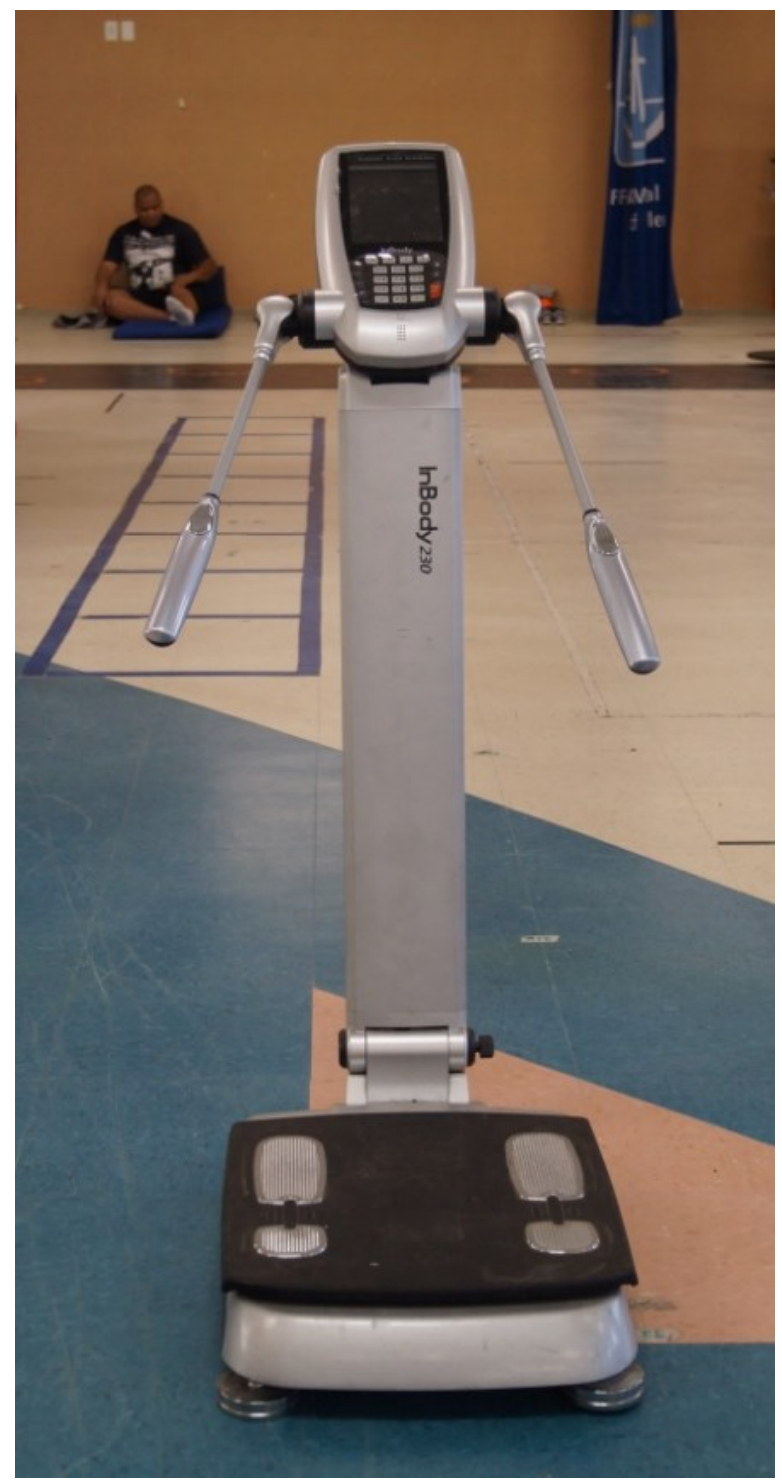

Figura 9 - Analisador de composição corporal $\ln B o d y \circledast 230$ utilizado no estudo. Fotografia obtida no Laboratório de Estudos do Movimento, IOT HCFMUSP

FONTE: Arquivo do autor 


\subsection{Questionários de função do joelho}

Para avaliação da função e sintomas da articulação do joelho utilizamos questionários específicos, com a função de padronizar a análise dos resultados, tentando excluir a subjetividade do pesquisador e do paciente. $O$ questionário IKDC subjetivo (International Knee Documentation Committee Subjective Knee Form $)^{78}$, foi desenvolvido como uma medida de avaliação para detectar evolução dos sintomas, atividades habituais e esportivas em pacientes com uma variedade de condições do joelho (Anexo 6). Este questionário foi adaptado e validado para o Brasil ${ }^{80}$. Portanto, a avaliação subjetiva do joelho pelo questionário IKDC é marcado pela soma das pontuações para os itens individuais e, em seguida, a transformação do resultado em uma escala que varia de 0 a 100. A resposta ao item 10 "Função Antes da Lesão do Joelho" não está incluída na pontuação geral. Os passos para marcar o questionário de avaliação subjetiva do joelho pelo IKDC são as seguintes: 1. Atribuir uma pontuação para a resposta individual de cada item, de modo que a pontuação mais baixa representa o menor nível de função ou nível mais elevado de sintomas. 2. Calcule a pontuação bruta somando as respostas de todos os itens, com exceção da resposta ao item 10 "Função Antes de sua lesão no joelho" 3. Transformar a pontuação total bruta numa escala de 0 a 100 como segue:

Pontuação IKDC $=\frac{\text { Pontuação total }- \text { pontuação mais baixa possível }}{\text { Pontuação mais alta possível }- \text { pontuação mais baixa possível }} X 100$

Onde o valor mais baixo possível é 18 e a diferença da pontuação possível é 87 . Assim, se a soma das pontuações (escores) para os 18 itens é 60, o IKDC será calculado da seguinte forma: 


$$
\text { Pontuação IKDC }=\frac{60-18}{87} \times 100
$$

Pontuação $I K D C=48,3$

O questionário proposto por Lysholm ${ }^{81}$ foi desenvolvido para avaliar o seguimento de cirurgias para lesões ligamentares do joelho e enfatiza os sintomas de instabilidade. É constituído de oito questões, com alternativas de respostas fechadas, com diferentes pontuações atribuídas a cada questão (Anexo 7). O resultado final é obtido pela soma das respostas e expresso quantitativa e qualitativamente. Um resultado de 95 a 100 pontos é classificado como excelente, 84 a 94 como bom, 65 a 83 regular e abaixo de 64 como ruim. Este questionário foi adaptado e validado para o Brasil ${ }^{82}$. Os pacientes e indivíduos do grupo controle responderam aos questionários IKDC e Lysholm. Estes questionários foram novamente aplicados nos indivíduos submetidos a reconstrução do LCA seis meses após a cirurgia, para avaliar o resultado do procedimento quanto à função do joelho.

\subsection{Cálculo da amostra}

Para estimativa do cálculo da amostra realizamos um estudo piloto com seis atletas com lesão do LCA, submetidos a teste ergoespirométrico de esforço máximo em esteira. Obtivemos o $\mathrm{VO}_{2 \max }$ destes atletas, que é o desfecho primário deste estudo. O $V_{2 \max }$ observado foi 41,91 $\pm 5,59$ $\mathrm{mL} / \mathrm{kg} / \mathrm{min}$ (média e desvio padrão). Baseados em estudos que avaliam o efeito do destreinamento sobre o $\mathrm{VO}_{2 \max }$, que estimam este efeito em $10 \%$ a $20 \%{ }^{45,47}$ consideramos que $15 \%$ sobre o $\mathrm{VO}_{2 \max }$ obtido neste piloto representaria um efeito clinicamente significativo, o que resultou em 48,20 $\pm 6,43 \mathrm{mLO}_{2} / \mathrm{kg} / \mathrm{min}$. Com estas premissas, calculamos a amostra necessária para um nível de 
significância ( $\alpha$ ) de $5 \%$ e um poder da amostra $(\beta)$ de $90 \%$, o que resultou em uma amostra (n) de 20 casos por grupo.

\subsection{Análise estatística}

Os dados coletados foram armazenados em uma planilha Excel que receberam a entrada de dados pelo pesquisador responsável do estudo. Para a análise estatística os dados foram importados para o programa SPSS 23 for MAC.

Para o desfecho primário deste estudo, o $\mathrm{VO}_{2 \max }$ consideramos a hipótese nula $\left(\mathrm{H}_{0}\right)$, que determina que a média populacional $(\mu)$ do $\mathrm{VO}_{2 \max }$ nos diferentes grupos não é significativamente diferente, ou:

$$
\mathrm{H}_{0}=\mu \mathrm{LCA}=\mu \mathrm{RLCA}=\mu \text { Controle }
$$

A análise estatística busca testar a hipótese nula. Ao rejeitar a hipótese nula, aceitamos a hipótese alternativa $\left(\mathrm{H}_{1}\right)$ :

$$
\mathrm{H}_{1}=\mu \mathrm{LCA} \neq \mu \mathrm{RLCA} \neq \mu \text { Controle }
$$

As variáveis independentes neste estudo foram a presença de lesão do LCA (grupo LCA), cirurgia de reconstrução do LCA (grupo RLCA) e grupo 
controle de indivíduos sem histórico de lesão nos joelhos (grupo controle). As demais variáveis foram consideradas variáveis dependentes.

Os dados contínuos foram descritos pela média e seu respectivo desvio padrão. Para estatística inferencial, todos os dados contínuos foram testados quanto a normalidade da sua distribuição com o teste de Kolmogorov-Smirnov. As comparações entre o grupo controle e os grupos LCA e RLCA foram analisados com testes independentes para comparação entre grupos (teste $\mathrm{t}$ de Student ou teste de Mann-Whitney). As comparações entre os grupos LCA e RLCA foram realizadas com testes pareados (teste $t$ de Student pareado ou teste de Wilcoxon).

Além das análises de comparação dos grupos, testes de correlação (Pearson ou Spearman) foram utilizados para verificar correlação entre o $\mathrm{VO}_{2}$ max e a EC com desfechos dos testes funcionais (IKDC e Lysholm).

Consideramos como diferença estatisticamente significativa o valor de $p$ $<0,05$ e utilizamos um poder de $90 \%(ß=, 10)$. 
5 Resultados 


\section{RESULTADOS}

Foram selecionados consecutivamente 25 pacientes, que preencheram os critérios de participação no estudo. Destes pacientes, um não conseguiu completar o teste de esteira devido a uma lesão meniscal em alça de balde. Um paciente foi reoperado devido a um ciclope e excluído no pós-operatório. Outros três pacientes não retornaram para seguimento. Desta forma, 20 pacientes completaram as avaliações.

O intervalo de tempo entre a lesão e a cirurgia variou entre a um a doze meses, com média de cinco meses e mediana de três meses.

Recrutamos um grupo de vinte jogadores de futebol profissional em atividade competitiva, sem histórico de lesões no joelho, para realizar os mesmos testes, cujos resultados foram utilizados como controle para comparação. Os atletas de futebol do grupo controle pertenciam a clubes profissionais vinculados a Federação Paulista de Futebol, São Paulo, SP, Brasil.

A idade dos pacientes com lesão do LCA variou entre 18 e 28 anos, com média e desvio padrão de 21,7 $\pm 3,3$ anos, enquanto nos atletas do grupo controle variou entre 18 e 34 anos, com média e desvio padrão de 22,1 \pm 4,6 anos. A análise estatística não demonstrou diferença significativa com relação à idade $(p=0,99)$.

As características antropométricas e a composição corporal foram avaliadas por bioimpedância nos atletas do grupo controle e nos atletas com lesão do LCA (grupo LCA) e após a reconstrução do LCA (RLCA). Não observamos diferenças estatisticamente significativas nestes parâmetros em qualquer uma das avaliações, conforme demonstramos na Tabela 1.

$\mathrm{O} \mathrm{VO}_{2 \max }$ e limiares ventilatórios foram avaliados nos momentos préoperatório e aos seis meses após RLCA e nos atletas do grupo controle 
(Tabela 2). $\mathrm{O} \mathrm{VO}_{2 \max }$ (Gráfico 1) no período pré-operatório variou entre 36,3 e $53,5 \mathrm{~mL} / \mathrm{kg} / \mathrm{min}$, com média de $45,15 \mathrm{~mL} / \mathrm{kg} / \mathrm{min}$ (IC 95\% 43,1; 47,1) e seis meses após RLCA aumentou para 48,94 $\mathrm{mL} / \mathrm{kg} / \mathrm{min}(p<, 001)$, variando entre 42,9 e $57,6 \mathrm{~mL} / \mathrm{kg} / \mathrm{min}$ (IC $95 \% 47,1 ; 50,7$ ). Observamos $\mathrm{VO}_{2 \max }$ no grupo controle entre 45,5 e $63,9 \mathrm{~mL} / \mathrm{kg} / \mathrm{min}$, com média de $56,85 \mathrm{~mL} / \mathrm{kg} / \mathrm{min}$ (IC 54,9; $58,8)$, significativamente superior aos encontrados nos pacientes com lesão do LCA e após RLCA ( $p<, 001$ em ambas as situações).

A velocidade média em que os atletas atingiram $\circ \mathrm{VO}_{2 \max }$ (Tabela 2) aumentou significativamente de $14,3 \mathrm{~km} / \mathrm{h}$ para $15,3 \mathrm{~km} / \mathrm{h}$ entre os períodos pré e pós-operatório $(p=, 007)$ enquanto a velocidade média atingida pelo grupo controle foi de $17,1 \mathrm{~km} / \mathrm{h}$, significativamente superior à dos pacientes com lesão do LCA e após RLCA de ( $p<, 001$ em ambas as situações) (Gráfico 3).

O LV2, ou ponto de compensação respiratória (Gráfico 3) aumentou significativamente de $38,3 \mathrm{~mL} / \mathrm{kg} / \mathrm{min}$ entre o período pré-operatório para 41,42 $\mathrm{mL} / \mathrm{kg} / \mathrm{min}$ após RLCA $(p=, 008)$, enquanto no grupo controle observamos média de $49,07 \mathrm{~mL} / \mathrm{kg} / \mathrm{min}$ ( $p<, 001 \mathrm{em}$ ambas as situações). 
Tabela 1 - Análise da composição corporal dos atletas com lesão do LCA nos momentos pré-operatório e pós-operatório e nos atletas do grupo controle

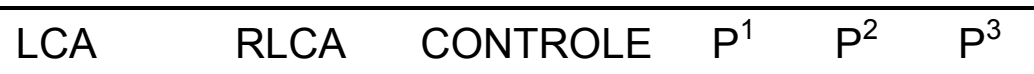

\begin{tabular}{lllllll}
\hline Massa corpórea & $79,2 \pm 10,1$ & $79,3 \pm 8,9$ & $74,8 \pm 6,2$ & 0,2 & 0,12 & 0,07 \\
(kg) & &
\end{tabular}

\begin{tabular}{|c|c|c|c|c|c|c|}
\hline $\begin{array}{l}\text { Massa muscular } \\
(\mathrm{kg})\end{array}$ & $38,4 \pm 4,8$ & $38,4 \pm 4,1$ & $37,3 \pm 3,6$ & 0,36 & 0,43 & 0,37 \\
\hline $\begin{array}{l}\text { Massa de } \\
\text { gordura (kg) }\end{array}$ & $11,7 \pm 3,9$ & $12 \pm 5,1$ & $9,6 \pm 3,1$ & 0,55 & 0,07 & 0,07 \\
\hline
\end{tabular}

\begin{tabular}{llllll|l}
$\begin{array}{l}\text { Água corporal } \\
\text { total } \mathbf{( k g )}\end{array}$ & $49,2 \pm 5,8$ & $49,3 \pm 5$ & $47,7 \pm 4,5$ & 0,33 & 0,37 & 0,3
\end{tabular}

$\begin{array}{lllllll}\text { Massa livre de } & 67,2 \pm 8 & 67,3 \pm 6,8 & 65,2 \pm 6,1 & 0,34 & 0,38 & 0,32 \\ \text { gordura (kg) } & & \end{array}$

$\begin{array}{lcccrrr}\begin{array}{l}\text { Gordura corporal } \\ \text { (\%) }\end{array} & 14,7 \pm 3,7 & 14,9 \pm 5,4 & 12,8 \pm 4 & 0,76 & 0,12 & 0,16 \\ \begin{array}{l}\text { Relação cintura } \\ \text { quadril }\end{array} & 0,82 \pm 0,2 & \begin{array}{c}0,82 \pm \\ 0,03\end{array} & 0,83 \pm 0,3 & 0,33 & 0,95 & 0,63\end{array}$

\begin{tabular}{lcccccc|} 
Taxa metabólica & $1822,1 \pm$ & $1823,5 \pm$ & $1778,5 \pm$ & 0,33 & 0,38 & 0,32 \\
basal & 172,3 & 147,6 & 132,01 & & & \\
\hline IMC & $23,7 \pm 2$ & $24 \pm 2$ & $23,4 \pm 1,8$ & 0,11 & 0,68 & 0,34 \\
\hline
\end{tabular}

LCA: atletas com lesão do LCA, antes da cirurgia; RLCA: atletas após reconstrução do LCA. IMC: índice de massa corpórea

$\mathrm{P}^{1}$ : valor de $\mathrm{p}$ na comparação entre o grupo LCA e RLCA (pareado); $p^{2}$ : valor de $p$ na comparação entre o grupo LCA e controle; $p^{3}$ : valor de $p$ na comparação entre o grupo RLCA e controle. 
Tabela 2 - Resultados do consumo máximo de oxigênio $\left(\mathrm{VO}_{2 \mathrm{max}}\right)$ e limiares ventilatórios um (LV1) e dois (LV2) obtidos no teste ergoespirométrico em esteira

\begin{tabular}{|c|c|c|c|c|c|c|}
\hline & LCA & RLCA & CONTROLE & $\mathbf{P}^{1}$ & $\begin{array}{c}\mathrm{P}^{2} \\
\text { (IC } 95 \% \text { da difere }\end{array}$ & $\mathbf{P}^{3}$ \\
\hline $\begin{array}{l}\mathrm{VO}_{2 \max } \\
(\mathrm{mL} / \mathrm{kg} / \mathrm{min})\end{array}$ & $45,15 \pm 4,3$ & $48,94 \pm 3,8$ & $56,85 \pm 4,19$ & $<, 001(-5,6 ;-2)$ & $<, 001(8,9 ; 14,4)$ & $<, 001(5,4 ; 10,5)$ \\
\hline $\mathrm{vVO}_{2 \max }(\mathrm{km} / \mathrm{h})$ & $14,3 \pm 1,8$ & $15,3 \pm 1,6$ & $17,1 \pm 1,2$ &, $007(1,8 ; 3,8)$ & $<, 001(1,8 ; 3,8)$ & $<, 001(0,9 ; 2,7)$ \\
\hline LV2 (mL/kg/min) & $38,3 \pm 4,1$ & $41,42 \pm 4,53$ & $49,07 \pm 3,58$ &, $008(-5,5 ;-0,9)$ & $<, 001(8,3 ; 13,2)$ & $<, 001(5 ; 10,2)$ \\
\hline vLV2 (km/h) & $11,3 \pm 1$ & $11,9 \pm 1$ & $13,6 \pm 0,9$ & ,006 (1,7; 2,9) & $<, 001(1,7 ; 2,9)$ & $<, 001(1,1 ; 2,3)$ \\
\hline$\% \mathrm{VO}_{2 \max } \mathrm{LV2}$ & $84,9 \pm 6,3$ & $84,7 \pm 7,2$ & $86,5 \pm 4,3$ &, $92(-4,8 ; 5,3)$ &, $38(-1,9 ; 4,9)$ &, $36(-2,1 ; 5,6)$ \\
\hline LV1 (mL/kg/min) & $30,26 \pm 5,13$ & $34,28 \pm 3,54$ & $37,23 \pm 3,76$ &, $006(-6,7 ;-1,3)$ & $<, 001(4,1 ; 9,8)$ & ,015 (0,6; 5,3) \\
\hline vLV1 (km/h) & $9,2 \pm 0,9$ & $9,8 \pm 0,7$ & $10,2 \pm 0,7$ &, $025(0,5 ; 1,5)$ & $<, 001(0,5 ; 1,5)$ & ,095 (-0,4; 0,9) \\
\hline$\% V_{2 \max } L V 1$ & $66,9 \pm 8,6$ & $70,3 \pm 7,4$ & $65,7 \pm 6,4$ &, $22(-9 ; 2,2)$ &, $61(-6,1 ; 3,6)$ & $0,04(-9,1 ;-0,2)$ \\
\hline EC (mL/kg/km) & $208,8 \pm 15,5$ & $217,6 \pm 16,9$ & $212 \pm 22,8$ & ,050 (-17,6; 0,01) & ,43 (-10,3; 16,7) &, $75(-19,7 ; 8,5)$ \\
\hline
\end{tabular}

LCA: atletas com lesão do LCA, antes da cirurgia; RLCA: atletas após reconstrução do LCA. IMC: índice de massa corpórea

$\mathrm{P}^{1}$ : valor de $\mathrm{p}$ na comparação entre o grupo LCA e RLCA (pareado); $\mathrm{p}^{2}$ : valor de $p$ na comparação entre o grupo LCA e controle; $\mathrm{p}^{3}$ : valor de $p$ na comparação entre o grupo RLCA e controle. IC: Intervalo de confiança

$\mathrm{VVO}_{2 \max }, \mathrm{VLV} 2$ e vLV1: velocidades de corrida no $\mathrm{VO}_{2 \max }$, LV2 e LV1, respectivamente.

$\% \mathrm{VO}_{2 \max } \mathrm{LV} 2 \mathrm{e} \% \mathrm{VO}_{2 \max } \mathrm{LV} 1$ : porcentagem do $\mathrm{VO}_{2 \max }$ correspondentes ao LV2 e LV1, respectivamente. EC: economia de corrida 
Gráfico 1 - Consumo máximo de oxigênio $\left(\mathrm{VO}_{2 \max }\right)$ nos grupos avaliados

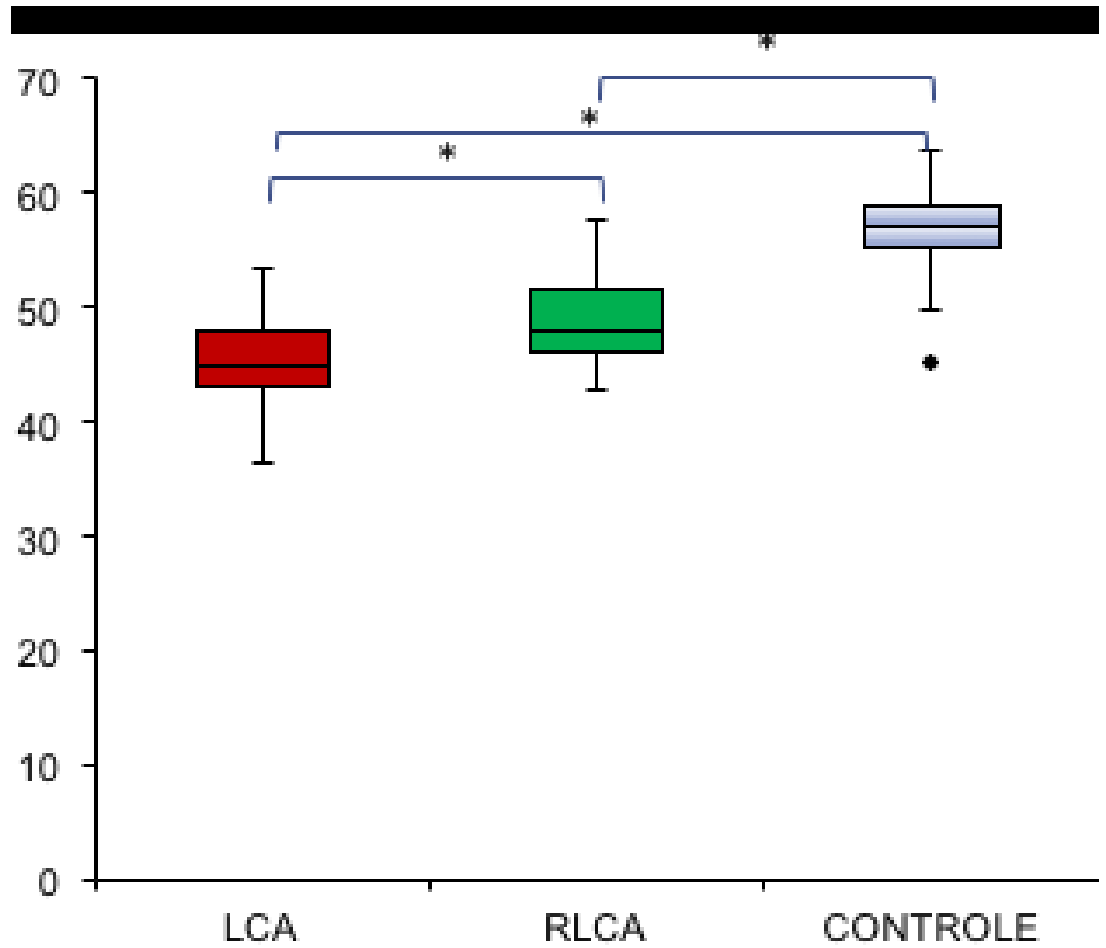

Dados em $\mathrm{mL} / \mathrm{kg} / \mathrm{min}$. Os colchetes e asteriscos indicam $\mathrm{p}<, 05$

Gráfico 2 - Velocidade no $\mathrm{VO}_{2 \max }\left(\mathrm{VVO}_{2 \max }\right)$ nos grupos avaliados

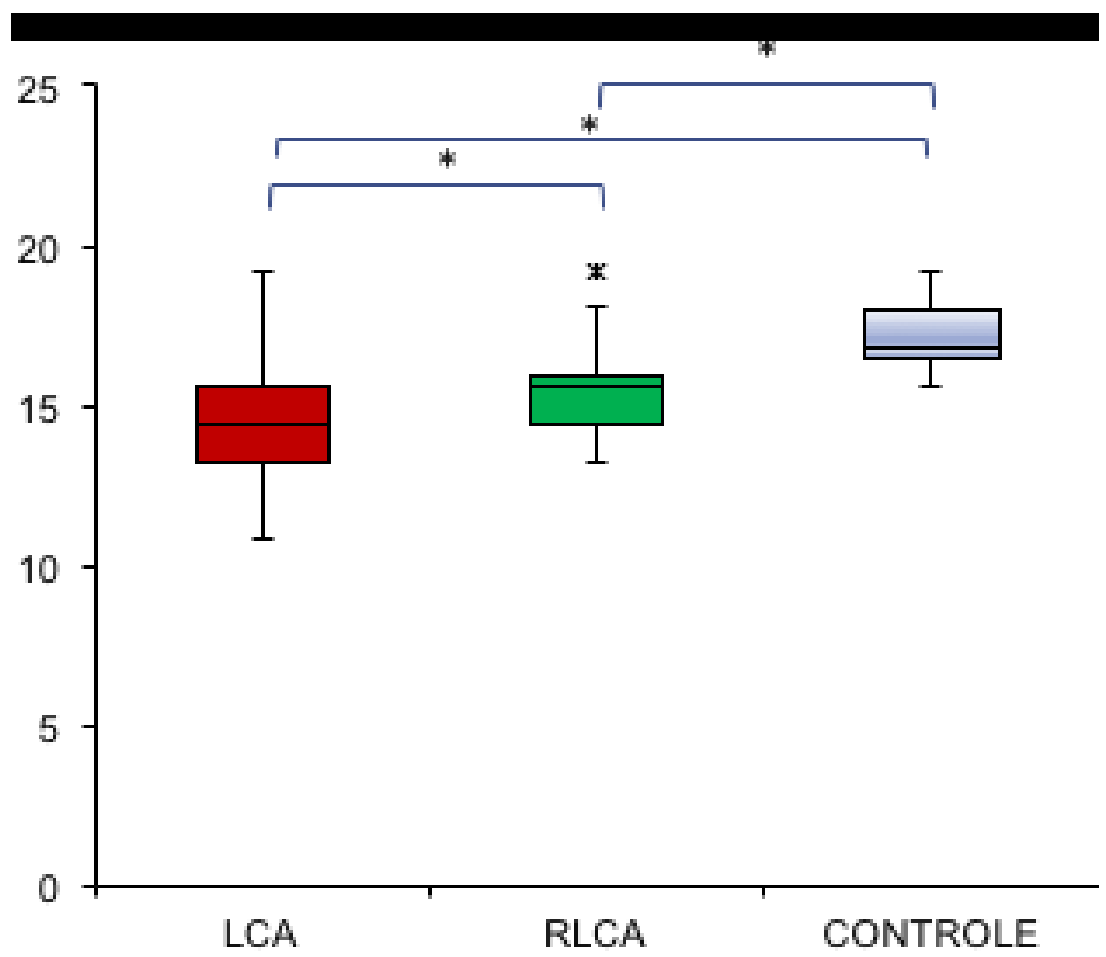

Dados em $\mathrm{km} / \mathrm{h}$. Os colchetes e asteriscos indicam $\mathrm{p}<, 05$. 
Gráfico 3 - Limiar ventilatório dois (LV2), ou ponto de compensação respiratória, nos grupos avaliados

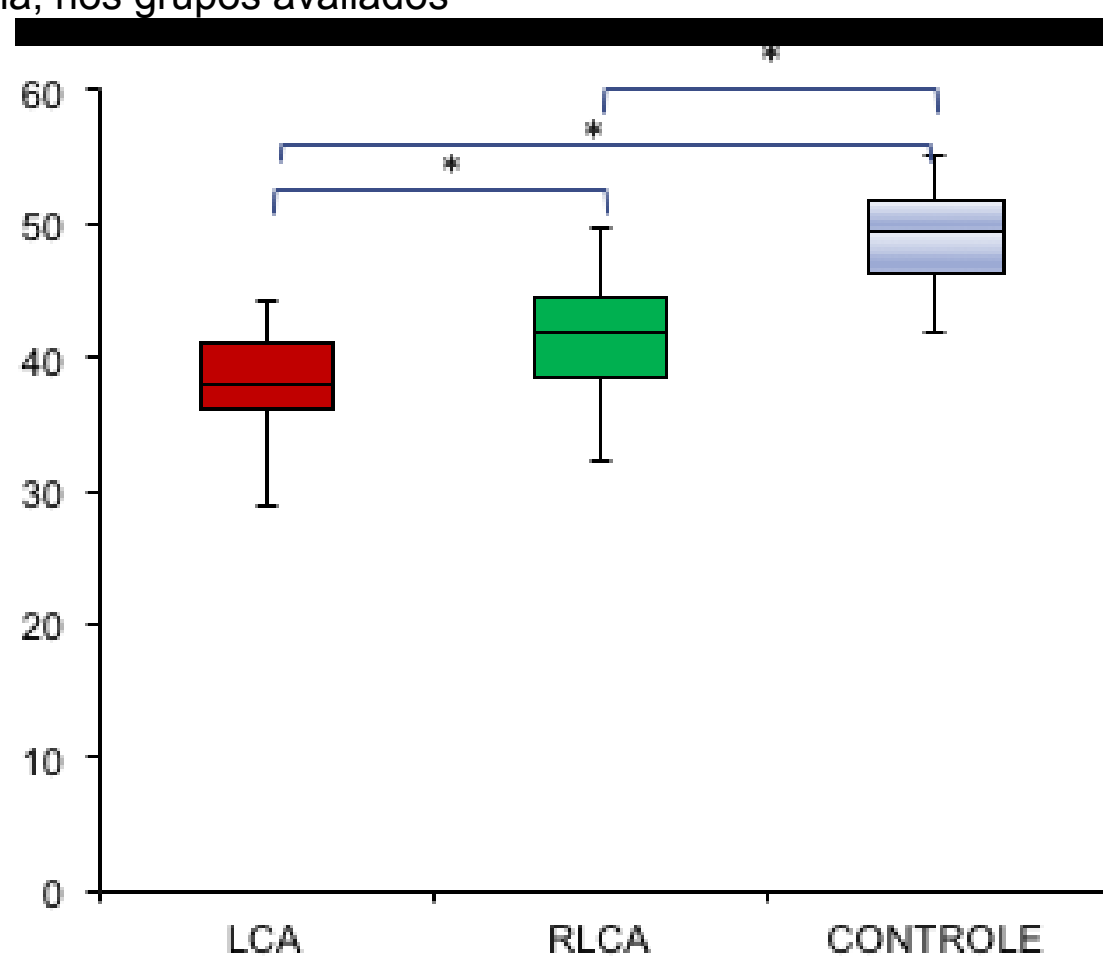

Dados em $\mathrm{mL} / \mathrm{kg} / \mathrm{min}$. Os colchetes e asteriscos indicam $\mathrm{p}<, 05$ 
A velocidade média em que os atletas atingiram o LV2 (Tabela 2) aumentou significativamente de $11,3 \mathrm{~km} / \mathrm{h}$ para $11,9 \mathrm{~km} / \mathrm{h}$ entre os períodos pré-operatório e após RLCA $(p=, 006)$ enquanto a velocidade média em que o grupo controle atingiu o LV2 foi de $13,6 \mathrm{~km} / \mathrm{h}$, significativamente superior à dos pacientes com lesão do LCA e após RLCA ( $p<, 001$ em ambas as situações) (Gráfico 4).

Os valores obtidos no LV2 no pré-operatório (Tabela 2) representaram $84,9 \%$ do $\mathrm{VO}_{2 \max }$ observado para este grupo enquanto os valores obtidos no LV2 após RLCA representaram $84,7 \%$ do $\mathrm{VO}_{2 \max }(p=, 92)$. No grupo controle os valores obtidos no LV2 representaram $86,5 \%$ do $\mathrm{VO}_{2 \max }$, sem diferença estatisticamente significativa quando comparado aos resultados préoperatórios ou após reconstrução do LCA (Gráfico 7).

O LV1, ou limiar anaeróbio aumentou significativamente de 30,26 $\mathrm{mL} / \mathrm{kg} / \mathrm{min}$ entre o período pré-operatório para $34,28 \mathrm{~mL} / \mathrm{kg} / \mathrm{min}$ após RLCA $(p=, 006)$, enquanto no grupo controle observamos média de $37,23 \mathrm{~mL} / \mathrm{kg} / \mathrm{min}$ ( $p<, 001$ e $p=0,015$ na comparação com os resultados de LCA e RLCA, respectivamente) (Gráfico 5).

A velocidade média em que os atletas atingiram o LV1 (Tabela 2) aumentou significativamente de $9,2 \mathrm{~km} / \mathrm{h}$ para $9,8 \mathrm{~km} / \mathrm{h}$ entre os períodos préoperatório e após RLCA $(p=, 025)$ enquanto a velocidade média em que o grupo controle atingiu o LV1 foi de $10,2 \mathrm{~km} / \mathrm{h}$, significativamente superior à dos pacientes com lesão do LCA $(p<, 001)$, mas não após RLCA $(p=, 095)$ (Gráfico 6).

Os valores obtidos no LV1 no pré-operatório representaram $66,9 \%$ do $\mathrm{VO}_{2 \max }$ observado para este grupo (Gráfico 7), enquanto os valores obtidos no LV1 após RLCA representaram $70,3 \%$ do $\mathrm{VO}_{2 \max }(\mathrm{p}=, 22)$. No grupo controle os valores obtidos no LV1 representaram $65,7 \%$ do $\mathrm{VO}_{2 \max }$, com diferença significativa quando comparado aos resultados após reconstrução do LCA $(p=, 04)$. 
Gráfico 4 - Velocidade no LV2 (vLV2) nos grupos avaliados

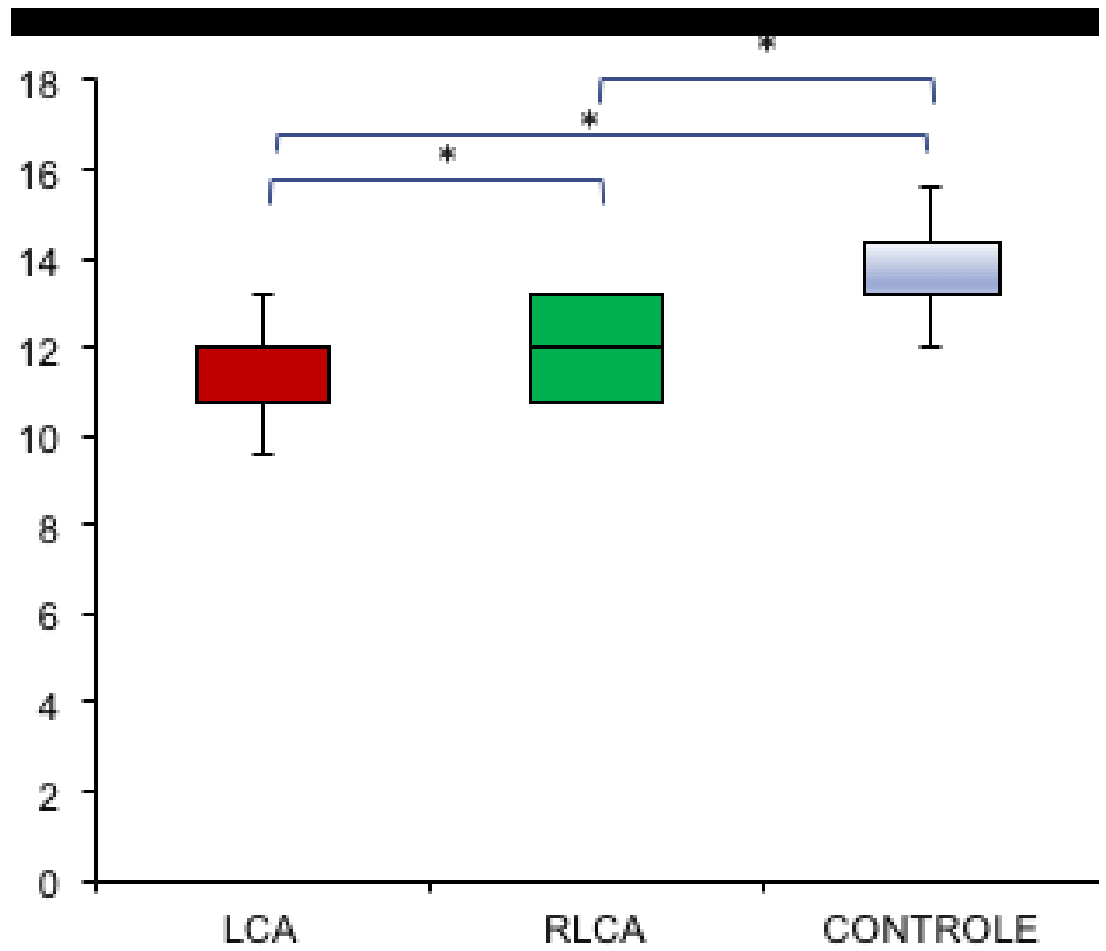

Dados em $\mathrm{km} / \mathrm{h}$. Os colchetes e asteriscos indicam $\mathrm{p}<, 05$.

Gráfico 5 - Limiar ventilatório um (LV1), ou limiar anaeróbio, nos grupos avaliados

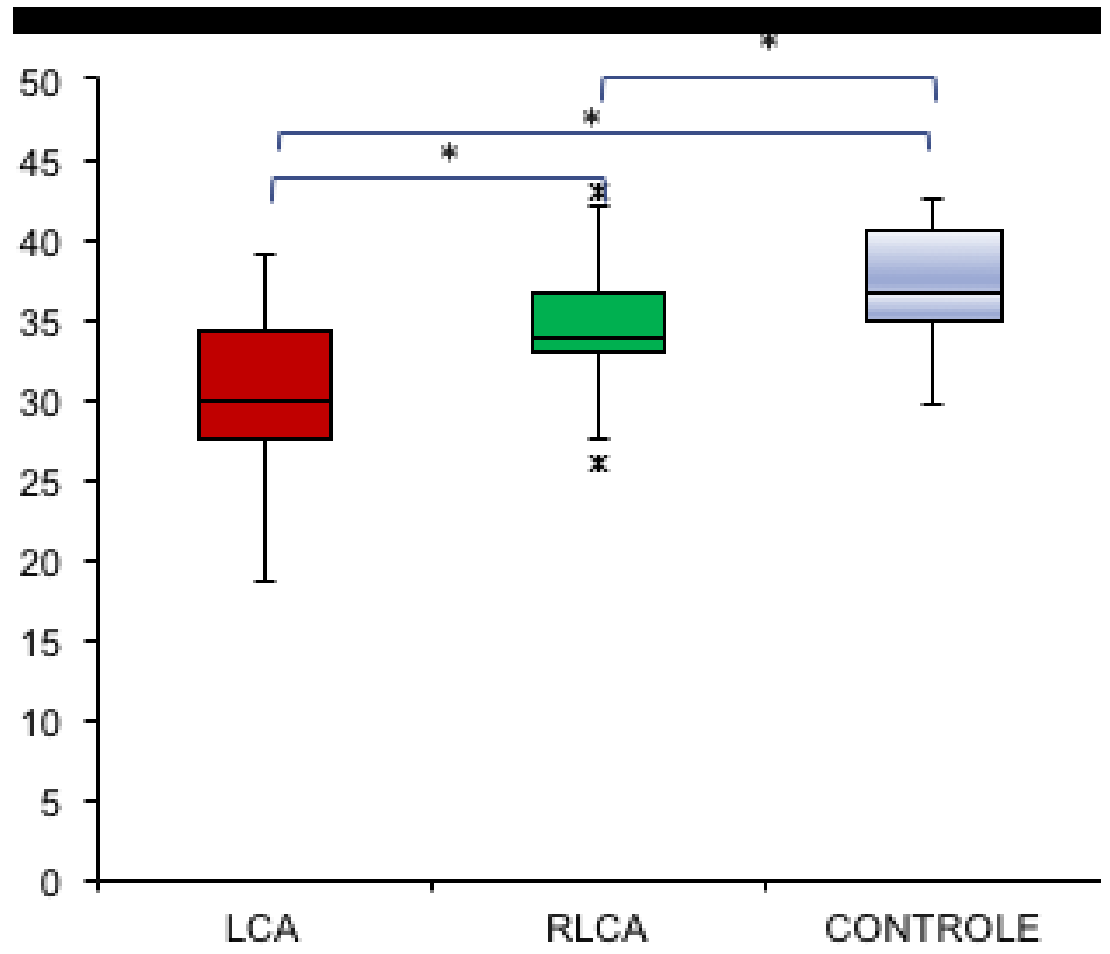

Dados em $\mathrm{mL} / \mathrm{kg} / \mathrm{min}$. Os colchetes e asteriscos indicam $\mathrm{p}<, 05$ 
Gráfico 6 - Velocidade no LV1 (vLV1) nos grupos avaliados

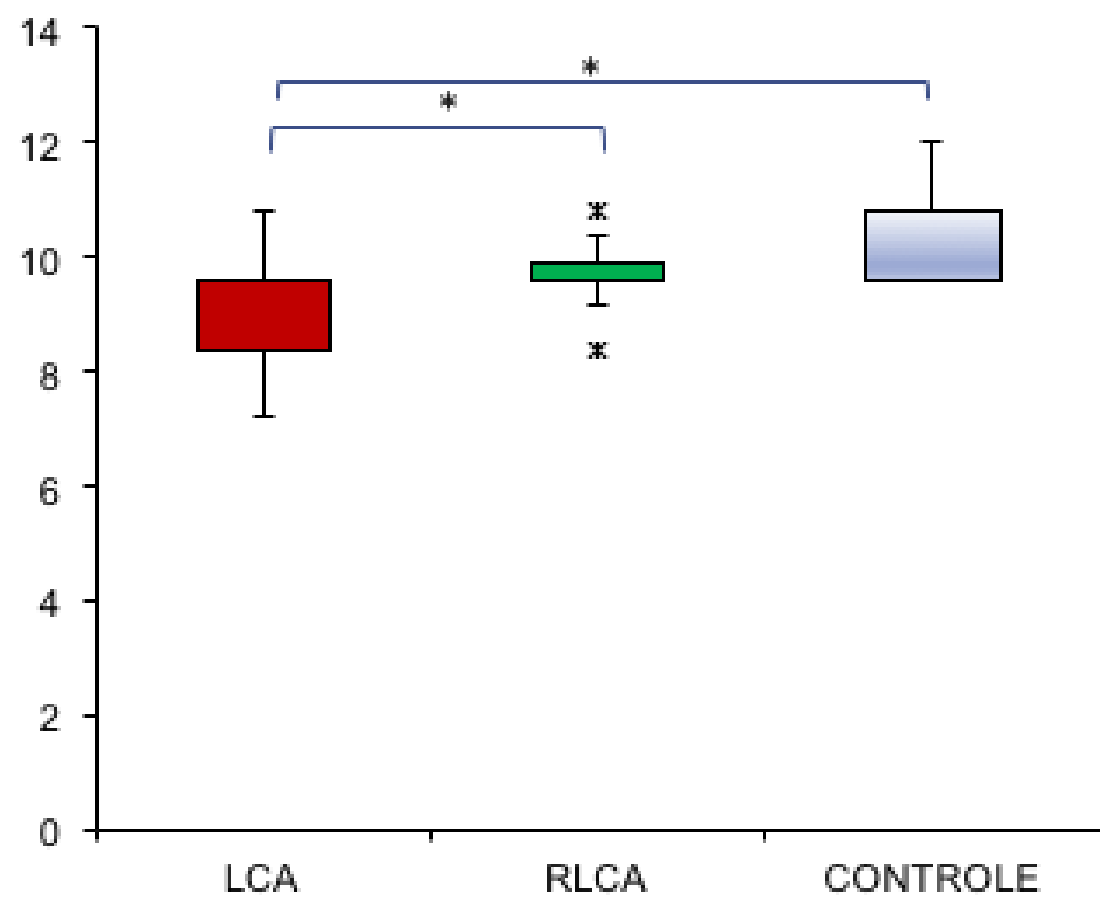

Dados em $\mathrm{km} / \mathrm{h}$. Os colchetes e asteriscos indicam $\mathrm{p}<, 05$.

Gráfico 7 - Composição do $\mathrm{VO}_{2 \max }$ nos diferentes grupos

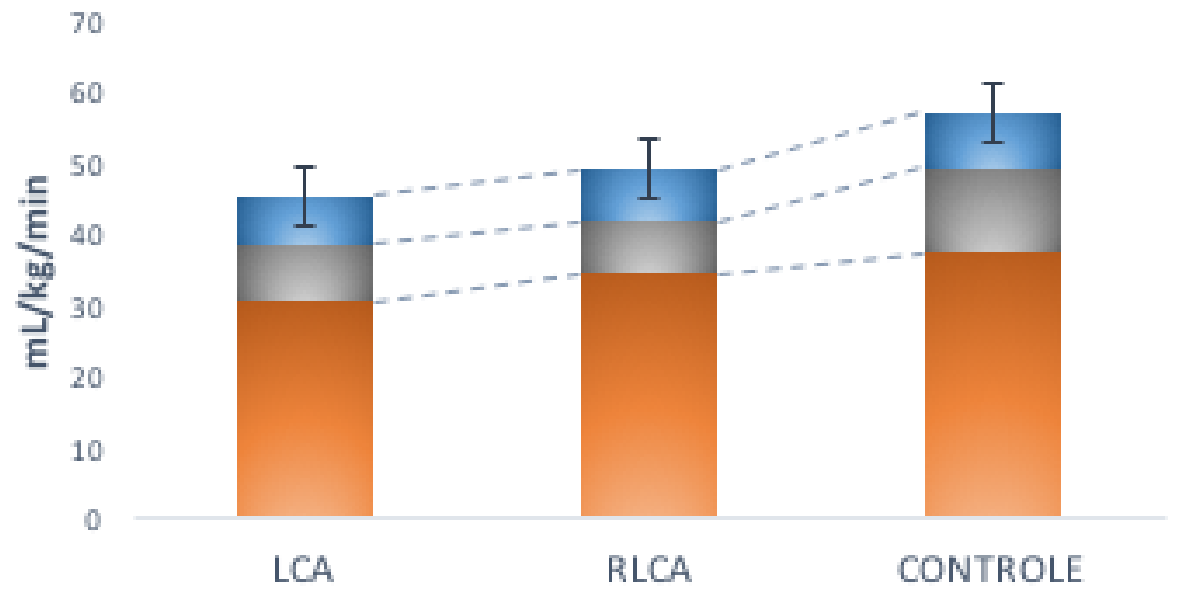

nLV1 nLV2 nVO2max 
A economia de corrida (Tabela 2) no período pré-operatório foi de 208,8 $\mathrm{mL} / \mathrm{kg} / \mathrm{km}$ e seis meses após RLCA aumentou para 217,6 mL/kg/km ( $p=, 0502)$. Observamos economia de corrida de $212 \mathrm{~mL} / \mathrm{kg} / \mathrm{min}$ no grupo controle, sem diferença estatisticamente significativa quando comparado aos resultados préoperatórios ou após reconstrução do LCA (Gráfico 8).

Os questionários de função do joelho Lysholm e IKDC foram aplicados nos momentos pré-operatório e seis meses após RLCA e nos atletas do grupo controle (Tabela 3). O resultado do questionário IKDC no momento préoperatório foi de 59,46, e apresentou um aumento significativo seis meses após RLCA para 87,75 ( $p<, 001$ ), enquanto no grupo controle foi de 97,28, significativamente superior à dos pacientes com lesão do LCA e após RLCA ( $p<, 001$ em ambas as situações) (Gráfico 9).

O resultado do questionário Lysholm no momento pré-operatório foi de 77,25 , e apresentou um aumento significativo seis meses após RLCA para $94,12$ ( $p<, 001)$, enquanto no grupo controle foi de 97,5, significativamente superior à dos pacientes com lesão do LCA e após RLCA $(p<, 001$ e $p=0,03$ na comparação com os resultados de LCA e RLCA, respectivamente) (Gráfico 10). A distribuição dos resultados categorizados do questionário Lysholm está demonstrada no Gráfico 11. Observamos diferença estatisticamente significativa em todas as comparações entre os grupos. 
Gráfico 8 - Economia de corrida (EC) nos grupos avaliados

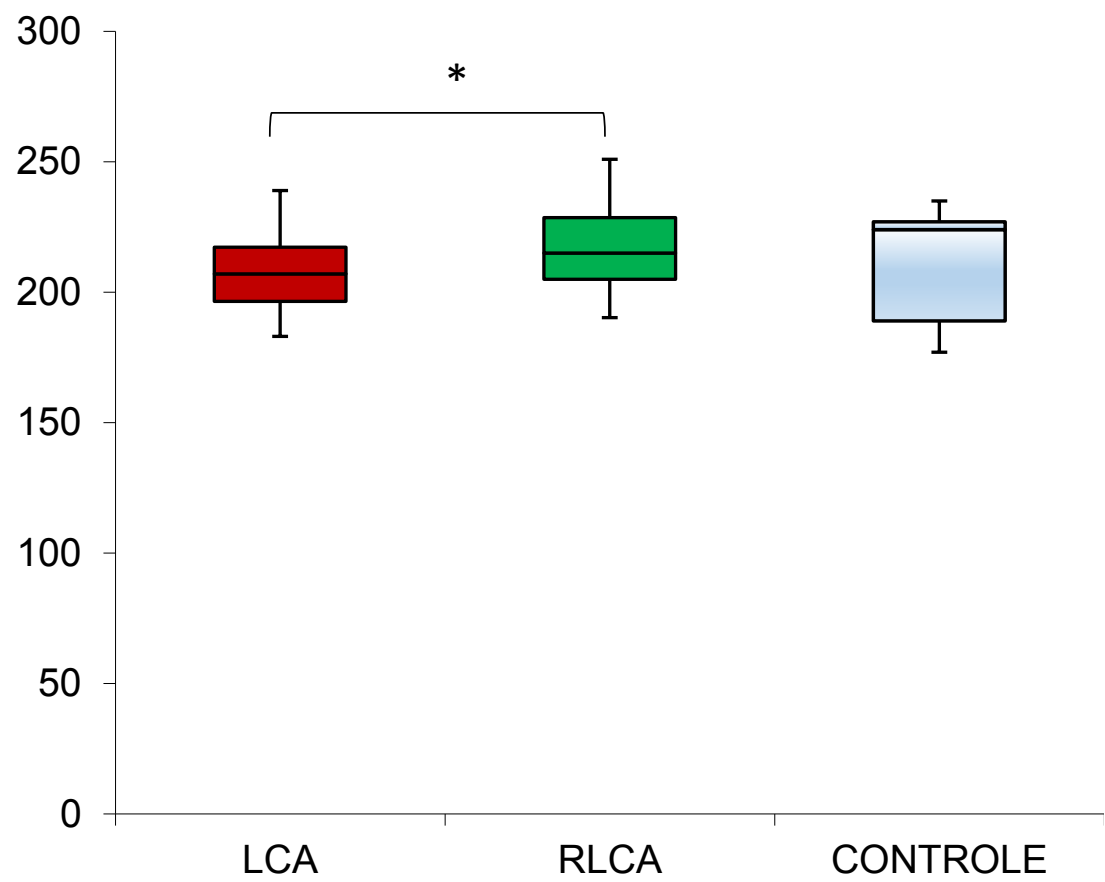

Dados em $\mathrm{mL} / \mathrm{kg} / \mathrm{km}$. Os colchetes e asteriscos indicam $\mathrm{p}<, 05$.

Gráfico 9 - Resultados do questionário IKDC nos grupos avaliados

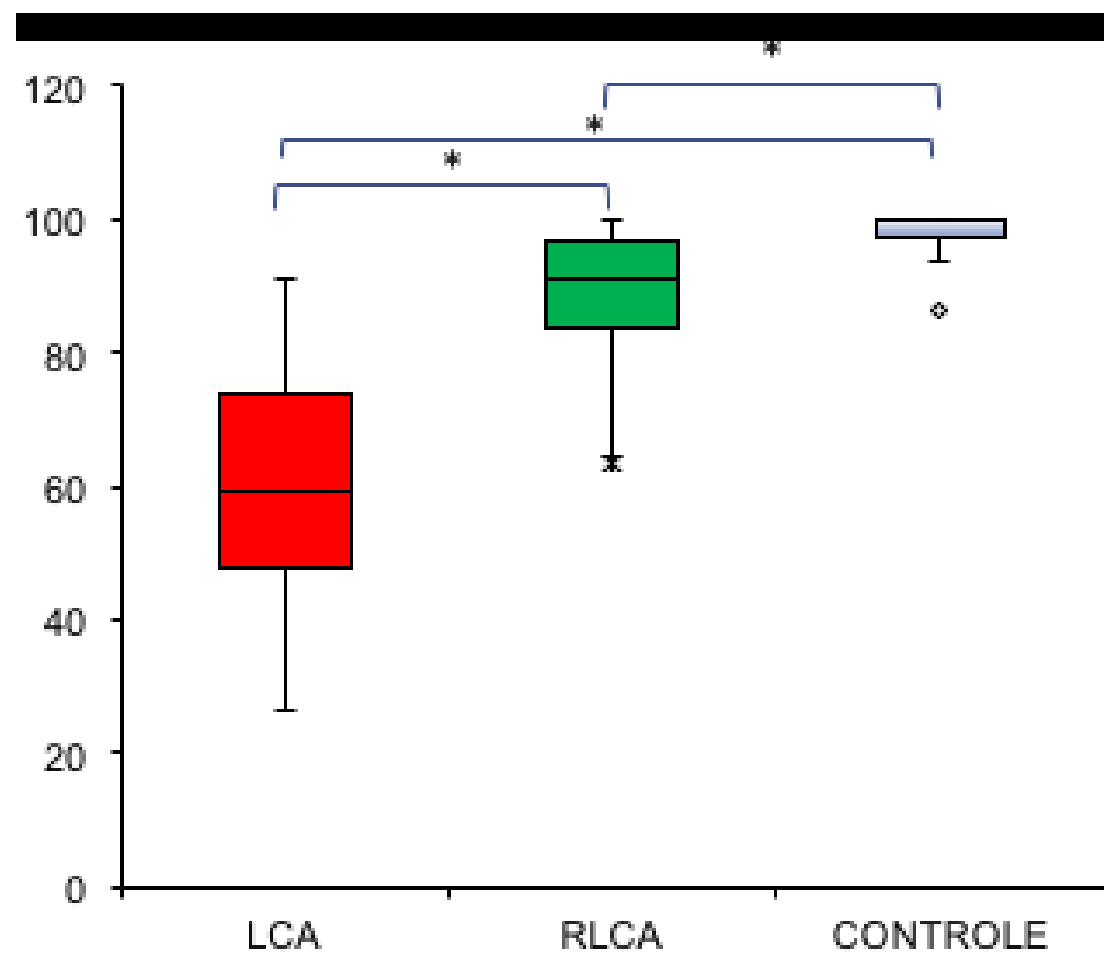


Tabela 3 - Resultados dos questionários Lysholm e IKDC no pré-operatório, após reconstrução e no grupo controle (média \pm desvio padrão)

\begin{tabular}{|c|c|c|c|c|c|c|}
\hline & LCA & RLCA & CONTROLE & $\mathrm{P}^{1}$ & $\mathrm{P}^{2}$ & $\mathrm{P}^{3}$ \\
\hline Lysholm & $\begin{array}{c}77,25 \pm \\
14,5\end{array}$ & $\begin{array}{c}94,12 \pm \\
5,9\end{array}$ & $97,5 \pm 3,8$ & $<, 001$ & $<, 001$ & 0,03 \\
\hline IKDC & $\begin{array}{c}59,46 \pm \\
18,2\end{array}$ & $\begin{array}{c}87,75 \pm \\
12\end{array}$ & $97,28 \pm 4,6$ & $<, 001$ & $<, 001$ & $<, 001$ \\
\hline
\end{tabular}

LCA: atletas com lesão do LCA, antes da cirurgia; RLCA: atletas após reconstrução do LCA. IMC: índice de massa corpórea

$P^{1}$ : valor de $p$ na comparação entre o grupo LCA e RLCA (pareado); $p^{2}$ : valor de $p$ na comparação entre o grupo LCA e controle; $p^{3}$ : valor de $p$ na comparação entre o grupo RLCA e controle. IKDC: International Knee Documentation Committe Subjective Knee Form 
Gráfico 10 - Resultados do questionário Lysholm nos grupos avaliados

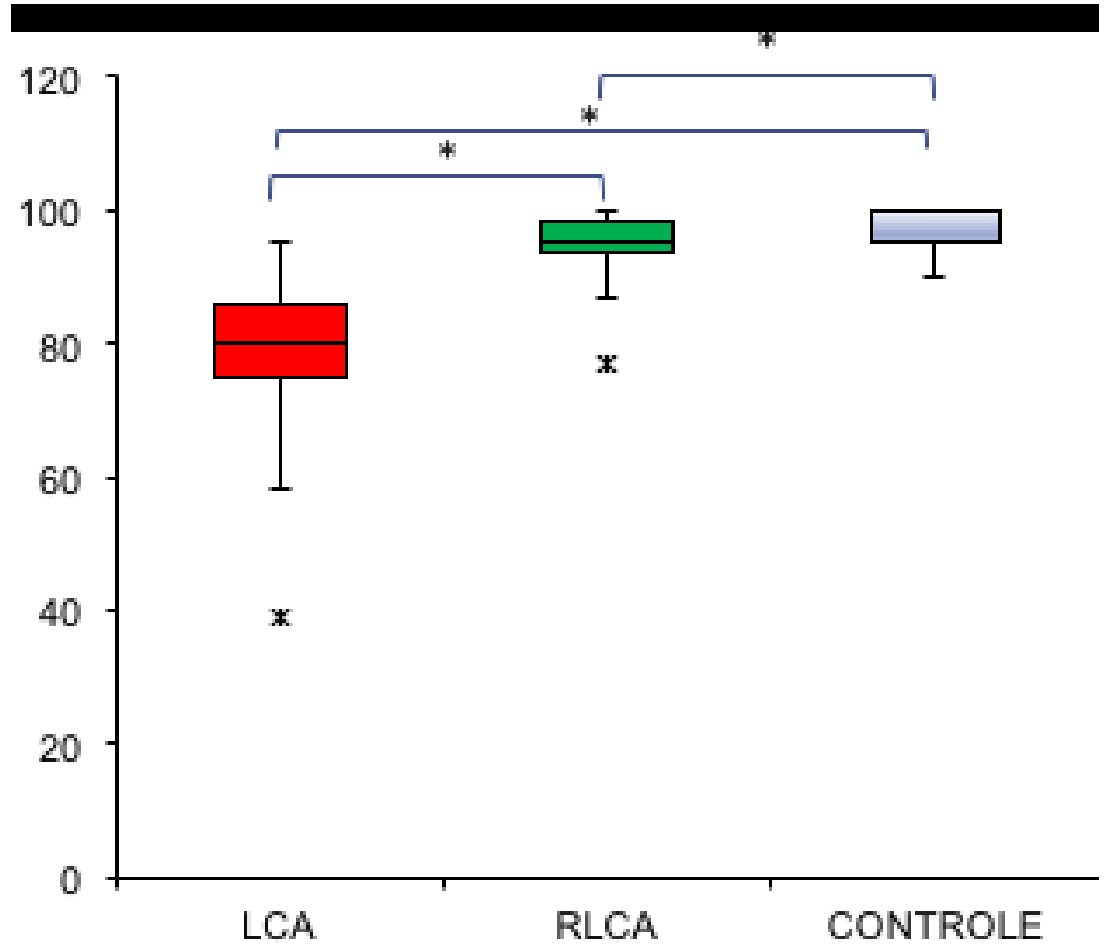

Gráfico 11 - Distribuição dos resultados categorizados do questionário Lysholm nos grupos avaliados (em número de indivíduos)

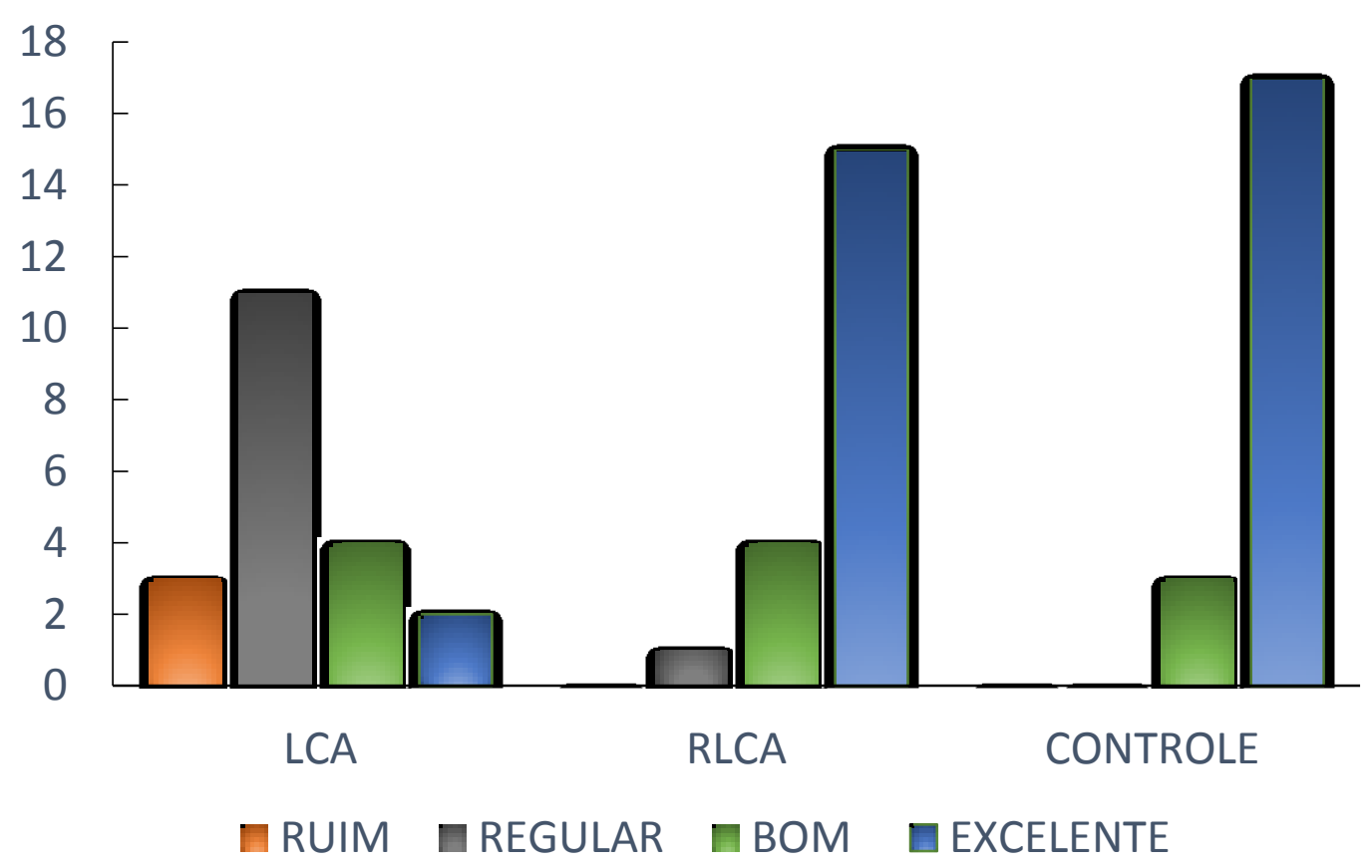


Os resultados da dinamometria isocinética dos músculos extensores e flexores do joelho a $60 \%$ s e $240 \%$ s estão detalhados nas Tabelas 4 a 7 e nos gráficos detalhados no Apêndice. Pudemos observar que os menores valores de pico de torque, trabalho total e potência média foram observados no préoperatório, apresentando um aumento após RLCA, mas com valores inferiores aos observados no grupo controle. Apenas ao avaliarmos os déficits de pico de torque e déficit de potência média a $240 \%$ s pudemos observar maiores déficits de flexão após RLCA em comparação ao pré-operatório (Tabela 7).

Com relação ao pico de torque de extensão houve diferenças estatisticamente significativas entre os grupos em todas as comparações (Tabelas 4 e 6). Com relação ao pico de torque de flexão observamos diferenças significativas entre os momentos pré-operatório e após RLCA e grupo controle, mas não observamos diferenças significativas entre o grupo RLCA e o controle (Tabelas 5 e 7).

Ao avaliar os parâmetros pico de torque de extensão e flexão divididos pela massa corpórea houve diferenças estatisticamente significativas entre os grupos em todas as comparações, exceto entre o grupo controle e após RLCA em flexão a $240 \%$ s. 
Tabela 4 - Resultados de dinamometria isocinética para os músculos extensores do joelho a $60 \%$

\begin{tabular}{|c|c|c|c|c|c|c|}
\hline & LCA & RLCA & CONTROLE & $\mathbf{P}^{1}$ & $\mathbf{P}^{2}$ & $\mathbf{P}^{3}$ \\
\hline Pico de torque (N.m) & $\begin{array}{c}199,7 \pm \\
51,8\end{array}$ & $\begin{array}{c}232,6 \pm \\
45,2\end{array}$ & $264,7 \pm 37,5$ & 0,01 & $<, 001$ & 0,018 \\
\hline $\begin{array}{l}\text { Pico de torque } \\
\text { (déficit \%) }\end{array}$ & $\begin{array}{c}21,5 \pm \\
18,6\end{array}$ & $\begin{array}{c}20,6 \pm \\
25,2\end{array}$ & $-3,1 \pm 13,9$ &, 627 & $<, 001$ & $<, 001$ \\
\hline $\begin{array}{l}\text { Pico de torque I } \\
\text { massa corpórea (\%) }\end{array}$ & $\begin{array}{l}252,2 \pm \\
60,6\end{array}$ & $\begin{array}{c}291,3 \pm \\
45,5\end{array}$ & $357,9 \pm 44,2$ & 0,008 & $<, 001$ & $<, 001$ \\
\hline Trabalho total (J) & $\begin{array}{c}621,4 \pm \\
241,6\end{array}$ & $\begin{array}{c}779,8 \pm \\
145,2\end{array}$ & $867 \pm 130,4$ & 0,004 & $<, 001$ & 0,05 \\
\hline $\begin{array}{l}\text { Trabalho total } \\
\text { (déficit \%) }\end{array}$ & $29,3 \pm 30$ & $\begin{array}{c}14,4 \pm \\
12,7\end{array}$ & $-5,2 \pm 15,4$ & ,057 & $<, 001$ & $<, 001$ \\
\hline $\begin{array}{l}\text { Trabalho total / } \\
\text { massa corpórea (\%) }\end{array}$ & $\begin{array}{c}235,3 \pm \\
103,9\end{array}$ & $\begin{array}{c}260,2 \pm \\
44,6\end{array}$ & $303,4 \pm 38$ & 0,028 & $<, 001$ & 0,002 \\
\hline Potência média (W) & $123,6 \pm 42$ & $\begin{array}{c}160,3 \pm \\
35,4\end{array}$ & $178,7 \pm 29,3$ & $<, 001$ & $<, 001$ & 0,078 \\
\hline $\begin{array}{l}\text { Potência média } \\
\text { (déficit \%) }\end{array}$ & $24,8 \pm 21$ & $\begin{array}{c}18,7 \pm \\
26,2\end{array}$ & $-3,8 \pm 15,6$ & ,333 & $<, 001$ & 0,003 \\
\hline $\begin{array}{l}\text { Relação } \\
\text { flexores/extensores }\end{array}$ & $62 \pm 16,6$ & $\begin{array}{c}58,4 \pm \\
12,4\end{array}$ & $53,9 \pm 8,1$ & 0,221 & 0,134 & 0,251 \\
\hline
\end{tabular}

LCA: atletas com lesão do LCA, antes da cirurgia; RLCA: atletas após reconstrução do LCA. IMC: índice de massa corpórea

$\mathrm{P}^{1}$ : valor de $\mathrm{p}$ na comparação entre o grupo LCA e RLCA (pareado); $p^{2}$ : valor de $p$ na comparação entre o grupo LCA e controle; $p^{3}$ : valor de $p$ na comparação entre o grupo RLCA e controle. 
Tabela 5 - Resultados de dinamometria isocinética para os músculos flexores do joelho a $60 \%$

\section{LCA RLCA CONTROLE $\quad P^{1} \quad P^{2} \quad P^{3}$}

\begin{tabular}{lccccccc}
\hline $\begin{array}{l}\text { Pico de torque } \\
\text { (N.m) }\end{array}$ & $\begin{array}{c}119,1 \pm \\
27,7\end{array}$ & $\begin{array}{c}131 \pm \\
26,9\end{array}$ & $141,2 \pm 20$ & 0,016 & 0,005 & 0,174 \\
\hline $\begin{array}{l}\text { Pico de torque } \\
\text { (déficit \%) }\end{array}$ & $7,2 \pm 17$ & $\begin{array}{c}10,7 \pm \\
14,6\end{array}$ & $2 \pm 8$ & 0,414 & 0,22 & 0,026 \\
\hline $\begin{array}{l}\text { Pico de torque I } \\
\text { massa corpórea (\%) }\end{array}$ & $\begin{array}{c}151,2 \pm \\
34,3\end{array}$ & $\begin{array}{c}166,1 \pm \\
30,9\end{array}$ & $190,5 \pm 18,5$ & 0,023 & $<, 001$ & 0,005 \\
\hline Trabalho total (J) & $\begin{array}{c}428,9 \pm \\
105,7\end{array}$ & $\begin{array}{c}468,4 \pm \\
96\end{array}$ & $506,2 \pm 70,4$ & 0,045 & 0,009 & 0,157 \\
\hline $\begin{array}{l}\text { Trabalho total } \\
\text { (déficit \%) }\end{array}$ & $8,3 \pm 17,7$ & $\begin{array}{c}13,2 \pm \\
14,9\end{array}$ & $0,6 \pm 10,7$ & 0,253 & 0,105 & 0,004 \\
\hline $\begin{array}{l}\text { Trabalho total I } \\
\text { massa corpórea (\%) }\end{array}$ & $144,9 \pm 33$ & $\begin{array}{c}155,9 \pm \\
29\end{array}$ & $180,4 \pm 13,5$ & 0,05 & $<, 001$ & 0,002 \\
\hline Potência média (W) & $79,5 \pm 27,8$ & $\begin{array}{c}95,8 \pm \\
21,5\end{array}$ & $103,3 \pm 15,5$ & 0,004 & 0,002 & 0,209 \\
\hline $\begin{array}{l}\text { Potência média } \\
\text { (déficit \%) }\end{array}$ & $4,9 \pm 21,7$ & $\begin{array}{c}13,3 \pm \\
14,3\end{array}$ & $1,4 \pm 12,9$ & 0,097 & 0,532 & 0,008 \\
\hline
\end{tabular}

LCA: atletas com lesão do LCA, antes da cirurgia; RLCA: atletas após reconstrução do LCA. IMC: índice de massa corpórea

$\mathrm{P}^{1}$ : valor de $p$ na comparação entre o grupo LCA e RLCA (pareado); $p^{2}$ : valor de $p$ na comparação entre o grupo LCA e controle; $p^{3}$ : valor de $p$ na comparação entre o grupo RLCA e controle. 
Tabela 6 - Resultados de dinamometria isocinética para os músculos extensores do joelho a $240 \% \mathrm{~s}$

\begin{tabular}{|c|c|c|c|c|c|c|}
\hline & LCA & RLCA & CONTROLE & $\mathbf{P}^{1}$ & $\mathbf{P}^{2}$ & $\mathbf{P}^{3}$ \\
\hline Pico de torque (N.m) & $\begin{array}{c}134 \pm \\
29,3\end{array}$ & $\begin{array}{c}147,7 \pm \\
23,5\end{array}$ & $161,6 \pm 20,5$ & 0,009 & $<, 001$ & 0,05 \\
\hline $\begin{array}{l}\text { Pico de torque déficit } \\
(\%)\end{array}$ & $\begin{array}{c}13,5 \pm \\
15,1\end{array}$ & $\begin{array}{c}12,2 \pm \\
9,4\end{array}$ & $-2,2 \pm 10,8$ & ,713 & 0,002 & $<, 001$ \\
\hline $\begin{array}{l}\text { Pico de torque I } \\
\text { massa corpórea (\%) }\end{array}$ & $\begin{array}{c}170 \pm \\
33,1\end{array}$ & $\begin{array}{c}186,9 \pm \\
20,5\end{array}$ & $218,6 \pm 23,5$ & 0,012 & $<, 001$ & $<, 001$ \\
\hline Trabalho total (J) & $\begin{array}{r}1565,4 \\
\pm 369,8\end{array}$ & $\begin{array}{r}1806,1 \\
\pm 274,7\end{array}$ & $\begin{array}{c}1961,1 \pm \\
191,1\end{array}$ & $<, 001$ & $<, 001$ & 0,057 \\
\hline $\begin{array}{l}\text { Trabalho total (déficit } \\
\% \text { ) }\end{array}$ & $\begin{array}{c}15,3 \pm \\
17,6\end{array}$ & $11,3 \pm 7$ & $0,2 \pm 8,4$ & $<, 001$ & 0,003 & $<, 001$ \\
\hline $\begin{array}{l}\text { Trabalho total / massa } \\
\text { corpórea (\%) }\end{array}$ & $\begin{array}{c}132,5 \pm \\
30,8\end{array}$ & $\begin{array}{c}150,1 \pm \\
18,3\end{array}$ & $174,2 \pm 19$ & 0,006 & $<, 001$ & $<, 001$ \\
\hline Potência média (W) & $\begin{array}{c}198 \pm \\
48\end{array}$ & $\begin{array}{c}222,2 \pm \\
36,7\end{array}$ & $244,5 \pm 24,6$ & 0,004 & $<, 001$ & 0,027 \\
\hline $\begin{array}{l}\text { Potência média } \\
\text { (déficit \%) }\end{array}$ & $\begin{array}{c}14,8 \pm \\
16,9\end{array}$ & $\begin{array}{c}12,2 \pm \\
7,1\end{array}$ & $1,8 \pm 8,2$ & 0,444 & 0,005 & $<, 001$ \\
\hline $\begin{array}{l}\text { Relação } \\
\text { flexores/extensores }\end{array}$ & $\begin{array}{c}63,8 \pm \\
13\end{array}$ & $\begin{array}{c}62,6 \pm \\
12,8\end{array}$ & $59,3 \pm 10,1$ & 0,591 & 0,222 & 0,359 \\
\hline
\end{tabular}

LCA: atletas com lesão do LCA, antes da cirurgia; RLCA: atletas após reconstrução do LCA. IMC: índice de massa corpórea

$\mathrm{P}^{1}$ : valor de $\mathrm{p}$ na comparação entre o grupo LCA e RLCA (pareado); $\mathrm{p}^{2}$ : valor de $\mathrm{p}$ na comparação entre o grupo LCA e controle; $p^{3}$ : valor de $p$ na comparação entre o grupo RLCA e controle. 
Tabela 7 - Resultados de dinamometria isocinética para os músculos flexores do joelho a $240 \%$ s

\begin{tabular}{lcccccc}
\hline & LCA & RLCA & CONTROLE & $\mathbf{P}^{1}$ & $\mathbf{P}^{2}$ & $\mathbf{P}^{3}$ \\
\hline $\begin{array}{l}\text { Pico de torque } \\
\text { (N.m) }\end{array}$ & $\begin{array}{c}83,5 \pm \\
16,5\end{array}$ & $\begin{array}{c}91,2 \pm \\
17,5\end{array}$ & $98,3 \pm 22,2$ & 0,01 & 0,009 & 0,297 \\
$\begin{array}{l}\text { Pico de torque } \\
\text { (déficit \%) }\end{array}$ & $3,4 \pm 14,6$ & $12 \pm 12,1$ & $2,1 \pm 9,7$ & 0,015 & 0,969 & 0,012 \\
\end{tabular}

\begin{tabular}{|c|c|c|c|c|c|c|}
\hline $\begin{array}{l}\text { Pico de torque I } \\
\text { massa corpórea (\%) }\end{array}$ & $\begin{array}{c}106 \pm \\
19,4\end{array}$ & $\begin{array}{c}116,6 \pm \\
22\end{array}$ & $132,4 \pm 23,4$ & 0,005 & $<, 001$ & 0,078 \\
\hline rabalho total (J) & $\begin{array}{c}1020,9 \pm \\
214,9\end{array}$ & $\begin{array}{c}1073,2 \pm \\
251\end{array}$ & $\begin{array}{c}1208,7 \pm \\
285\end{array}$ & 0,368 & 0,023 & 0,115 \\
\hline
\end{tabular}

$\begin{array}{lllllll}\begin{array}{l}\text { Trabalho total } \\ \text { (déficit \%) }\end{array} \quad 6,9 \pm 14,1 & 16 \pm 15,8 & 4,1 \pm 10,9 & 0,066 & 0,477 & 0,007\end{array}$

\begin{tabular}{lcccccc}
$\begin{array}{l}\text { Trabalho total / } \\
\text { massa corpórea (\%) }\end{array}$ & $\begin{array}{c}81,4 \pm \\
16,2\end{array}$ & $90 \pm 20,3$ & $108,3 \pm 19$ & 0,038 & $<, 001$ & 0,013 \\
\hline Potência média (W) & $\begin{array}{c}121,4 \pm \\
30,2\end{array}$ & $\begin{array}{c}129,2 \pm \\
31,6\end{array}$ & $143,8 \pm 34$ & 0,271 & 0,011 & 0,144 \\
\hline $\begin{array}{l}\text { Potência média } \\
\text { (déficit \%) }\end{array}$ & $5,8 \pm 14,3$ & $\begin{array}{c}15,7 \pm \\
15,4\end{array}$ & $6,9 \pm 11,4$ & 0,015 & 0,784 & 0,043 \\
\hline
\end{tabular}

LCA: atletas com lesão do LCA, antes da cirurgia; RLCA: atletas após reconstrução do LCA. IMC: índice de massa corpórea

$\mathrm{P}^{1}$ : valor de $\mathrm{p}$ na comparação entre o grupo LCA e RLCA (pareado); $\mathrm{p}^{2}$ : valor de $\mathrm{p}$ na comparação entre o grupo LCA e controle; $p^{3}$ : valor de $p$ na comparação entre o grupo RLCA e controle. 
O déficit de pico de torque de extensão, calculado em relação à perna contralateral, foi significativamente maior no pré-operatório e após RLCA do que no grupo controle, mas não houve diferença significativa entre os grupos LCA e RLCA (Tabelas 4 e 6). O déficit de pico de torque de flexão a $60 \%$ foi significativamente maior após RLCA comparado ao grupo controle (Tabela 5). O déficit de pico de torque de flexão a $240 \%$ foi significativamente maior após RLCA comparado ao grupo controle e pré-operatório (Tabela 7).

Com relação ao trabalho total houve diferenças estatisticamente significativas entre os grupos LCA e controle em todas as comparações, e entre os grupos LCA e RLCA em todas as comparações, exceto em flexão a $240 \%$ s. Não observamos diferenças estatisticamente significativas entre os resultados de RLCA e controle em nenhuma das situações. Entretanto, ao avaliar os parâmetros trabalho total de extensão e flexão divididos pela massa corpórea observamos diferenças significativas em todas as comparações.

Os déficits de trabalho total de flexão e extensão, calculados em relação à perna contralateral, foram significativamente maiores após RLCA do que no grupo controle. $O$ déficit de trabalho de extensão foi significativamente maior no grupo LCA do que no grupo controle. Não encontramos diferença significativa no déficit de trabalho em flexão entre o grupo LCA e controle. Entre os grupos LCA e RLCA observamos diferença significativa no déficit de trabalho de extensão apenas pra os músculos extensores do joelho a $240 \%$ s.

Com relação à potência média, observamos diferenças significativas entre os grupos LCA e RLCA e entre o grupo LCA e controle em extensão e flexão a $60 \%$ s. Com relação à potência de extensão a $240 \%$ s observamos diferenças estatisticamente significativas em todas as comparações, enquanto com relação à potência de flexão a $240 \%$ observamos diferenças significativas apenas na comparação entre o grupo LCA e controle.

O déficit de potência de extensão, calculado em relação à perna contralateral, foi significativamente maior no pré-operatório e após RLCA do que no grupo controle. O déficit de potência de flexão a $60 \%$ foi 
significativamente maior no grupo LCA e RLCA comparado ao grupo controle. O déficit de potência de flexão a $240 \%$ s foi significativamente maior após RLCA comparado ao pré-operatório e grupo controle.

A relação entre o pico de torque de flexão e extensão a $60 \%$ foi de $62 \%$ no pré-operatório, $58,4 \%$ após RLCA e $53,9 \%$ no grupo controle, sem diferenças estatisticamente significativas. Esta relação a $240 \%$ s foi de $63,8 \%$ no pré-operatório, $62,6 \%$ após RLCA e $59,3 \%$ no grupo controle, também sem diferenças estatisticamente significativas.

Foram avaliadas correlações entre $\mathrm{O} \mathrm{VO}_{2 \max } \mathrm{e} E \mathrm{EC}$ os resultados dos questionários funcionais (Tabela 8 ). Observamos resultados significativos $(p<, 05)$ entre o $\mathrm{VO}_{2 \max }$ e os questionários Lysholm e IKDC no grupo controle, com coeficiente rho de Spearman de 0,547 e 0,486, respectivamente. Observamos também resultado estatisticamente significativo entre a economia de corrida e o resultado do questionário Lysholm após RLCA (rho=0,507). 
Tabela 8 - Correlação entre os resultados dos escores funcionais e dos questionários Lysholm e IKDC

\begin{tabular}{|c|c|c|}
\hline Correlação & Coeficiente* & $\mathbf{p}$ \\
\hline 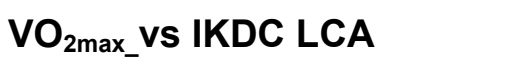 & 0,191 & 0,42 \\
\hline $\mathrm{VO}_{2 \text { max }}$ vs IKDC_RLCA & 0,259 & 0,27 \\
\hline $\mathrm{VO}_{\text {2max }_{-} \text {Vs IKDC_controle }}$ & 0,486 & 0,03 \\
\hline $\mathrm{VO}_{2 \text { max_}}$ vs Lysholm LCA & 0,034 & 0,888 \\
\hline $\mathrm{VO}_{2 \text { max_}}$ vs Lysholm_RLCA & 0,228 & 0,334 \\
\hline $\begin{array}{l}\mathrm{VO}_{2 \max } \text { vs Lysholm } \\
\text { controle }\end{array}$ & 0,547 & 0,013 \\
\hline EC_vs IKDC_LCA & 0,216 & 0,36 \\
\hline EC vs IKDC RLCA & 0,437 & 0,054 \\
\hline EC vs IKDC controle & $-0,371$ & 0,212 \\
\hline EC_vs Lysholm LCA & 0,034 & 0,888 \\
\hline EC_vs Lysholm RLCA & 0,507 & 0,023 \\
\hline EC vs Lysholm controle & $-0,364$ & 0,221 \\
\hline
\end{tabular}

* coeficiente rô de Spearman 
6 Discussão 


\section{DISCUSSÃO}

\subsection{Consumo máximo de oxigênio $\left(\mathrm{VO}_{2} \mathrm{max}\right)$ após $\mathrm{RLCA}$}

Os resultados deste estudo mostram que seis meses após RLCA os jogadores profissionais de futebol de campo apresentam capacidade aeróbia significativamente inferior comparados aos atletas em atividade, embora apresentem aumento significativo comparado ao pré-operatório. Observamos que os indicadores de desempenho aeróbio $\left(\mathrm{VO}_{2 \max }, \mathrm{LV} 2, \mathrm{LV} 1\right)$ aos seis meses de pós-operatório se encontram abaixo do nível desejável para o futebol profissional $^{23,47}$.

Neste estudo, o $\mathrm{VO}_{2 \max }$ nos jogadores do grupo controle foi em média de $56,85 \mathrm{~mL} / \mathrm{kg} / \mathrm{min}$, comparado com $\mathrm{VO}_{2 \max }$ de $48,94 \mathrm{~mL} / \mathrm{kg} / \mathrm{min}$ aos seis meses após RLCA (13,9\% abaixo do observado no grupo controle) e 45,15 mL/kg/min nos jogadores com lesão do LCA (20,6\% abaixo do observado no grupo controle e $7,8 \%$ abaixo do observado após RLCA).

Embora o tratamento cirúrgico da lesão do LCA e a reabilitação sejam bem estabelecidos, parâmetros de capacidade aeróbia não são habitualmente utilizados para avaliar a aptidão física do atleta para o retorno ao esporte de alto desempenho após RLCA. Entretanto, as alterações da capacidade aeróbia resultantes do destreinamento em jogadores de futebol são bem documentadas. Um período de 6 a 8 semanas de destreinamento está associado a redução de 5 a $6 \%$ do $\mathrm{VO}_{2 \max }{ }^{48}$ e períodos mais longos, de até 12 semanas, reduziram o $\mathrm{VO}_{2 \max }$ em até $20 \%{ }^{53}$. Em uma das poucas citações na literatura sobre a avaliação do $\mathrm{VO}_{2 \max }$ no retorno ao esporte após RLCA, Djokić ${ }^{61}$ relatou um aumento de $7,3 \%$ no $\mathrm{VO}_{2 \max }$ em três meses de reabilitação após RLCA em uma jogadora de handebol na Sérvia. 
O $\mathrm{VO}_{2 m a x}$ é um dos parâmetros mais importantes de aptidão física, e tem sido muito estudado em jogadores profissionais de futebol ${ }^{23,24,29,47}$. Sugere-se como referência para este esporte um $\mathrm{VO}_{2 \max }$ em torno de $60 \mathrm{~mL} / \mathrm{kg} / \mathrm{min}^{47}$, ou entre 55 e $70 \mathrm{~mL} / \mathrm{kg} / \mathrm{min}^{23,57}$. Dados de 1.545 jogadores de futebol noruegueses indicam um $\mathrm{VO}_{2 \max }$ bastante homogêneo, entre 62 e 64 $\mathrm{mL} / \mathrm{kg} / \mathrm{min}^{46}$. Há estudos que demonstram correlação positiva entre o nível de $\mathrm{VO}_{2 \max }$ e a performance em campo ${ }^{45}$.

Diversos fatores estão envolvidos nos níveis de $\mathrm{VO}_{2 \max }$ em um indivíduo, como idade, sexo, massa corpórea, nível de atividade física, tipo de treinamento, força muscular, genética, entre outros ${ }^{25}$. O $\mathrm{VO}_{2 \max }$ envolve o sistema cardiorrespiratório e grandes grupos musculares ${ }^{41}$. As adaptações fisiológicas adquiridas com o treinamento físico são decorrentes tanto da função cardiorrespiratória, determinado como fator central, como do músculo esquelético, determinado como fator periférico ${ }^{25}$.

A fórmula estabelecida por Fick, apud Albouaini ${ }^{41}$ ilustra os fatores que interferem no $\mathrm{VO}_{2 \max }$ :

$\mathrm{VO}_{2}=$ débito cardíaco $\mathrm{x}$ diferença arteriovenosa de $\mathrm{O}_{2}$.

O débito cardíaco é o produto da frequência cardíaca pelo volume sistólico. As alterações no débito cardíaco máximo ocorrem principalmente por alterações no volume sistólico, uma vez que a frequência cardíaca máxima sofre poucas alterações com o treinamento ${ }^{50}$. Portanto, nos atletas com lesão do LCA a redução do $\mathrm{VO}_{2 \max }$ pode ser causada tanto pela redução do volume sistólico quanto por uma menor diferença arteriovenosa de $\mathrm{O}_{2}{ }^{25,44}$. Conforme demonstrado por Olivier et al. (2007) ${ }^{44}$ ocorre uma redução de cerca de $27 \%$ do volume sistólico no período pós-operatório imediato de cirurgias do joelho em jogadores de futebol, relacionada a uma redução do volume plasmático e redução do volume diastólico final do ventrículo esquerdo. 
A diferença arteriovenosa de $\mathrm{O}_{2}$ representa o componente periférico envolvido no $\mathrm{VO}_{2 \max }$, ou seja, a quantidade de $\mathrm{O}_{2}$ extraído por grandes grupos musculares durante o exercício ${ }^{25}$. Os principais fatores envolvidos são a densidade de vasos capilares no músculo, que altera o tempo de difusão sanguínea, e alterações no número e tamanho das mitocôndrias e enzimas oxidativas musculares. Em indivíduos jovens e saudáveis, os estudos mostram que o treinamento promove aumento do $\mathrm{VO}_{2 \max }$ tanto por um aumento no débito cardíaco quanto na diferença arteriovenosa de $\mathrm{O}_{2}$.

Para jogadores profissionais de futebol é importante manter $\circ \mathrm{VO}_{2 \max }$ dentro de uma faixa ideal, pois a capacidade de recuperação e normalização da concentração de metabólitos em exercícios repetidos de alta intensidade e curta duração são dependentes da aptidão física máxima ${ }^{101}{ }^{102}$. Apesar de ser um esporte com predominância do metabolismo aeróbio devido a longa duração de uma partida, cerca de $90 \%$ das corridas em velocidade realizadas pelos jogadores de futebol tem duração menor do que cinco segundos, e portanto dependentes do metabolismo anaeróbio ${ }^{103}$. O futebol exige movimentos explosivos, velocidade e mudanças rápidas de direção. O melhor condicionamento restaura mais rapidamente as taxas de creatina fosfato e ATP do músculo esquelético. Portanto, ocorre menor participação do metabolismo anaeróbio durante o esforço e menor acúmulo de ácido lático, o que promove melhor recuperação fisiológica e menos fadiga ${ }^{104}$. Estudos comprovam que quanto mais elevado o nível competitivo da equipe, maior a capacidade aeróbia. Este aspecto foi muito bem demonstrado por Helgerud et al. (2001) ${ }^{45}$ que verificaram que um aumento de $11 \%$ no $\mathrm{VO}_{2 \max }$ (de 58,1 para 64,3 $\mathrm{mL} / \mathrm{kg} / \mathrm{min}$ ) em jogadores de futebol esteve correlacionado a um aumento de $20 \%$ na distância percorrida durante as partidas, em $100 \%$ no número de corridas em velocidade e em $24 \%$ no número de envolvimentos com a bola. Portanto, os dados encontrados na literatura mostram que jogadores profissionais de futebol apresentam níveis elevados e homogêneos de $\mathrm{VO}_{2 \max }$, com clara influência no seu desempenho. No presente estudo, demonstramos que os atletas após RLCA ficaram distantes dessa realidade fisiológica. 


\subsection{Pico de velocidade de corrida no $\mathrm{VO}_{2 \max }\left(\mathrm{VVO}_{2 \max }\right)$}

Outra variável importante que tem sido considerada no desempenho do atleta é a velocidade máxima atingida na esteira, durante o $\mathrm{VO}_{2 \max }\left(\mathrm{VVO}_{2 \max }\right)$. $\mathrm{O}$ $\mathrm{VVO}_{2 \max }$ integra o $\mathrm{VO}_{2 \max }$ e a economia de corrida em um único fator, o que ajuda a explicar diferenças em performance que apenas o $\mathrm{VO}_{2 \max }$ ou a $\mathrm{EC}$ não esclarecem isoladamente ${ }^{42}$. Este parâmetro é considerado uma boa medida de capacidade atlética no pico do esforço. Nesta velocidade, o sistema cardiovascular, pulmonar, e a difusão de $\mathrm{O}_{2}$ para os músculos atingiram o nível máximo.

Atletas capazes de atingir $\mathrm{VVO}_{2 \max }$ mais elevado apresentam maior capacidade de sustentação do exercício acima do limiar anaeróbio. Isto é importante em um esporte de componente metabólico misto (aeróbio e anaeróbio) como o futebol, pois o jogador deve ter condições de repetir estímulos em alta velocidade com intervalos curtos de recuperação ${ }^{103}$. Atletas com capacidade aeróbia mais eficiente terão maior capacidade de geração de ATP e, por conseguinte, atingirão maior $\mathrm{VVO}_{2 \max }{ }^{105}$.

No presente estudo, observa-se que a $\mathrm{VVO}_{2 \max }$ após RLCA foi significativamente inferior comparada ao grupo controle (15,3 vs 17,1 km/h em média, diferença de 10,5\%), mas foi significativamente superior comparada ao pré-operatório $(14,3 \mathrm{~km} / \mathrm{h}$, diferença de $7 \%)$. Esta melhora pode ser explicada pelo aumento progressivo da intensidade do treinamento devido a reabilitação, demonstrada pelo aumento do $\mathrm{VO}_{2 \max }$, e também pelo aumento da força muscular ${ }^{106}$, verificado no teste isocinético. 


\subsection{Limiares ventilatórios um (LV1) e dois (LV2)}

A avaliação dos limiares ventilatórios, que integram os sistemas cardiovascular, respiratório e energético, possibilita a prescrição da carga de treinamento adequada ao nível de aptidão física ${ }^{107,} 108$.

O intervalo entre o LV1 (limiar anaeróbio) e o LV2 (ponto de compensação respiratória) é de grande importância para definir a carga de treinamento durante a reabilitação dos atletas. A intensidade de exercício abaixo do LV1 é classificada como zona 1 (intensidade leve), a intensidade entre LV1 e LV2 como zona 2 (intensidade moderada) e a intensidade acima do LV2 como zona 3 (intensidade alta) ${ }^{109}$

Os limiares ventilatórios são indicadores submáximos de desempenho, e há autores que os consideram indicadores de aptidão física mais sensíveis do que o $\mathrm{VO}_{2 \max }{ }^{110}$, por apresentarem maior resposta ao treinamento. Além disso, são menos dependentes da motivação do indivíduo ${ }^{41}$. Observamos aumento significativo de $13 \%$ no LV1 e $8 \%$ no LV2 após RLCA, porém ainda significativamente abaixo do grupo controle, $8 \%$ e 15\%, respectivamente. Em todos os grupos o LV1 ocorreu entre $65 \%$ e $70 \%$ do $V_{2 \max }$ e o LV2 ocorreu em torno de $85 \%$ do $\mathrm{VO}_{2 \max }$. Isto indica que os atletas em todos os grupos poderiam se exercitar em uma intensidade entre 70 e $85 \%$ do seu $\mathrm{VO}_{2 \max }$ (intensidade moderada) antes do desenvolvimento de fadiga central e periférica decorrente do exercício de alta intensidade.

Por outro lado, o exercício prolongado acima do LV2 (acima de $85 \%$ do $\mathrm{VO}_{2 \max }$ ) provoca acúmulo de metabólitos (amônia, lactato) e consequente acidose metabólica devido a predominância do metabolismo anaeróbio ${ }^{99}$. Alterações intracelulares das concentrações de eletrólitos no músculo durante exercício intenso envolvem diminuição do potássio (6\% a 20\%), creatina fosfato (70\% a 100\%), aumento na concentração de lactato (superior a dez vezes) e sódio (duas vezes) ${ }^{111}$. Devido a menor eficiência na produção de ATP, a fadiga 
muscular se manifestaria por um declínio na capacidade de contrações musculares máxima e submáxima.

Este grande número de eventos metabólicos impossibilita que o atleta consiga sustentar o exercício de alta intensidade, acima do LV2, por muito tempo. Em uma partida de futebol de 90 min o atleta percorre de 8 a $12 \mathrm{~km}$, em uma intensidade de esforço de aproximadamente $75 \%$ do $\mathrm{VO}_{2 \max }{ }^{23}$. Portanto, a velocidade no LV2 (vLV2) é uma variável importante, porque coincide com a velocidade de deslocamento em que o jogo é realizado ${ }^{23,45}$. A vLV2 é normalmente superior a $14 \mathrm{~km} / \mathrm{h}$ em jogadores de futebol de elite ${ }^{23,112}$. No presente estudo a vLV2 aumentou de $11,3 \mathrm{~km} / \mathrm{h}$ para $11,9 \mathrm{~km} / \mathrm{h}$ após RLCA, porém significativamente abaixo do grupo controle, com 13,6 km/h. Esses indicadores de desempenho demonstram menor capacidade aeróbia nos pacientes após RLCA quando comparados ao grupo controle (Tabela 2).

\subsection{Economia de corrida (EC)}

A EC é um parâmetro de desempenho comumente utilizado em esportes de resistência, porém pouco utilizada em esportes coletivos, como no futebol ${ }^{28}$, 29. Todavia, alguns estudos com jogadores de futebol indicam que uma melhor EC contribui para uma maior capacidade de esforço prolongado, verificando-se maior distância percorrida durante uma partida de futebol em atletas com melhor $\mathrm{EC}^{23,45}$. Uma vez que os níveis de $\mathrm{VO}_{2 \max }$ são elevados e muito homogêneos no futebol competitivo, a EC pode ser determinante para diferenciar o desempenho do atleta ${ }^{113}$.

Observamos uma economia de corrida de 208,8 mL/kg/km no préoperatório e 217,6 mL/kg/km após RLCA ( $p=, 050)$. Não observamos diferenças significativas em comparação ao grupo controle, que apresentou média de 212 $\mathrm{mL} / \mathrm{kg} / \mathrm{km}$. 
Valores maiores representam pior EC, e em nosso estudo observamos aumento da EC após RLCA. Contudo, a correlação entre EC e $\mathrm{VO}_{2 \max }$ é pequena, sendo que apenas de $7 \%$ a $12 \%$ da economia de corrida está relacionada ao $\mathrm{VO}_{2 \max }{ }^{114}$. Esta reduzida associação reflete a natureza distinta dessas duas variáveis e seus determinantes fisiológicos. $\mathrm{O} \mathrm{VO}_{2 \max }$ é determinado por fatores como o débito cardíaco, a capacidade de difusão pulmonar, a massa total de hemoglobina e a massa muscular e capacidade mitocondrial no tecido muscular, enquanto a EC é influenciada por fatores técnicos e biomecânicos, treinamento específico, variáveis antropométricas e parâmetros periféricos, incluindo o armazenamento eficaz e reutilização da energia elástica do músculo, oscilação vertical e tempo de contato com o solo e as características musculares esqueléticas ${ }^{114}$.

Portanto, estas variáveis são praticamente independentes, verificando-se uma variabilidade da $\mathrm{EC}$ em relação ao $\mathrm{VO}_{2 \max }{ }^{115}$. Inclusive, a economia de corrida é muito útil para diferenciar atletas com $\mathrm{VO}_{2 \max }$ semelhante, mas apresenta limitações quando se compara atletas com capacidades aeróbias distintas. Além disso, alguns estudos mostram que o aumento do $\mathrm{VO}_{2 m a x}$ está relacionado ao aumento da economia de corrida, ou seja, maior consumo de oxigênio para a corrida ${ }^{114}$. Todavia, isto não invalida o importante conceito da $E C$, pois ao melhorar seus aspectos específicos haverá melhora do rendimento esportivo. A vVO ${ }_{2 \max }, \mathrm{VLV} 2$ e vLV1 são importantes variáveis que integram o $\mathrm{VO}_{2 \max }$ e limiares ventilatórios com a economia de corrida ${ }^{42}$.

Em valores absolutos, nossos resultados de EC foram semelhantes àqueles encontrados por Boone et al. (2001) ${ }^{30}$ que observaram EC de 214,4 $\mathrm{mL} / \mathrm{kg} / \mathrm{km}$ em jogadores de futebol. Por outro lado, McHugh et al. (1994) ${ }^{116}$ demonstraram pior economia de corrida em pacientes com lesão do LCA comparados a um grupo controle, enquanto Colak et al. (2011) demonstraram melhora da economia de corrida em pacientes após a reconstrução do LCA, o que difere dos nossos resultados. Entretanto, em seu estudo, Colak et al. (2011) ${ }^{117}$ avaliaram pacientes caminhando na esteira, a uma velocidade máxima de $5,4 \mathrm{~km} / \mathrm{h}$, enquanto em nosso estudo a velocidade testada foi de corrida a $9 \mathrm{~km} / \mathrm{h}$. 
Outro aspecto que poderia influenciar a EC seria a diferença de composição corporal entre os jogadores. Todavia, essa hipótese não foi confirmada, pois não houve diferença na composição corporal entre os grupos (Tabela 1). Acreditamos que uma explicação plausível para este maior custo energético seja a redução da eficiência metabólica periférica por alterações biomecânicas. É possível aumentar em $5 \%$ a EC em jogadores de futebol realizando treinamento em campo reduzido, o que demonstra o valor da especificidade do esporte no treinamento do jogador de futebo ${ }^{118}$. Em corredores, uma melhora de $5 \%$ na EC aumenta a distância percorrida em $3,8 \%{ }^{119}$.

\subsection{Questionários Lysholm e IKDC}

A avaliação clínica foi realizada com os questionários de Lysholm e IKDC no pré-operatório, aos seis meses pós RLCA e no grupo controle. Estes questionários foram desenvolvidos para avaliar a função do joelho, e representam principalmente os resultados do procedimento cirúrgico de reconstrução do LCA. Nosso intuito foi avaliar o êxito do procedimento cirúrgico em melhorar a função articular, que é o principal objetivo da cirurgia. O bom resultado da cirurgia é fundamental para o retorno do atleta ao futebol profissional em condições competitivas. Como demonstramos, talvez não seja condição suficiente para o retorno ao esporte competitivo, mas sem dúvida é condição necessária.

O questionário de Lysholm e Gillquist $(1982)^{81}$ foi desenvolvido para avaliar resultados de cirurgias no joelho, enfatizando os sintomas de instabilidade. Foi validado para a língua portuguesa em 200682. O questionário IKDC avalia não apenas sintomas mas também a função do joelho e o 
comprometimento na execução de tarefas ou atividades habituais, não apenas esportivas $^{78}$. Foi validado para a língua portuguesa em $2010^{80}$.

Estes questionários são importantes métricas de avaliação da função do joelho, e permitem comparações entre tratamentos e avaliação dos resultados. Observamos melhora significativa nos questionários Lysholm e IKDC após a RLCA, embora, estatisticamente, não tenham atingido os resultados do grupo controle. Nos atletas operados neste estudo, o resultado do questionário IKDC no pós-operatório foi 87,75 em média, bastante próximo dos valores médios populacionais para este escore nesta faixa etária (89 pontos) segundo estudos na população norte-americana ${ }^{79}$. Alguns autores estabelecem o valor mínimo de 70 pontos para retorno ao esporte após RLCA ${ }^{14}$.

Com relação ao escore de Lysholm, a média dos resultados pósoperatórios foi de 94,12. Neste questionário, um resultado de 95 é considerado excelente. Ou seja, os atletas operados tiveram média pós-operatória próxima de excelente (ou excelente, se considerarmos a mediana, que foi 95). Dos vinte pacientes operados, quinze apresentaram escore de Lysholm excelente, ou seja, 95 pontos ou mais. Desta forma, podemos considerar que os resultados da RLCA em termos de função articular foram satisfatórios.

\subsection{Avaliação isocinética computadorizada dos músculos flexores e extensores do joelho}

O teste de dinamometria isocinética tem sido cada vez mais utilizado como um parâmetro para permitir o retorno ao esporte após a RLCA ${ }^{72}$. Estudos demonstram a associação entre o déficit de força ou desequilíbrios musculares e o risco de relesão do $L C A^{22}$. 
Utilizamos o teste isocinético para avaliar a força, potência e resistência musculares em valores absolutos e os déficits do membro operado em relação à perna não lesionada. Os testes isocinéticos não reproduzem perfeitamente os movimentos e contrações musculares das atividades cotidianas, porém permitem avaliações objetivas, possibilitam distinguir os pacientes aptos a retornar de forma mais segura às atividades esportivas, e correlacionam-se, ao menos de forma moderada, a avaliações subjetivas de função do joelho ${ }^{68}$.

O teste foi realizado a $60 \%$ s e $240 \%$ s, tanto no pré-operatório quanto aos seis meses de pós-operatório. Avaliamos o pico de torque, trabalho total e potência média de extensão e flexão do joelho. O pico de torque avalia melhor a força máxima, enquanto o trabalho total e potência média são melhores medidas da capacidade de resistência muscular. Da mesma forma, as medidas a $60 \%$, avaliam melhor a força máxima, enquanto as medidas a $240 \% \mathrm{~s}$ avaliam melhor a resistência. Na literatura, o parâmetro mais utilizado é o déficit de pico de torque a $60 \%$ s comparado à perna contralateral ${ }^{72}$. O trabalho e potência também estão relacionados ao torque, sendo a potência média o produto do torque médio pela velocidade angular, e o trabalho o produto do torque pelo deslocamento angular.

A literatura cita como desejável um índice de simetria entre $70 \%$ e 90\%, ou seja, $10 \%$ a $30 \%$ de déficit comparado à perna contralateral ${ }^{22,37,72}$. No presente estudo os atletas apresentaram um déficit de pico de torque de extensão a $60 \%$ de $20,6 \%$, sem diferença significativa com relação ao préoperatório, de $21,5 \%$. O déficit de pico de torque de flexão a $60 \%$ foi de $10,7 \%$, sem diferença significativa com relação ao pré-operatório, que foi de $7,2 \%$. Entretanto, a análise dos valores absolutos, ou normalizados pela massa corpórea, mostra que houve um aumento significativo da força muscular no pós-operatório com relação ao pré-operatório. Os picos de torque de extensão e flexão aumentaram significativamente, o que indica que o déficit foi similar ou superior devido a fortalecimento concomitante da perna contralateral.

Há estudos na literatura que avaliam os valores absolutos de pico de torque em jogadores profissionais de futebol. Ruas et al. (2015) ${ }^{67}$ observaram 
um pico de torque entre 244 e 270 N.m em jogadores profissionais em atividade, enquanto os atletas no presente estudo apresentaram média de 232,6 N.m após RLCA, comparado a 199,7 N.m no pré-operatório. Os atletas do grupo controle apresentaram pico de torque de extensão de 264,7 N.m, ou seja, 13,8\% superior ao do grupo RLCA. Portanto, apesar do déficit do pico de torque em relação ao membro contralateral ser um parâmetro importante, a existência de dados normativos para esta população específica permite também a análise dos resultados em termos absolutos.

A importância de se avaliar os resultados em termos absolutos, e não apenas com relação à perna contralateral, fica nítida quando avaliamos o déficit de trabalho em flexão a $60 \%$ s. Observamos um aumento significativo no déficit de trabalho total de $8,3 \%$ para $13,2 \%$ após RLCA. Entretanto ao avaliarmos o trabalho total médio em flexão a $60 \%$ s houve um aumento de 428,9 J para 468,4 J. Ou seja, em termos absolutos houve um aumento de força, resistência e potência musculares nos atletas após RLCA.

Como vimos anteriormente, o $\mathrm{VO}_{2 \max }$ possui um componente central e um componente periférico, sendo este último composto pela atividade de grandes grupos musculares. Alterações da força, potência e resistência musculares estão relacionadas a alterações na circulação sanguínea muscular, tamanho da fibra muscular, produção de ATP mitocondrial e de suas atividades enzimáticas. Todos estes fatores interferem na extração de oxigênio tecidual e na diferença arteriovenosa de $\mathrm{O}_{2}$, interferindo no $\mathrm{VO}_{2 \max } 51,52$.

\subsection{Avaliação da composição corporal por bioimpedância}

Os elevados níveis de atividade física durante os treinos e jogos no futebol profissional levam a alterações específicas na composição corporal. Micheli et al. (2014) ${ }^{77}$ avaliaram a composição corporal por bioimpedância de 
893 jogadores profissionais italianos e encontraram os valores médios de IMC de 23,9, massa livre de gordura de 66,3kg e porcentagem de gordura corporal de $16,1 \%$. Em nosso estudo, os jogadores do grupo controle apresentaram IMC de 23,9, massa livre de gordura de 65,2 kg e porcentagem de gordura corporal de $12,8 \%$. A comparação entre os atletas do grupo controle e os atletas com lesão do LCA e após RLCA não mostrou diferença estatística em nenhum dos parâmetros de composição corporal. Embora saibamos da possível variabilidade dos resultados de bioimpedância ${ }^{74}$, tentamos reduzi-la em nosso estudo realizando as avaliações sempre no mesmo período do dia, com as mesmas orientações, no mesmo local e no mesmo aparelho.

Portanto, a homogeneidade da composição corporal entre os atletas do grupo controle e dos atletas com lesão do LCA, bem como a semelhança de idade entre os grupos, nos leva a crer que os grupos são comparáveis entre si, o que favorece a validade interna do estudo. A comparação com outros estudos da literatura, como citado anteriormente, também indica que os indivíduos alocados neste estudo são de fato representativos da população estudada, ou seja, jogadores profissionais de futebol.

\subsection{Fadiga e risco de lesão do LCA}

Há estudos associando a fadiga ao risco de lesão do LCA, e poucos estudos associando a fadiga ao risco de relesão do LCA, provavelmente com os mesmos mecanismos envolvidos. Estes estudos são experimentais, e empregam uma série de exercícios para desenvolver fadiga, para então avaliarem alterações biomecânicas que podem estar envolvidas na lesão do $\operatorname{LCA}^{84,98,87}$. Watson et al. (2016) ${ }^{89}$, em 2016, avaliaram a incidência de lesões de todos os tipos em jogadores de futebol e observaram que os jogadores que sofreram lesões apresentavam menor $\mathrm{VO}_{2 \max }$ na pré-temporada, comparados aos jogadores que não sofreram lesão $(57,5 \mathrm{~mL} \mathrm{~kg} / \mathrm{min}$ versus $63,4 \mathrm{~mL} / \mathrm{kg} / \mathrm{min}$, 
$\mathrm{p}=$,014). Concluíram que o $\mathrm{VO}_{2 \max }$ foi um preditor independente de risco de lesão.

No presente estudo demonstramos que após RLCA os atletas apresentam níveis menores de $\mathrm{VO}_{2 m a x}$ e limiares ventilatórios comparados aos atletas em atividade. Portanto, estes atletas apresentam maior tendência a fadiga durante os treinos e principalmente partidas de futebol, quando comparados aos atletas sem histórico de lesão. Isto pode estar associado a um maior risco de relesão. Entretanto, isto é especulativo, e não foi avaliado por este estudo.

Existe também a possibilidade de que os atletas com lesão do LCA já apresentassem capacidade aeróbia inferior à dos atletas sem histórico de lesão, o que poderia ter contribuído com a ocorrência de lesão. Entretanto, não temos os dados referentes ao período anterior à lesão para testar esta hipótese. Por outro lado, esta afirmação reforça a necessidade de corrigirmos a deficiência de aptidão cardiorrespiratória após a cirurgia, com o objetivo de prevenir uma nova lesão.

\subsection{Retorno ao esporte e $\mathrm{VO}_{2 \max }$}

Há critérios definidos na literatura para retorno ao futebol após RLCA. A maioria dos estudos cita, entre estes critérios, ausência de instabilidade, dor ou derrame articular, déficit de pico de torque inferior a 10 a 20\% comparado à perna não lesionada e bons resultados nos questionários de função do joelho ${ }^{14,33}$. Poucos estudos incluem algum método de avaliação de performance cardiorrespiratória, na maioria dentro do campo ${ }^{19,} 39$.

Ao nosso conhecimento, nenhum estudo avaliou de forma objetiva o consumo máximo de oxigênio de jogadores profissionais de futebol submetidos a RLCA. O tratamento cirúrgico desta lesão evoluiu muito nas últimas décadas, 
apresentando bons ou excelentes resultados em mais de $90 \%$ dos casos, permitindo inclusive o retorno à prática esportiva ${ }^{[10]}$. Portanto, mesmo tratandose de uma lesão grave ${ }^{7}$, há expectativa por parte do atleta lesionado, médicos, fisioterapeutas, treinadores e preparadores físicos de que, após um período de reabilitação estimado em seis meses, o atleta esteja apto a retornar à sua atividade esportiva ${ }^{11,15,16}$.

Entretanto, revisões sistemáticas mostram que apenas $44 \%$ a $55 \%$ dos atletas retornam ao esporte competitivo no mesmo nível anterior à lesão após uma cirurgia de reconstrução do $\operatorname{LCA}^{20,21}$. Por consequência, se a cirurgia restaura a função do joelho em mais de $90 \%$ dos casos, mas cerca de $50 \%$ não retornam às atividades esportivas prévias, é provável que existam outros fatores, além da função do joelho, que limitem ou influenciem o retorno ao esporte de alto nível ${ }^{21}$.

Muitos estudos tentam associar a taxa de retorno ao esporte a fatores cirúrgicos, como tipo de enxerto ou posicionamento dos túneis ${ }^{17}$. Fatores individuais, relacionados ao atleta, como motivação, tempo de carreira, gênero, expectativas profissionais, nível de atividade, e até mesmo fatores psicológicos, também tem sido estudados ${ }^{21}$.

O futebol é um esporte que inclui gestos esportivos complexos, como mudanças bruscas de direção, saltos, aceleração e desaceleração, chute, passe, contato físico, e exige um elevado condicionamento físico para a prática em alto nível. Uma função adequada do joelho é uma condição essencial, mas não suficiente, para o retorno ao esporte competitivo.

Até o nosso conhecimento, este é o primeiro trabalho a avaliar o consumo máximo de oxigênio em jogadores profissionais de futebol submetidos a reconstrução do $\mathrm{LCA}$. $\mathrm{O} \mathrm{VO}_{2 \max }$ é um importante parâmetro associado ao desempenho esportivo, e certamente influencia o desempenho em campo de jogadores de futebol. Portanto acreditamos que o descondicionamento aeróbio, conforme demonstrado neste estudo, seja um importante determinante do desempenho esportivo após RLCA. Futuras investigações poderão 
complementar esta tese avaliando a relação entre o condicionamento aeróbio e o retorno satisfatório ao esporte competitivo.

Estratégias visando o aumento ou manutenção do $\mathrm{VO}_{2 \max }$ podem ser implementadas após a lesão e reconstrução do LCA. Por exemplo, Helgerud et al. ${ }^{45}$, em 2011 , demonstraram um aumendo de $8,6 \%$ no $\mathrm{VO}_{2 \max }$ de jogadores de futebol profissional, de 60,5 para $65,7 \mathrm{~mL} / \mathrm{kg} / \mathrm{min}$, com um treino intervalado a $90-95 \%$ da frequência cardíaca máxima duas vezes por semana por oito semanas. Isto pode ser implementado durante a reabilitação pós-operatória dos atletas, utilizando diversas estratégias, como cicloergômetros, exercícios aquáticos, entre outros. O conhecimento das alterações fisiológicas ocorridas após a lesão e reconstrução do LCA permitirá o desenvolvimento de estratégias para corrigí-las.

\subsection{Limitações}

Este não é um estudo randomizado, e desta forma estivemos atentos desde o início à possibilidade de vieses. Tentamos evitar o viés de seleção no desenho inicial da pesquisa com critérios de inclusão e de exclusão bem definidos, principalmente com relação ao nível de atividade dos indivíduos lesionados e do grupo controle. Nossos resultados mostram que o grupo controle, composto de jogadores profissionais de futebol, foi comparável aos atletas lesionados em termos de composição corporal e faixa etária. Isto indica que os indivíduos alocados neste estudo são de fato representativos da população estudada, e favorece a validade interna do estudo.

Uma das limitações deste estudo é não apresentar os resultados de $\mathrm{VO}_{2 \max }$ dos pacientes com lesão do LCA antes da lesão, para avaliarmos a evolução do $\mathrm{VO}_{2 \max }$ nos mesmos jogadores em atividade. Entretanto, dada a incidência de lesão do LCA, necessitaríamos de um enorme banco de dados 
com dados de jogadores para conseguirmos esta casuística. Portanto necessitamos de um grupo controle, composto de jogadores de futebol profissional, comparável aos jogadores com lesão do LCA. As diferenças de força muscular encontradas estiveram de acordo com o esperado pela literatura para indivíduos com lesão do LCA e após RLCA.

Pode ser levantada também a hipótese de que os jogadores com lesão do LCA apresentavam menores níveis de $\mathrm{VO}_{2 \max }$ antes da lesão. Esta é uma hipótese plausível, uma vez que há estudos mostrando que o baixo $\mathrm{VO}_{2 \max }$ é um fator de risco independente para lesões de qualquer natureza em jogadores de futebol ${ }^{89}$. Esta hipótese favorece a conclusão final deste estudo, mostrando que os níveis de $\mathrm{VO}_{2 \max }$ observados aos seis meses de pós-operatório são insatisfatórios para a prática do futebol profissional.

Um outro problema foi o tempo médio decorrido entre a lesão e a cirurgia, que foi de 5 meses (mediana de 3 meses). $O$ descondicionamento poderia ser evitado ou poderia ser menor com cirurgias mais precoces. Entretanto este período está de acordo com a realidade do sistema de saúde do nosso país. Por outro lado, a informação de que $\circ V O_{2 \max }$ e limiares ventilatórios apresentam os piores resultados antes da RLCA também é importante, pois nos indica que medidas para prevenir o descondicionamento aeróbio devem ser iniciadas antes mesmo da cirurgia.

Poderia ser argumentado que o teste de corrida em esteira poderia ser prejudicado pela lesão do joelho no indivíduo, desta forma provocando alteração nos resultados do teste ergoespirométrico, com resultados não representativos do real $\mathrm{VO}_{2 \max }$ do indivíduo. Entretanto, durante os testes, todos os atletas atingiram os critérios fisiológicos para um teste máximo, descritos na metodologia. Apenas um paciente, que apresentava uma lesão meniscal em alça de balde, foi incapaz de concluir o teste devido a sintomas no joelho. Além disso, os limiares ventilatórios, que são indicadores fisiológicos submáximos menos dependentes da motivação do atleta ${ }^{41}$, também mostraram diferenças significativas em todas as avaliações. Devemos também salientar que a corrida em esteira é mais próxima da atividade específica do jogador de 
futebol, e o $\mathrm{VO}_{2 \max }$ obtido com um cicloergômetro ou bicicleta são inferiores aos obtidos com teste em esteira ${ }^{23}$.

No futuro, maior atenção deve ser dada ao condicionamento físico de jogadores profissionais de futebol no retorno ao esporte após RLCA. A relação entre a aptidão física e a prática esportiva bem-sucedida e continuada após RLCA deve ser investigada. Pesquisas futuras devem focar em estratégias para prevenir o descondicionamento em atletas com lesão do LCA, antes e após a cirurgia. 
7 Conclusão 


\section{CONCLUSÃO}

Concluímos, baseados nesta amostra, que os jogadores de futebol profissional aos seis meses após RLCA apresentam $\mathrm{VO}_{2 \max }$ significativamente abaixo do observado em jogadores de futebol não lesionados em atividade. Apesar do $\mathrm{VO}_{2 \max }$ aumentar de forma significativa no pós-operatório comparado ao período pré-operatório, ainda se encontra significativamente abaixo do encontrado no grupo controle. O mesmo comportamento foi encontrado para os limiares ventilatórios.

Desta forma, concluímos que a função aeróbia de jogadores profissionais de futebol de campo submetidos a reconstrução do LCA é inferior ao observado em jogadores profissionais de futebol de campo em atividade, aos seis meses de pós-operatório.

A economia de corrida foi significativamente inferior no pós-operatório comparado ao pré-operatório. Não observamos diferenças estatisticamente significativas entre os indivíduos lesionados e o grupo controle.

Houve uma melhora significativa nos escores de função do joelho entre o período pré-operatório e pós-operatório. 
9 Anexos 


\section{ANEXO 1 \\ Aprovação do Comissão de Ética para Análise de Projetos de Pesquisa (CAPPesq) do Hospital das Clínicas da Faculdade de Medicina da Universidade de São Paulo}

\section{PROJETO DE PESQUISA}

Título: AVALIAÇ̃̃O DO CONSUMO MÁXIMO DE OXIGÊNIO (VO2MAX) E DA ECONOMIA DE CORRIDA (EC) EM PACIENTES SUBMETIDOS A RECONSTRUÇÃO DO LIGAMENTO CRUZADO ANTERIOR (LCA)

Pesquisador Responsável: Prof. Dr. Arnaldo José Hernandez Versão: 1

Pesquisador Executante: Adriano Marques de Almeida $\quad$ CAAE: 14440613.9.0000.0068

Co-autores: Dr. Paulo Roberto Santos Silva

Finalidade Acadêmica: Doutorado

Orientador: Prof. Dr. Arnaldo José Hernandez

Instituição: HCFMUSP

Departamento: ORTOPEDIA E TRAUMATOLOGIA

\section{PARECER CONSUBSTANCIADO DO CEP}

Registro on-line: 10537

Número do Parecer: 368.105

Data da Relatoria: 21/08/13

Apresentação do Projeto: AVALIAÇÃO DO CONSUMO MÁXIMO DE OXIGÊNIO (VO2MAX) E DA ECONOMIA DE CORRIDA (EC) EM PACIENTES SUBMETIDOS A RECONSTRUÇÃO DO LIGAMENTO CRUZADO ANTERIOR.

Objetivo da Pesquisa: O objetivo do presente estudo é avaliar o VO2max e economia de corrida em pacientes com lesão do LCA e comparar com os resultados pós-operatórios no momento da liberação do paciente para atividade esportiva e com os resultados de controles saudáveis.

Avaliação dos Riscos e Benefícios: Riscos: o teste de exercício máximo em esteira é um procedimento considerado seguro, porém deve ser realizado com precauções. Segundo dados do American College of Sports Medicine (ACSM)(18), o risco de morte em laboratórios de exercícios clínicos é inferior a $0,01 \%$, o risco de complicação que exija internação hospitalar é inferior a 0,02\%, e o risco de um ataque cardíaco agudo é inferior a 0,04\%. Em clínicas de medicina esportiva, com enfoque em atletas, o risco é ainda menor. Devemos ressaltar que, segundo o ACSM, o teste de esforço é considerado obrigatório para indivíduos de alto risco que desejam iniciar um programa de exercícios. Nos pacientes com lesão do LCA, normalmente não há contraindicação à corrida em esteira, exceto em casos agudos ou com sinais e sintomas tais como derrame articular ou bloqueio articular. Estes casos não serão incluídos no estudo. Nos pacientes em pós-operatório, o teste será realizado na fase de liberação à prática esportiva. Portanto os critérios para liberação ao esporte, como

Rua Dr. Ovídio Pires de Campos, 225 - Prédio da Administração - 5a andar CEP 05403-010 - São Paulo - SP.

5511 2661-7585 - 5511 2661-6442 ramais: 16, 17, 18 | marcia.carvalho@hc.fm.usp.br 


\section{Hospital das Clínicas da FMUSP}

Comissão de Ética para Análise de Projetos de Pesquisa - CAPPesq

estabilidade articular, ausência de derrame, adequado trofismo muscular, devem estar preenchidos. Portanto, nestas condições, a realização do teste acrescenta um risco mínimo ao indivíduo. Benefícios: A realização destes testes, normalmente realizados em atletas para avaliação do desempenho, será uma oportunidade para avaliar o seu preparo físico e gerará dados importantes que poderão ser utilizados pelo próprio atleta e seu preparador físico.

Comentários e Considerações sobre a Pesquisa: Projeto com desenho e metodologia adequados.

Considerações sobre os Termos de apresentação obrigatória: Ok.

Recomendações: Aprovação.

Conclusões ou Pendências e Lista de Inadequações: Ok.

Situação do Parecer: Aprovado.

Necessita Apreciação da CONEP: Não.

Considerações Finais a critério do CEP: Em conformidade com a Resolução CNS nํ 466/12 cabe ao pesquisador: a) desenvolver o projeto conforme delineado; b) elaborar e apresentar relatórios parciais e final; c)apresentar dados solicitados pelo CEP, a qualquer momento; d) manter em arquivo sob sua guarda, por 5 anos da pesquisa, contendo fichas individuais e todos os demais documentos recomendados pelo CEP; e) encaminhar os resultados para publicação, com os devidos créditos aos pesquisadores associados e ao pessoal técnico participante do projeto; f) justificar perante ao CEP interrupção do projeto ou a não publicação dos resultados.

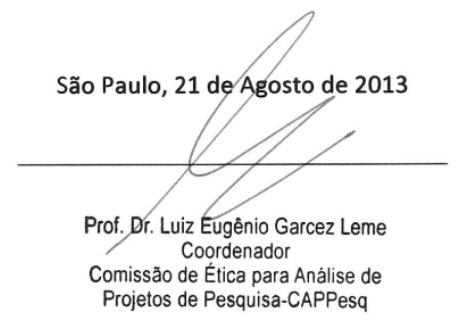

Rua Dr. Ovídio Pires de Campos, 225 - Prédio da Administração - 5 andar CEP 05403-010 - São Paulo - SP.

5511 2661-7585 - 5511 2661-6442 ramais: 16, 17, 18 | marcia.carvalho@hc.fm.usp.br 


\section{ANEXO 2}

TERMO DE CONSENTIMENTO LIVRE E ESCLARECIDO

\section{HOSPITAL DAS CLÍNICAS DA FACULDADE DE MEDICINA DA UNIVERSIDADE DE SÃO PAULO-HCFMUSP}

\section{DADOS DE IDENTIFICAÇÃO DO SUJEITO DA PESQUISA OU RESPONSÁVEL LEGAL}

1. NOME:

DOCUMENTO DE IDENTIDADE No : SEXO : .M $\square$ F

DATA NASCIMENTO: /................

ENDERECO No APTO:

BAIRRO: CIDADE

CEP: TELEFONE: DDD

$$
\text { ). }
$$

2.RESPONSÁVEL LEGAL

NATUREZA (grau de parentesco, tutor, curador, etc.).

DOCUMENTO DE IDENTIDADE : SEXO: $M \square F \square$

DATA NASCIMENTO : ...............

ENDERECO: No APTO:

BAIRRO: CIDADE:

CEP: TELEFONE: DDD ................

\section{DADOS SOBRE A PESQUISA}

1. TÍTULO DO PROTOCOLO DE PESQUISA

AVALIAÇÃO DO CONSUMO MÁXIMO DE OXIGÊNIO (VO $\left.{ }_{2 M A X}\right)$ E DA ECONOMIA DE CORRIDA (EC) EM PACIENTES SUBMETIDOS A RECONSTRUÇÃO DO LIGAMENTO CRUZADO ANTERIOR (LCA)

PESQUISADOR : Prof. Dr. Arnaldo Hernandez

CARGO/FUNCÃO: Professor Livre-Docente INSCRICÃO CONSELHO REGIONAL No 40030 UNIDADE DO HCFMUSP: INSTITUTO DE ORTOPEDIA E TRAUMATOLOGIA

3. AVALIACÃO DO RISCO DA PESQUISA:

RISCO MÍNIMO $\square$ RISCO MÉDIO $\square$

RISCO BAIXO X RISCO MAIOR $\square$

4.DURAÇÃO DA PESQUISA : 24 MESES

Rubrica do sujeito de pesquisa ou responsável

Rubrica do pesquisador

HOSPITAL DAS CLÍNICAS DA FACULDADE DE MEDICINA DA UNIVERSIDADE DE SÃO PAULO-HCFMUSP 


\section{1 - Desenho do estudo e objetivo(s).}

Essas informações estão sendo fornecidas para sua participação voluntária neste estudo, que visa avaliar o desempenho dos jogadores de futebol com lesão do ligamento cruzado anterior após o tratamento cirúrgico, e verificar se estão em boas condições físicas para o melhor desempenho no esporte na fase final de recuperação. O estudo terá duração de dois anos (24 meses). A lesão do ligamento cruzado anterior (LCA) é uma lesão comum em atletas, especialmente em esportes que envolvam mudança de direção, desacelerações bruscas e movimentos rotacionais da articulação do joelho, como o futebol. Acomete atletas de todas as idades, e é responsável pelo afastamento de grande parte destes indivíduos da atividade esportiva. O tratamento cirúrgico é o tratamento de escolha em atletas, visando reconstruir o ligamento para estabilizar a articulação, o que é atingido em mais de $90 \%$ dos casos. $O$ objetivo final do tratamento é o retorno pleno ao esporte, sem restrições, em um prazo estimado de seis meses.

2 - Descrição dos procedimentos que serão realizados, com seus propósitos e identificação dos que forem experimentais e não rotineiros;

Os pacientes praticantes de futebol com lesão do LCA serão avaliados por uma junta médica do Grupo de Medicina do Esporte do HCFMUSP. No caso de apresentarem lesão com indicação de cirurgia serão convidados a participar do estudo. O tratamento da lesão será realizado de acordo com as melhores técnicas disponíveis, e de forma alguma será alterado pela sua participação no estudo. O objetivo deste estudo é avaliar o seu condicionamento físico na fase final de recuperação da cirurgia, quando estiver retornando ao futebol competitivo. Para isso será realizado um teste de esforço em esteira para medir o consumo máximo de oxigênio e a economia de corrida. O teste será realizado antes da cirurgia e seis meses depois, e os resultados serão comparados. Também realizaremos testes em indivíduos que não tem lesão no joelho, que servirão como grupo controle. Solicitamos, se possível, que seja alguém da sua própria equipe para fazer o teste em esteira. Os indivíduos do grupo controle, que não tem lesão no joelho, obviamente não passarão por nenhuma intervenção no joelho.

\section{3 - Relação dos procedimentos rotineiros e como são realizados}

As avaliações ergoespirométricas serão agendadas em dia e horário pelo Laboratório de Estudos do Movimento do Instituto de Ortopedia e Traumatologia do Hospital das Clínicas da Faculdade de Medicina da USP localizado na Rua - Dr. Ovídio Pires de Campos, $3332^{\circ}$. Andar. Essa Rua fica localizada uma abaixo da Rua do Instituto da Criança a 100 metros do metrô Clínicas. A avaliação ergoespirométrica verificará o ar (oxigênio e dióxido de carbono) que saem dos seus pulmões enquanto se exercita na esteira. Também por meio de um monitor do coração, chamado eletrocardiograma indicará ao médico examinador os batimentos do coração e a pressão arterial será medida frequentemente durante o teste por um aparelho (esfigmomanômetro) colocado no seu braço. Você vai respirar o ar por meio de um bocal, que será colocado entre os lábios e os dentes enquanto realizar o exercício na esteira e também será colocado um prendedor nasal, para impedir que o ar escape pelos orifícios do meu nariz. Durante esse exame, a intensidade (carga) de esforço será aumentada de forma progressiva, lentamente, até onde você possa tolerar. Por outro lado, você pode solicitar o término do exame a qualquer momento em que não se sinta bem e o médico também poderá interromper o teste, por critérios médicos a qualquer momento. Depois do esforço, você sentirá cansaço físico, com os músculos cansados pelo esforço e até podem ficar um pouco doloridos, porque a proposta é que você dê o seu máximo esforço, e esse esforço naturalmente deixará você cansado.

\section{Rubrica do sujeito de pesquisa ou responsável}

\section{Rubrica do pesquisador}

Este é um teste rotineiro para avaliação de atletas e utilizado, principalmente em atletas de alto desempenho, para avaliação da sua capacidade física. Também serão realizados os testes rotineiros de avaliação dos pacientes com lesão do LCA, através de questionários por escrito, teste isocinético de força muscular (Cybex) e avaliação da 
composição corporal (impedância). Nenhum destes teste é invasivo ou acrescenta cortes, picadas ou coletas de material ou fluidos corporais, e nem altera de forma alguma a indicação de tratamento da sua lesão no joelho.

4 - Descrição dos desconfortos e riscos esperados nos procedimentos dos itens 2 e 3 ;

Todos os testes descritos acima são realizados sem cortes ou intervenções invasivas e apresentam baixos riscos ao participante. O teste realizado é um teste de esforço. É necessário correr e atingir o esforço máximo. Caso sinta algum desconforto o teste pode ser interrompido a qualquer momento, bem como se você solicitar.

5 - Benefícios para o participante

O teste ergoespirométrico é indicado para avaliação do desempenho em atletas de alta performance, e também para indivíduos que apresentam problemas de saúde e querem avaliar qual o esforço máximo podem realizar. Conhecer a sua capacidade máxima será útil para avaliar se você está apto a retornar ao futebol competitivo, e, se não estiver, será muito útil para que nós possamos propor um programa de treinamento individualizado para atingir este objetivo. A pesquisa que estamos realizando servirá justamente para sabermos se os jogadores de futebol estão aptos a retornar ao futebol com boa forma física após esta cirurgia.

6 - Relação de procedimentos alternativos que possam ser vantajosos, pelos quais o paciente pode optar:

Todos os procedimentos serão aplicados de forma padronizada com todos os participantes.

7 - Garantia de acesso: em qualquer etapa do estudo, você terá acesso aos profissionais responsáveis pela pesquisa para esclarecimento de eventuais dúvidas. O pesquisador responsável é o Prof. Dr. Arnaldo Hernandez, que pode ser encontrado na Rua Dr. Ovídio Pires de Campos, 333, no Laboratório de Estudos do Movimento (LEM), $2^{\circ}$ andar (Ala C) do Instituto de Ortopedia e Traumatologia do Hospital das Clinicas, onde estará disposição às terças e quintas feiras pela manhã, das 8:00 as 11:00 horas, ou pelo telefone (011) 2661-6041. Se você tiver alguma consideração ou dúvida sobre a ética da pesquisa, por favor, entre em contato com o Comitê de Ética em Pesquisa (CEP) - Rua Dr. Ovídio Pires de Campos, 225 - $5^{\circ}$ andar - Tel.: 2661-6442; Ramais 16, 17, 18 ou 20 - E-mail: cappesq@hcnet.usp.br;

8 - É garantida a liberdade da retirada de consentimento a qualquer momento e deixar de participar do estudo, sem qualquer prejuízo à continuidade de seu tratamento na Instituição.

09 - Direito de confidencialidade - As informações obtidas serão analisadas em conjunto com outros pacientes, não sendo divulgado a identificação de nenhum paciente;

10 - Direito de ser mantido atualizado sobre os resultados parciais das pesquisas, quando em estudos abertos, ou de resultados que sejam do conhecimento dos pesquisadores;

11 - Despesas e compensações: não há despesas pessoais para o participante em qualquer fase do estudo, incluindo exames e consultas. Também não há compensação financeira relacionada à sua participação.

12 - O pesquisador compromete-se a utilizar os dados e o material coletado somente para esta pesquisa.

Rubrica do sujeito de pesquisa ou responsável

Rubrica do pesquisador

\section{HOSPITAL DAS CLÍNICAS DA FACULDADE DE MEDICINA DA UNIVERSIDADE DE SÃO PAULO-HCFMUSP}

Acredito ter sido suficientemente informado a respeito das informações que li ou que foram lidas para mim, descrevendo o estudo AVALIAÇÃO DO CONSUMO MÁXIMO DE OXIGÊNIO 


\section{$\left(V_{2 M A X}\right)$ E DA ECONOMIA DE CORRIDA (EC) EM PACIENTES SUBMETIDOS A RECONSTRUÇÃO DO LIGAMENTO CRUZADO ANTERIOR (LCA).}

Eu discuti com os pesquisadores Dr. Adriano Marques de Almeida e Dr. Arnaldo Hernandez sobre a minha decisão em participar nesse estudo. Ficaram claros para mim quais são os propósitos do estudo, os procedimentos a serem realizados, seus desconfortos e riscos, as garantias de confidencialidade e de esclarecimentos permanentes. Ficou claro também que minha participação é isenta de despesas e que tenho garantia do acesso a tratamento hospitalar quando necessário. Concordo voluntariamente em participar deste estudo e poderei retirar o meu consentimento a qualquer momento, antes ou durante o mesmo, sem penalidades ou prejuízo ou perda de qualquer benefício que eu possa ter adquirido, ou no meu atendimento neste Serviço.

Assinatura do paciente/representante legal

Data / /

Assinatura da testemunha

Data / /

para casos de pacientes menores de 18 anos, analfabetos, semi-analfabetos ou portadores de deficiência auditiva ou visual.

(Somente para o responsável do projeto)

Declaro que obtive de forma apropriada e voluntária o Consentimento Livre e Esclarecido deste paciente ou representante legal para a participação neste estudo. 


\section{ANEXO 3}

\section{PROTOCOLO DE REABILITAÇÃO APÓS RECONSTRUÇÃO DE LCA}

\section{NO HOSPITAL (PÓS-OPERATÓRIO IMEDIATO)}

- Posicionamento no leito: manter a perna operada em extensão;

- Pode movimentar o pé, tornozelo e o quadril;

- Manter o dreno, que será retirado pelo médico ou enfermeiro.

- Após retirada do dreno:

- Manter cuidados anteriores;

- Iniciar movimentação do quadril e joelho;

- Estender o joelho completamente, dobrar livremente, de acordo com o tolerado (interromper se sentir dor intensa).

- Exercícios isométricos para o joelho.

- O curativo será trocado pelo medico ou enfermeiro.

\section{APÓS A ALTA HOSPITALAR (até 7 dias)}

- Manter cuidados anteriores;

- Bolsa com gelo, durante 20 minutos, pelo menos 3 vezes por dia. Pode repetir até de 3 em 3 horas; (não é necessário durante a noite).

- Treino de marcha com muletas, apoiando levemente a perna operada.

- Movimentar sem restrição, de acordo com o tolerado;

- Iniciar a fisioterapia;

- Manter o imobilizador apenas para o próprio conforto;

\section{A 21 DIAS}

- Treino de marcha com carga parcial e muletas, apoiando progressivamente a perna operada;

- Na primeira semana apoiar de leve a perna operada ("pisando em ovos").

- A partir da segunda semana pode apoiar completamente o pé.

- Critérios para retirar a muleta: extensão completa do joelho; sem inchaço importante; capacidade de elevar a perna sozinho, sem dificuldade; sem dor para pisar;

- Liberado para dirigir quando estiver sem muletas; 


\section{$1^{\circ}$ mês $-2^{\circ}$ mês}

- Nesta fase a movimentação deve estar completa

- Bicicleta ergométrica;

- Aumento de carga dos exercícios resistidos, acrescentar exercícios de cadeia cinética fechada (leg press);

- Evitar cadeia cinética aberta;

- Propriocepção estável com apoio dos dois pés;

- Elevação na ponta dos pés (panturrilha);

- Liberado para natação leve ( após 6 semanas);

- Iniciar caminhada leve em terrenos regulares.

\section{$3^{\circ}$ mês}

- Bicicleta com carga;

- Aumento da carga dos exercícios com peso;

- Propriocepção estável unipodálica.

- Iniciar trote

\section{$4^{\circ}$ - $5^{\circ}$ mês}

- Corrida em linha reta;

- Saltos sem mudanças bruscas;

- Apoio unipodal na cama elástica com movimento.

- Iniciar treinamento do gesto esportivo

\section{$6^{\circ}$ mês}

- Correr com freadas bruscas;

- Correr em 8/ Z;

- Retorno ao esporte 
ANEXO 4

AVALIAÇÃO ISOCINÉTICA

\begin{tabular}{|c|c|c|c|c|c|}
\hline Nave: & & Smovion & & Windowing & bokhede \\
\hline o: & marcosses & Indinat: & Mght & Protoed: & bovhete Bliaseral \\
\hline Brth Dex & $(\mathrm{d} / \mathrm{N} / \mathrm{mm})$ & Clincien: & & Pemin & Esendionflecton \\
\hline it: & 130 & Fiderrat & & Mode: & boknete \\
\hline wh & 87.0 & Jart: & Knoe & Contrietion: & conecon \\
\hline Cander: & Make & Dlegrosis: & & ce्t: & is N-M at wo begre \\
\hline
\end{tabular}

\begin{tabular}{|c|c|c|c|c|c|c|c|}
\hline \multirow[b]{2}{*}{ or heps: foght 4} & & \multicolumn{2}{|c|}{$\begin{array}{l}\text { ExTENESION } \\
\text { EO DECArstC }\end{array}$} & \multicolumn{4}{|c|}{$\begin{array}{c}\text { FEXION } \\
\text { 60 DEQUSEC }\end{array}$} \\
\hline & & unouro & mavo & sencer & uevaran & nams & senar \\
\hline or faEs: Leh 4 & & im & morr & & $\ln$ & mase & \\
\hline reak tonous: & sum & 201 & 180.5 & 280 & 1585 & 103 & 102 \\
\hline peak tomew & $x$ & 2804 & 2182 & & 10028 & 1Es: & \\
\hline nuse to pus ta & nanec & $\cos$ & 510.0 & & 4800 & 5000 & \\
\hline Anols of pir Ta & ese & 8.0 & 500 & & 40 & 300 & \\
\hline roma e rober & $s$ & $\infty 0$ & ess & 318 & 138.1 & 113.5 & 147 \\
\hline Towa of ontese & su & 1890 & 1008 & 230 & 1382 & 118:S & 124 \\
\hline ceserf. of whe & $x$ & 23 & 1.8 & & 48 & 20 & \\
\hline maxke ror rakx & $\Delta$ & 221.2 & 188.4 & 24.6 & 158.2 & 100 & as \\
\hline 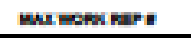 & - & 1 & 1 & & 1 & 1 & \\
\hline moksoerweant & $\approx$ & 2051 & 1819 & & 180.1 & 1Ets & \\
\hline TothL wow & $\Delta$ & 603.3 & 0012 & 24.18 & sel.s & soo.1 & 140 \\
\hline move. matar neke & $\Delta$ & $x 062$ & 2004.4 & & 200.5 & 178.4 & \\
\hline wows Lagr neeks & 4 & 2240 & 180.4 & & $1 \pi \pi .8$ & 100 & \\
\hline wonk ma nese & $x$ & 28.8 & 7.8 & & 14.4 & 120 & \\
\hline sva nowa & exma & 1720 & 10.5 & 16.6 & 117.1 & 1124 & 4.0 \\
\hline secherentros nue & vase & 20 & 200 & & 30 & 200 & \\
\hline tectloknow rast & vale & 800 & $-D$ & & 1700 & $\pi 00$ & \\
\hline nosen & ene & $=07$ & _os & & $-\infty$ & $=\infty 3$ & \\
\hline swo rexa to & $s$ & 281.0 & 184.4 & & - $^{151.1}$ & -130.8_ & \\
\hline 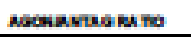 & $\approx$ & ens & Ts: & Q: 61.0 & & & \\
\hline
\end{tabular}
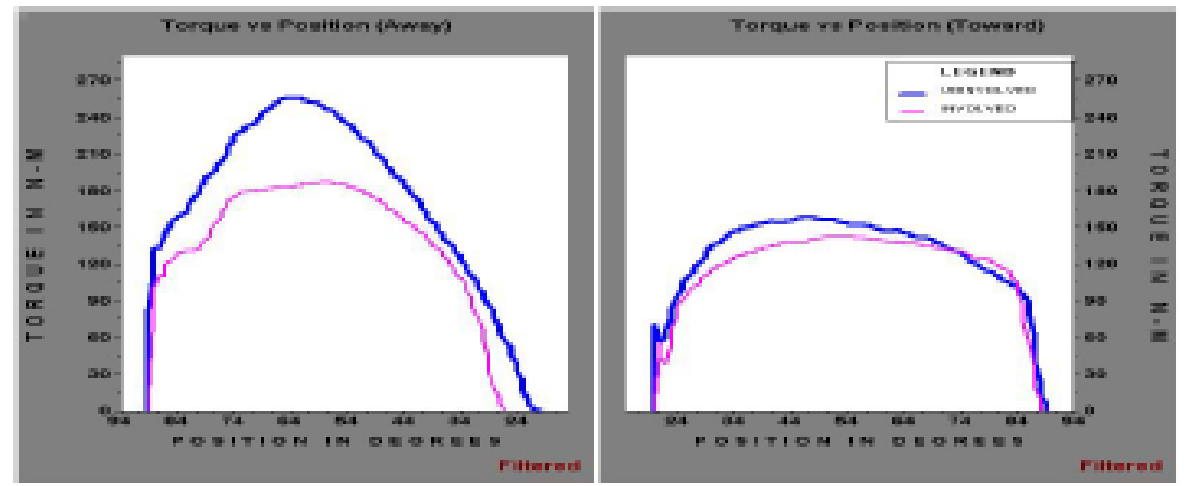


\section{ANEXO 5}

\section{AVALIAÇÃO DA COMPOSIÇÃO CORPORAL POR BIOIMPEDÂNCIA}

\section{InBody}

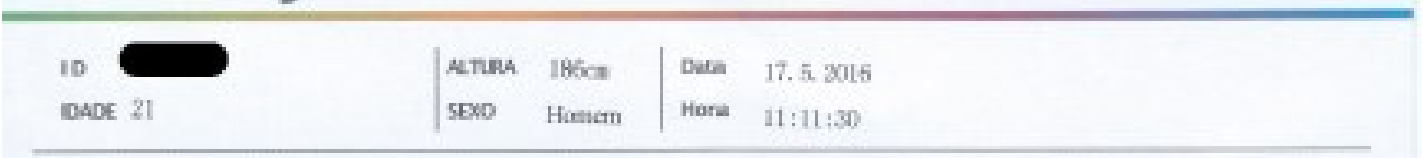

\section{Composiçåo Corporal}

\begin{tabular}{|c|c|c|c|c|}
\hline & Nomat. & Adras & intes & Faxziarmal \\
\hline Peso & $=75$ & $\mathrm{Ob}_{\mathrm{b}}$ tho the the Th & ite $x$ & $64.7 \sim 87.5$ \\
\hline 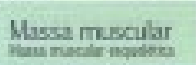 & 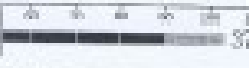 & 7.74 in the the & क 15 & $32.8-10.1$ \\
\hline Massa de gondura & 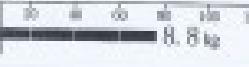 & 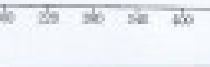 & का का & 9. $1 \sim 18.3$ \\
\hline $\begin{array}{l}\mathrm{ACT} \\
\text { tou Copous tew }\end{array}$ & $48.6 \mathrm{~kg}(\mathrm{a}, \mathrm{H} \sim 6 \mathrm{z}, 3)$ & $\begin{array}{l}\text { MLG } \\
\text { Mima unn de Coetros }\end{array}$ & dit. 2 kq & $55.6 \sim 89.39$ \\
\hline
\end{tabular}

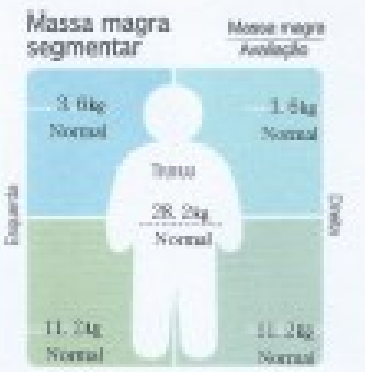

\section{Diagnóstico da obesidade}

\begin{tabular}{|c|c|c|c|}
\hline & Vex & valoga fomed & \\
\hline 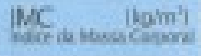 & 21.7 & $18.5 \sim 25.0$ & (A6)arater) \\
\hline PCC & 11.7 & $10.0-20.0$ & \multirow{2}{*}{ POC $=\frac{\text { Vons grotas }}{\text { Pomis }} \times 100$} \\
\hline 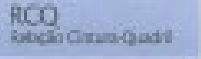 & D. 80 & 12. $80 \sim 0.90$ & \\
\hline $\begin{array}{l}\text { TME loodi } \\
\text { Tans wrotilica patal }\end{array}$ & 1801 & $1609-1855$ & 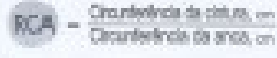 \\
\hline
\end{tabular}

Controle Músculo-Gordura

Controk muscilar $\quad 0.0 \mathrm{~kg}$

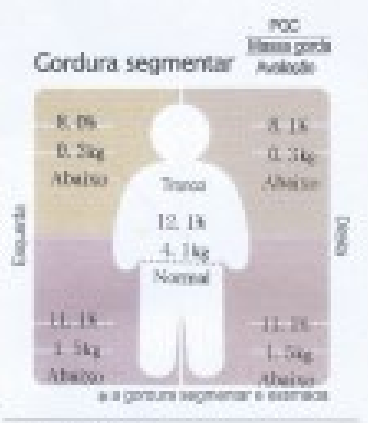

Impedància

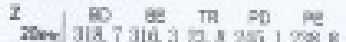
10006 283.9204 .8 19.7 21T. 1210.5 


\section{ANEXO 6 \\ FORMULÁRIO DE AVALIAÇÃO SUBJETIVA IKDC}

\section{Formulário de avaliação subjetiva do joelho - IKDC}

Nome completo

Data: / /

Data da lesão: / /

\section{SINTOMAS*:}

* Assinale os sintomas no nível de atividade mais alta que você imagina poderia fazer sem sintomas importantes, mesmo que você não esteja, de fato realizando atividades nesse nível.

1. Qual o nível mais alto de atividade que você consegue realizar sem dor significativa no joelho?

I( ) Incapaz de realizar qualquer das atividades acima devido a dor no joelho

( ( ) Atividades leves como caminhar, trabalho doméstico ou arrumar quintal ou jardim

I( ) Atividades moderadas como trabalho braçal moderado, correr ou trotear?

(1 ) Atividades vigorosas como trabalho braçal pesado, esquiar ou jogar tênis

I( ) Atividades muito vigorosas com pular ou "fintar" (girar) como no basquete ou futebol

2. Nas últimas 4 semanas, ou desde que você se machucou, com que freqüência você teve dor?

$\begin{array}{lllllllllllll}\text { Nunca } & 0 & 1 & 2 & 3 & 4 & 5 & 6 & 7 & 8 & 9 & 10 & \text { Constantemente }\end{array}$

3. Se você teve dor, qual a sua intensidade?

$\begin{array}{llllllllllll}\text { Sem dor } & 0 & 1 & 2 & 3 & 4 & 5 & 6 & 7 & 8 & 9 & 10 \text { Pior dor possível }\end{array}$

4. Nas últimas 4 semanas, ou desde que você se machucou, quanto o seu joelho ficou sem mobilidade ou inchado (duro? Preso? travado?)

Nunca

Um pouco

Moderadamente (médio)

Muito

Extremamente 
5. Qual é o mais alto nível de atividade que você pode realizar sem inchaço significativo do seu joelho?

(( ) Incapaz de realizar qualquer das atividades acima devido ao inchaço no joelho

(( ) Atividades leves como caminhar, trabalho doméstico ou arrumar quintal ou jardim

I( ) Atividades moderadas como trabalho braçal moderado, correr ou trotear?

I( ) Atividades vigorosas como trabalho braçal pesado, esquiar ou jogar tênis

I( ) Atividades muito vigorosas com pular ou "fintar" (girar) como no basquete ou futebol

6. Nas últimas 4 semanas, ou desde que você se machucou, o seu joelho travou ou falhou?

Sim INão

7. Qual é o mais alto nível de atividade que você consegue realizar sem o seu joelho falsear significativamente?

I( ) Incapaz de realizar qualquer das atividades acima devido a falseios no joelho

I( ) Atividades leves como caminhar, trabalho doméstico ou arrumar quintal ou jardim

I( ) Atividades moderadas como trabalho braçal moderado, correr ou trotear?

I( ) Atividades vigorosas como trabalho braçal pesado, esquiar ou jogar tênis

I( ) Atividades muito vigorosas com pular ou "fintar" (girar) como no basquete ou futebol

\section{ATIVIDADES ESPORTIVAS:}

8. Qual é o mais alto nível de atividade que você consegue realizar regularmente?

I( ) Incapaz de realizar qualquer das atividades acima devido a problemas no joelho

I( ) Atividades leves como caminhar, trabalho doméstico ou arrumar quintal ou jardim

I( ) Atividades moderadas como trabalho braçal moderado, correr ou trotear?

I( ) Atividades vigorosas como trabalho braçal pesado, esquiar ou jogar tênis

I( ) Atividades muito vigorosas com pular ou "fintar" (girar) como no basquete ou futebol 
9. Como o joelho afeta sua habilidade para:

\begin{tabular}{|l|l|l|l|l|l|l|}
\hline & & $\begin{array}{c}\text { Nenhuma } \\
\text { dificuldade }\end{array}$ & $\begin{array}{c}\text { Dificuldade } \\
\text { mínima }\end{array}$ & $\begin{array}{c}\text { Dificuldade } \\
\text { moderada }\end{array}$ & $\begin{array}{c}\text { Dificuldade } \\
\text { extrema }\end{array}$ & $\begin{array}{c}\text { Incapaz } \\
\text { de } \\
\text { realizar }\end{array}$ \\
\hline A & Subir escadas & & & & & \\
\hline B & Descer escadas & & & & & \\
\hline C & Ajoelhar-se & & & & & \\
\hline D & Agachar-se & & & & & \\
\hline E & Sentar-se & & & & & \\
\hline F & $\begin{array}{l}\text { Levantar-se de uma } \\
\text { cadeira }\end{array}$ & & & & & \\
\hline G & Correr em linha reta & & & & & \\
\hline H & $\begin{array}{l}\text { Saltar e aterrisar sobre } \\
\text { a perna afetada }\end{array}$ & & & & & \\
\hline I & $\begin{array}{l}\text { Parar e reiniciar } \\
\text { movimentos } \\
\text { rapidamente }\end{array}$ & & & & & \\
\hline
\end{tabular}

FUNÇÃO:

10. Como você avaliaria a função do seu joelho numa escala de 0 a 10 , onde 10 significa função normal ou excelente e 0 significando incapacidade de realizar qualquer uma de suas atividades diárias, incluindo atividade esportiva?

Função antes do problema do joelho:

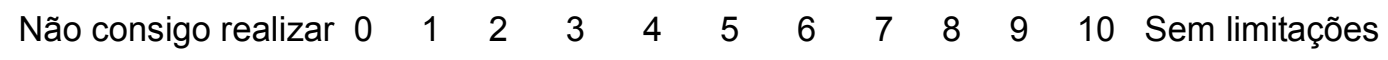

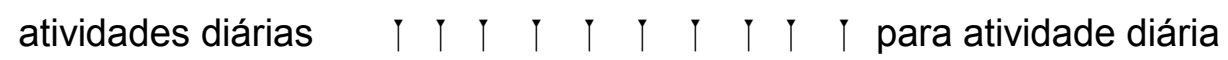

Função atual do seu joelho:

$\begin{array}{lllllllllllll}\text { Não consigo realizar } & 0 & 1 & 2 & 3 & 4 & 5 & 6 & 7 & 8 & 9 & 10 & \text { Sem limitações }\end{array}$

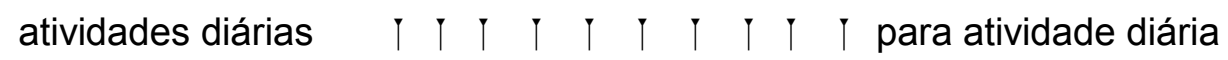




\section{ANEXO 7 \\ QUESTIONÁRIO LYSHOLM}

Para cada pergunta, circule a opção mãos apropriada que corresponde aos seus sintomas no joelho.

\section{Mancar (5 pontos)}
(a) Nunca (5)
(b) Leve ou periodicamente (3)
(c) Intenso ou constantemente (0)

\section{Apoio (5 pontos)}
(a) Nenhum (5)
(b) Bengala ou muleta (2)
(c) Impossivel (0)

\section{Travamento (15 pontos)}
(a) Nenhum travamento ou sensação de travamento (15)
(b) Tem sensação, mas sem travamento (10)
(c) Travamento ocasional (6)
(d) Frequente (2)
(e) Articulação (junta) travada no exame (0)

\section{Instabilidades ( 25 pontos)}
(a) Nunca falseia (25)
(b) Raramente, durante atividades atléticas ou outros exercícios pesados (20)
(c) Frequentemente durante atividades atléticas ou outros exercícios pesados, ou incapaz de participação (15)
(d) Ocasionalmente em atividades diárias (10)
(e) Frequentemente em atividades diárias (5)
(f) Em cada passo (0) 


\section{Dor (25 pontos)}
(a) Nenhuma (25)
(b) Inconstante ou leve durante exercícios pesados (20)
(c) Marcada durante exercícios pesados (15)
(d) Marcada durante ou após caminhar mais de $2 \mathrm{~km}$ (10)
(e) Marcada durante ou após caminhar menos de $2 \mathrm{~km}$ (5)
(f) Constante (0)

6. Inchaço (10 pontos)
(a) Nenhum (10)
(b) Com exercícios pesados (6)
(c) Com exercícios comuns (2)
(d) Constante (0)

\section{Subindo escadas (10 pontos)}
(a) Nenhum problema (10)
(b) Levemente prejudicado (6)
(c) Um degrau de cada vez (2)
(d) Impossível (0)

\section{Agachamento (5 pontos)}
(a) Nenhum problema (5)
(b) Levemente prejudicado (4)
(c) Não além de 90 graus (2)
(d) Impossível (0) 
8 Referências 


\section{REFERÊNCIAS}

1 FIFA C. FIFA Big Count 2006: 270 million people active in football. FIFA Communications Division: Zurique; 2007. Disponível em: http://www.fifa.com/mm/document/fifafacts/bcoffsurv/bigcount.statspacka ge_7024.pdf.

2 Hoff J, Wisløff U, Engen LC, Kemi OJ, Helgerud J. Soccer specific aerobic endurance training. Br J Sports Med. 2002;36(3):218-21.

3 Bangsbo J. Energy demands in competitive soccer. J Sports Sci. 1994;12 $($ Spec No):S5-12.

4 Bangsbo J, Mohr M, Krustrup P. Physical and metabolic demands of training and match-play in the elite football player. I Sports Sci 2006;24(7):665-74.

5 Granan LP, Bahr R, Steindal K, Furnes O, Engebretsen L. Development of a national cruciate ligament surgery registry: the Norwegian National Knee Ligament Registry. Am J Sports Med. 2008;36(2):308-15.

6 Ekstrand J, Gillquist J. Soccer injuries and their mechanisms: a prospective study. Med Sci Sports Exerc. 1983;15(3):267-70.

7 Chomiak J, Junge A, Peterson L, Dvorak J. Severe injuries in football players. Influencing factors. Am J Sports Med. 2000;28(5 Suppl):S58-68.

8 Prodromos CC, Han Y, Rogowski J, Joyce B, Shi K. A meta-analysis of the incidence of anterior cruciate ligament tears as a function of gender, sport, and a knee injury-reduction regimen. Arthroscopy. 2007;23(12):1320-6. 
9 Dai B, Mao D, Garrett WE, Bing Y. Anterior cruciate ligament injuries in soccer: Loading mechanisms, risk factors, and prevention programs. $J$ Sport Health Sci. 2014;3(4):299-306.

10 Maletis GB, Cameron SL, Tengan JJ, Burchette RJ. A prospective randomized study of anterior cruciate ligament reconstruction: a comparison of patellar tendon and quadruple-strand semitendinosus/gracilis tendons fixed with bioabsorbable interference screws. Am J Sports Med. 2007;35(3):384-94.

11 Ekstrand J. A 94\% return to elite level football after ACL surgery: a proof of possibilities with optimal caretaking or a sign of knee abuse? Knee Surg Sports Traumatol Arthrosc. 2011;19(1):1-2.

12 Tiamklang T, Sumanont S, Foocharoen T, Laopaiboon M. Double-bundle versus single-bundle reconstruction for anterior cruciate ligament rupture in adults. Cochrane Database Syst Rev. 2012;11:CD008413.

13 Walden M, Hagglund M, Magnusson $H$, Ekstrand J. Anterior cruciate ligament injury in elite football: a prospective three-cohort study. Knee Surg Sports Traumatol Arthrosc. 2011;19(1):11-9.

14 Myer GD, Paterno MV, Ford KR, Quatman CE, Hewett TE. Rehabilitation after anterior cruciate ligament reconstruction: criteria-based progression through the return-to-sport phase. $J$ Orthop Sports Phys Ther. 2006;36(6):385-402.

15 Erickson BJ, Harris JD, Fillingham YA, Cvetanovich GL, Busch-Joseph C, Cole BJ, et al. Orthopedic practice patterns relating to anterior cruciate ligament reconstruction in elite athletes. Am J Orthop (Belle Mead NJ). 2015;44(12):E480-5.

16 Farber J, Harris JD, Kolstad K, McCulloch PCl. Treatment of anterior cruciate ligament injuries by major league soccer team physicians. Orthop J Sports Med. 2014;2(11):2325967114559892. 
17 Howard JS, Lembach ML, Metzler AV, Johnson DL. Rates and determinants of return to play after anterior cruciate ligament reconstruction in National Collegiate Athletic Association Division I Soccer Athletes: A Study of the Southeastern Conference. Am J Sports Med. 2016;44(2):433-9.

18 Tudisco C, Bisicchia S, Cosentino A, Chiozzi F, Piva M. Knee stability, athletic performance and sport-specific tasks in non-professional soccer players after $A C L$ reconstruction: comparing trans-tibial and antero-medial portal techniques. Muscles Ligaments Tendons J. 2015;5(3):175-80.

19 Zaffagnini S, Grassi A, Marcheggiani Muccioli GM, Tsapralis K, Ricci M, Bragonzoni L, et al. Return to sport after anterior cruciate ligament reconstruction in professional soccer players. Knee. 2014;21(3):731-5.

20 Ardern CL, Webster KE, Taylor NF, Feller JA. Return to sport following anterior cruciate ligament reconstruction surgery: a systematic review and meta-analysis of the state of play. Br J Sports Med. 2011;45(7): 596-606.

21 Ardern CL, Taylor NF, Feller JA, Webster KE. Fifty-five per cent return to competitive sport following anterior cruciate ligament reconstruction surgery: an updated systematic review and meta-analysis including aspects of physical functioning and contextual factors. $\mathrm{Br} J$ Sports Med. 2014;48(21):1543-52.

22 Kyritsis P, Bahr R, Landreau P, Miladi R, Witvreouw E. Likelihood of ACL graft rupture: not meeting six clinical discharge criteria before return to sport is associated with a four times greater risk of rupture. $\mathrm{Br} J$ Sports Med. 2016;50(15):946-51.

23 Stølen T, Chamari K, Castagna C, Wisløff U. Physiology of soccer: an update. Sports Med. 2005;35(6):501-36.

24 Santos-Silva PR, Fonseca AJ, Castro AW de, Greve JM, Hernandez AJ. Reproducibility of maximum aerobic power $\left(\mathrm{VO}_{2 \max }\right)$ among soccer 
players using a modified heck protocol. Clinics (São Paulo). 2007;62(4):391-6.

25 Bassett DR Jr, Howley ET. Limiting factors for maximum oxygen uptake and determinants of endurance performance. Med Sci Sports Exerc. 2000;32(1):70-84.

26 Beaver WL, Wasserman K, Whipp BJ. A new method for detecting anaerobic threshold by gas exchange. J Appl Physiol. 1986;60(6): 20207.

27 Wasserman K, Whipp BJ, Koyl SN, Beaver WL. Anaerobic threshold and respiratory gas exchange during exercise. $J$ Appl Physiol. 1973;35(2):236-43.

28 Boone J, Deprez D, Burgois J. Running economy in elite soccer and basketball players: differences among positions on the field. Int $J$ Perform Anal Sport. 2014;14(3):775-87.

29 Zinner C, Sperlich B, Wahl P, Mester J. Classification of selected cardiopulmonary variables of elite athletes of different age, gender, and disciplines during incremental exercise testing. Springerplus. 2015;4:544.

30 Aune AK, Holm I, Risberg MA, Jensen HK, Steen H. Four-strand hamstring tendon autograft compared with patellar tendon-bone autograft for anterior cruciate ligament reconstruction. A randomized study with two-year follow-up. Am J Sports Med. 2001;29(6):722-8.

31 Beynnon BD, Johnson RJ, Fleming BC, Kannus P, Kaplan M, Samani J, et al. Anterior cruciate ligament replacement: comparison of bone-patellar tendon-bone grafts with two-strand hamstring grafts. A prospective, randomized study. J Bone Joint Surg Am. 2002;84(9):1503-13.

32 Webster KE, Feller JA, Hartnett N, Leigh WB, Richmond AK. Comparison of patellar tendon and hamstring tendon anterior cruciate ligament 
reconstruction: a 15-year follow-up of a randomized controlled trial. Am J Sports Med. 2016;44(1):83-90.

33 Brophy RH, Schmitz L, Wright RW, Dunn WR, Parker RD, Andrish JT, et al. Return to play and future $A C L$ injury risk after $A C L$ reconstruction in soccer athletes from the Multicenter Orthopaedic Outcomes Network (MOON) group. Am J Sports Med. 2012;40(11):2517-22.

34 Roos H, Ornell M, Gardsell P, Lohmander LS, Lindstrand A. Soccer after anterior cruciate ligament injury--an incompatible combination? A national survey of incidence and risk factors and a 7-year follow-up of 310 players. Acta Orthop Scand. 1995;66(2):107-12.

35 Fernandes TL, Fregni F, Weaver K, Pedrinelli A, Camanho GL, Hernandez AJ. The influence of femoral tunnel position in single-bundle $A C L$ reconstruction on functional outcomes and return to sports. Knee Surg Sports Traumatol Arthrosc. 2014;22(1):97-103.

36 Franceschi F, Papalia R, Rizzello G, et al. Anteromedial portal versus transtibial drilling techniques in anterior cruciate ligament reconstruction: any clinical relevance? a retrospective comparative study. Arthroscopy. 2013;29(8):1330-7.

37 Barber-Westin SD, Noyes FR. Factors used to determine return to unrestricted sports activities after anterior cruciate ligament reconstruction. Arthroscopy. 2011;27(12):1697-705.

38 Bizzini M, Hancock D, Impellizzeri F. Suggestions from the field for return to sports participation following anterior cruciate ligament reconstruction: soccer. J Orthop Sports Phys Ther. 2012;42(4):304-12.

39 Bizzini M, Silvers HJ. Return to competitive football after major knee surgery: more questions than answers? J Sports Sci. 2014;32(13): 120916. 
40 Hill AV, Lupton $\mathrm{H}$. Muscular exercise, lactic acid, and the supply and utilization of oxygen. QJM. 1923;16(62):135-71.

41 Albouaini K, Egred M, Alahmar A, Wright DJ. Cardiopulmonary exercise testing and its application. Postgrad Med J. 2007;83(985): 675-82.

42 Billat LV, Koralsztein JP. Significance of the velocity at $\mathrm{VO}_{2 \max }$ and time to exhaustion at this velocity. Sports Med. 1996;22(2):90-108.

43 Saltin B, Strange S. Maximal oxygen uptake: "old" and "new" arguments for a cardiovascular limitation. Med Sci Sports Exerc. 1992;24(1):30-7.

44 Olivier N, Legrand R, Rogez J, Berthoin S, Weissland T. Effects of knee surgery on cardiac function in soccer players. Am J Phys Med Rehabil. 2007;86(1):45-9.

45 Helgerud J, Engen LC, Wisloff U, Hoff J. Aerobic endurance training improves soccer performance. Med Sci Sports Exerc. 2001;33(11): 192531.

46 Tonnessen E, Hem E, Leirstein S, Haugen T, Seiler S. Maximal aerobic power characteristics of male professional soccer players, 1989-2012. Int J Sports Physiol Perform. 2013;8(3):323-9.

47 Castagna C, Impellizzeri FM, Chaouachi A, Manzi V. Preseason variations in aerobic fitness and performance in elite-standard soccer players: a team study. J Strength Cond Res. 2013;27(11):2959-65.

48 Koundourakis NE, Androulakis NE, Malliaraki N, Tsatsanis C, Venihaki M, Margioris AN. Discrepancy between exercise performance, body composition, and sex steroid response after a six-week detraining period in professional soccer players. PLoS One. 2014;9(2):e87803.

49 Milanović Z, Pantelić S, Čović N, Sporis G, Krustrup P. Is recreational soccer effective for improving $\mathrm{VO}_{2 \max }$ ? a systematic review and metaanalysis. Sports Med. 2015;45(9):1339-53. 
50 Ross R, Blair SN, Arena R, Church TS, Després JP, Franklin BA, et al. Importance of assessing cardiorespiratory fitness in clinical practice: A case for fitness as a clinical vital sign: a scientific statement from the American Heart Association. Circulation. 2016;134(24):e653-99.

51 Mujika I, Padilla S. Detraining: loss of training-induced physiological and performance adaptations. Part I: short term insufficient training stimulus. Sports Med. 2000;30(2):79-87.

52 Mujika I, Padilla S. Detraining: loss of training-induced physiological and performance adaptations. Part II: long term insufficient training stimulus. Sports Med. 2000;30(3):145-54.

53 Martin WH 3rd, Coyle EF, Bloomfield SA, Ehsani AA. Effects of physical deconditioning after intense endurance training on left ventricular dimensions and stroke volume. J Am Coll Cardiol. 1986;7(5):982-9.

54 Ostojic SM. Seasonal alterations in body composition and sprint performance of elite soccer players. J Exerc Physiol. 2003;6(3):24-7.

55 Caldwell BP, Peters DM. Seasonal variation in physiological fitness of a semiprofessional soccer team. J Strength Cond Res. 2009;23(5): 1370-7.

56 Clark NA, Edwards AM, Morton RH, Butterfly RJ. Season-to-season variations of physiological fitness within a squad of professional male soccer players. J Sports Sci Med. 2008;7(1):157-65.

57 Helgerud J, Rodas G, Kemi OJ, Hoff J. Strength and endurance in elite football players. Int J Sports Med. 2011;32(9):677-82.

58 McMaster DT, Gill N, Cronin J, McGuigan M. The development, retention and decay rates of strength and power in elite rugby union, rugby league and American football. Sports Med. 2013;43(5):367-84.

59 Amigó N, Cadefau JA, Ferrer I, Tarrados N, Cussó R. Effect of summer intermission on skeletal muscle of adolescent soccer players. $J$ Sports Med Phys Fitness. 1998;38(4):298-304. 
60 Cormie P, McGuigan MR, Newton RU. Developing maximal neuromuscular power: part 2 - training considerations for improving maximal power production. Sports Med. 2011;41(2):125-46.

61 Djokić Z. Post-operative rehabilitation program after surgery ACL reconstruction. Sport Mont J. 2013;XI(37-39):199-206.

62 Foster C, Lucia A. Running economy: the forgotten factor in elite performance. Sports Med. 2007;37(4-5):316-9.

63 Bangsbo J, laia FM, Krustrup P. The Yo-Yo intermittent recovery test : a useful tool for evaluation of physical performance in intermittent sports. Sports Med. 2008;38(1):37-51.

64 Morgan DW, Martin PE, Krahenbuhl GS. Factors affecting running economy. Sports Med. 1989;7(5):310-30.

65 Cometti G, Maffiuletti NA, Pousson M, Chatard JC, Maffulli N. Isokinetic strength and anaerobic power of elite, subelite and amateur French soccer players. Int J Sports Med. 2001;22(1):45-51.

66 Oberg B, Moller M, Gillquist J, Ekstrand J. Isokinetic torque levels for knee extensors and knee flexors in soccer players. Int $J$ Sports Med. $1986 ; 7(1): 50-3$.

67 Ruas CV, Minozzo F, Pinto MD, Brown LE, Pinto RS. Lower-extremity strength ratios of professional soccer players according to field position. $J$ Strength Cond Res. 2015;29(5):1220-6.

68 Pua YH, Bryant AL, Steele JR, Newton RU, Wrugley TV. Isokinetic dynamometry in anterior cruciate ligament injury and reconstruction. Ann Acad Med Singapore. 2008;37(4):330-40.

69 Dauty M, Tortellier L, Rochcongar P. Isokinetic and anterior cruciate ligament reconstruction with hamstrings or patella tendon graft: analysis of literature. Int J Sports Med. 2005;26(7):599-606. 
70 Xergia SA, McClelland JA, Kvist J, Vasiliadis HS, Georgoulkis AD. The influence of graft choice on isokinetic muscle strength 4-24 months after anterior cruciate ligament reconstruction. Knee Surg Sports Traumatol Arthrosc. 2011;19(5):768-80.

71 Czaplicki A, Jarocka M, Walawski J. Isokinetic identification of knee joint torques before and after anterior cruciate ligament reconstruction. PLoS One. 2015;10(12):e0144283.

72 Undheim MB, Cosgrave C, King E, Strike S, Marshall B, Falvey É, et al. Isokinetic muscle strength and readiness to return to sport following anterior cruciate ligament reconstruction: is there an association? A systematic review and a protocol recommendation. $\mathrm{Br} J$ Sports Med. 2015;49(20):1305-10.

73 Fosbol MØ, Zerahn B. Contemporary methods of body composition measurement. Clin Physiol Funct Imaging. 2015;35(2):81-97.

74 Moon JR. Body composition in athletes and sports nutrition: an examination of the bioimpedance analysis technique. Eur $J$ Clin Nutr. 2013;67 Suppl 1:S54-9.

75 Jaffrin MY. Body composition determination by bioimpedance: an update. Curr Opin Clin Nutr Metab Care. 2009;12(5):482-6.

76 Melchiorri G, Monteleone G, Andreoli A, Callà C, Sgroi M, De Lorenzo A. Body cell mass measured by bioelectrical impedance spectroscopy in professional football (soccer) players. J Sports Med Phys Fitness. 2007;47(4):408-12.

77 Micheli ML, Pagani L, Marella M, Gulisano M, Piccoli A, Angelini F, et al. Bioimpedance and impedance vector patterns as predictors of league level in male soccer players. Int J Sports Physiol Perform. 2014;9(3):5329. 
78 Irrgang JJ, Anderson AF, Boland AL, Harner CD, Kurosaka M, Neyret P, et al. Development and validation of the International Knee Documentation Committee Subjective Knee Form. Am J Sports Med. 2001;29(5):600-13.

79 Anderson AF, Irrgang JJ, Kocher MS, Mann BJ, Harrast JJ; International Knee Documentation Committee. The International Knee Documentation Committee Subjective Knee Evaluation Form: normative data. Am J Sports Med. 2006;34(1):128-35.

80 Metsavaht L, Leporace G, Riberto M, de Mello Sposito MM, Batista LA. Translation and cross-cultural adaptation of the Brazilian version of the International Knee Documentation Committee Subjective Knee Form: validity and reproducibility. Am J Sports Med. 2010;38(9):1894-9.

81 Lysholm J, Gillquist J. Evaluation of knee ligament surgery results with special emphasis on use of a scoring scale. Am $J$ Sports Med. 1982;10(3):150-4.

82 Peccin MS, Ciconelli R, Cohen M. Questionário específico para sintomas do joelho "Lysholm Knee Scoring Scale": tradução e validação para a língua portuguesa. Acta Ortop Bras. 2006;14(5):268-72.

83 Santamaria LJ, Webster KE. The effect of fatigue on lower-limb biomechanics during single-limb landings: a systematic review. J Orthop Sports Phys Ther. 2010;40(8):464-73.

84 Chappell JD, Herman DC, Knight BS, Kirkendall DT, Garrett WE, Yu B. Effect of fatigue on knee kinetics and kinematics in stop-jump tasks. Am J Sports Med. 2005;33(7):1022-9.

85 Sugimoto D, Alentorn-Geli E, Mendiguchia J, Samuelsson K, Karlsson J, Myer GD. Biomechanical and neuromuscular characteristics of male athletes: implications for the development of anterior cruciate ligament injury prevention programs. Sports Med. 2015;45(6):809-22. 
86 Tsai LC, Sigward SM, Pollard CD, Fletcher MJ, Powers CM. Effects of fatigue and recovery on knee mechanics during side-step cutting. Med Sci Sports Exerc. 2009;41(10):1952-7.

87 Quammen D, Cortes N, Van Lunen BL, Lucci S, Ringleb SI, Onate J. Two different fatigue protocols and lower extremity motion patterns during a stop-jump task. J Athl Train. 2012;47(1):32-41.

88 Gokeler A, Eppinga P, Dijkstra PU, Welling W, Padua DA, Otten E, et al. Effect of fatigue on landing performance assessed with the landing error scoring system (less) in patients after ACL reconstruction. A pilot study. Int J Sports Phys Ther. 2014;9(3):302-11.

89 Watson A, Brindle J, Brickson S, Allee T, Sanfilippo J. Preseason aerobic capacity is an independent predictor of in-season injury in collegiate soccer players. Clin J Sport Med. 2016 June 22 [Epub ahead of print].

90 Buchfuhrer MJ, Hansen JE, Robinson TE, Sue DY, Wasserman K, Whipp BJ. Optimizing the exercise protocol for cardiopulmonary assessment. $J$ Appl Physiol Respir Environ Exerc Physiol. 1983;55(5):1558-64.

91 Anastasakis A, Kotsiopoulou C, Rigopoulos A, Theopistou A, Protonotarios N, Panagiotakos $\mathrm{D}$, et al. Similarities in the profile of cardiopulmonary exercise testing between patients with hypertrophic cardiomyopathy and strength athletes. Heart. 2005;91(1):1477-8.

92 Metaxas TI, Koutlianos N, Sendelides T, Mandroukas A. Preseason physiological profile of soccer and basketball players in different divisions. J Strength Cond Res. 2009;23(6):1704-13.

93 Volek JS, Freidenreich DJ, Saenz C, Kunces LJ, Creighton BC, Bartley $\mathrm{JM}$, et al. Metabolic characteristics of keto-adapted ultra-endurance runners. Metabolism. 2016;65(3):100-10. 
94 Gaskill SE, Ruby BC, Walker AJ, Sanchez OA, Serfass RC, Leon AS. Validity and reliability of combining three methods to determine ventilatory threshold. Med Sci Sports Exerc. 2001;33(1):1841-8.

95 Lucia A, Hoyos J, Santalla A, Pérez M, Chicharro JL. Kinetics of VO(2) in professional cyclists. Med Sci Sports Exerc. 2002;34(2):320-5.

96 Dupont G, Blondel N, Berthoin S. Time spent at VO2max: a methodological issue. Int J Sports Med. 2003;24(4):291-7.

97 Tanaka H, Monahan KD, Seals DR. Age-predicted maximal heart rate revisited. J Am Coll Cardiol. 2001;37(1):153-6.

98 James NW, Adams GM, Wilson AF. Determination of anaerobic threshold by ventilatory frequency. Int $J$ Sports Med. 1989;10(3):192-6.

99 Wasserman K. Determinants and detection of anaerobic threshold and consequences of exercise above it. Circulation. 1987;76(6 Pt 2):VI29-39.

100 Bhambhani $Y$, Singh M. Ventilatory thresholds during a graded exercise test. Respiration. 1985;47(2):120-8.

101 Jansson E, Dudley GA, Norman B, Tesch PA. Relationship of recovery from intense exercise to the oxidative potential of skeletal muscle. Acta Physiol Scand. 1990;139(1):147-52.

102 Stone NM, Kilding AE. Aerobic conditioning for team sport athletes. Sports Med. 2009;39(8):615-42.

103 Andrzejewski M, Chmura J, Pluta B, Strzelczyk R, Kasprzask A. Analysis of sprinting activities of professional soccer players. J Strength Cond Res. 2013;27(8):2134-40.

104 Bangsbo J, laia FM, Krustrup P. Metabolic response and fatigue in soccer. Int J Sports Physiol Perform. 2007;2(2):111-27. 
105 Buchheit M, Haddad AI H, Millet GP, Lepretre PM, Newton M, Ahmaidi S. Cardiorespiratory and cardiac autonomic responses to 30-15 intermittent fitness test in team sport players. J Strength Cond Res. 2009;23(1):93100.

106 Häkkinen K. Neuromuscular adaptation during strength training, aging, detraining, and immobilization. Crit Rev Physiol Rehab Med. 1994;6:16198.

107 Hansen G, Blanchard C, Rodgers W, Bell G. Efficacy of prescribing endurance training intensity using the ventilatory equivalents for oxygen and carbon dioxide in untrained men and women. Res Sports Med. 2003;11(1):23-32.

108 Sporiš G, Jukic I, Ostojic SM, Milanovic D. Fitness profiling in soccer: physical and physiologic characteristics of elite players. J Strength Cond Res. 2009;23(7):1947-53.

109 Seiler KS, Kjerland GØ. Quantifying training intensity distribution in elite endurance athletes: is there evidence for an "optimal" distribution? Scand J Med Sci Sports. 2006;16(1):49-56.

110 Edwards AM, Clark N, Macfadyen AM. Lactate and ventilatory thresholds reflect the training status of professional soccer players where maximum aerobic power is unchanged. J Sports Sci Med. 2003;2(1):23-9.

111 McKenna MJ. The roles of ionic processes in muscular fatigue during intense exercise. Sports Med. 1992;13(2):134-45.

112 Melchiorri G, Ronconi M, Triossi T, Viero V, De Sanctis D, Tancredi V, et al. Detraining in young soccer players. J Sports Med Phys Fitness. 2014;54(1):27-33. 
113 Ziogas GG, Patras KN, Stergiou N, Georgoulis AD. Velocity at lactate threshold and running economy must also be considered along with maximal oxygen uptake when testing elite soccer players during preseason. J Strength Cond Res. 2011;25(2):414-9.

114 Shaw AJ, Ingham SA, Atkinson G, Folland JP. The correlation between running economy and maximal oxygen uptake: cross-sectional and longitudinal relationships in highly trained distance runners. PLoS One. 2015;10(4):e0123101.

115 Saunders PU, Pyne DB, Telford RD, Hawley JA. Factors affecting running economy in trained distance runners. Sports Med. 2004;34(7):465-85.

116 McHugh MP, Spitz AL, Lorei MP, Nicholas SJ, Hershman EB, Gleim GW.. Effect of anterior cruciate ligament deficiency on economy of walking and jogging. J Orthop Res. 1994;12(4):592-7.

117 Colak M, Ayan I, Dal U, Yaroglu T, Dag F, Yilmaz C, et al. Anterior cruciate ligament reconstruction improves the metabolic energy cost of level walking at customary speeds. Knee Surg Sports Traumatol Arthrosc. 2011;19(8):1271-6.

118 Owen AL, Wong DP, Paul D, Dellai A. Effects of a periodized small-sided game training intervention on physical performance in elite professional soccer. J Strength Cond Res. 2012;26(10):2748-54.

119 di Prampero PE, Atchou G, Bruckner JC, Moia C. The energetics of endurance running. Eur J Appl Physiol Occup Physiol.1986;55(3):259-66. 
Apêndice 


\section{GRÁFICOS DE DINAMOMETRIA ISOCINÉTICA}

Gráfico 12 - Pico de torque dos músculos extensores e flexores do joelho a $60 \%$ e $240 \%$ nos diferentes grupos. Os colchetes indicam diferença estatisticamente significativa $(p<, 05)$

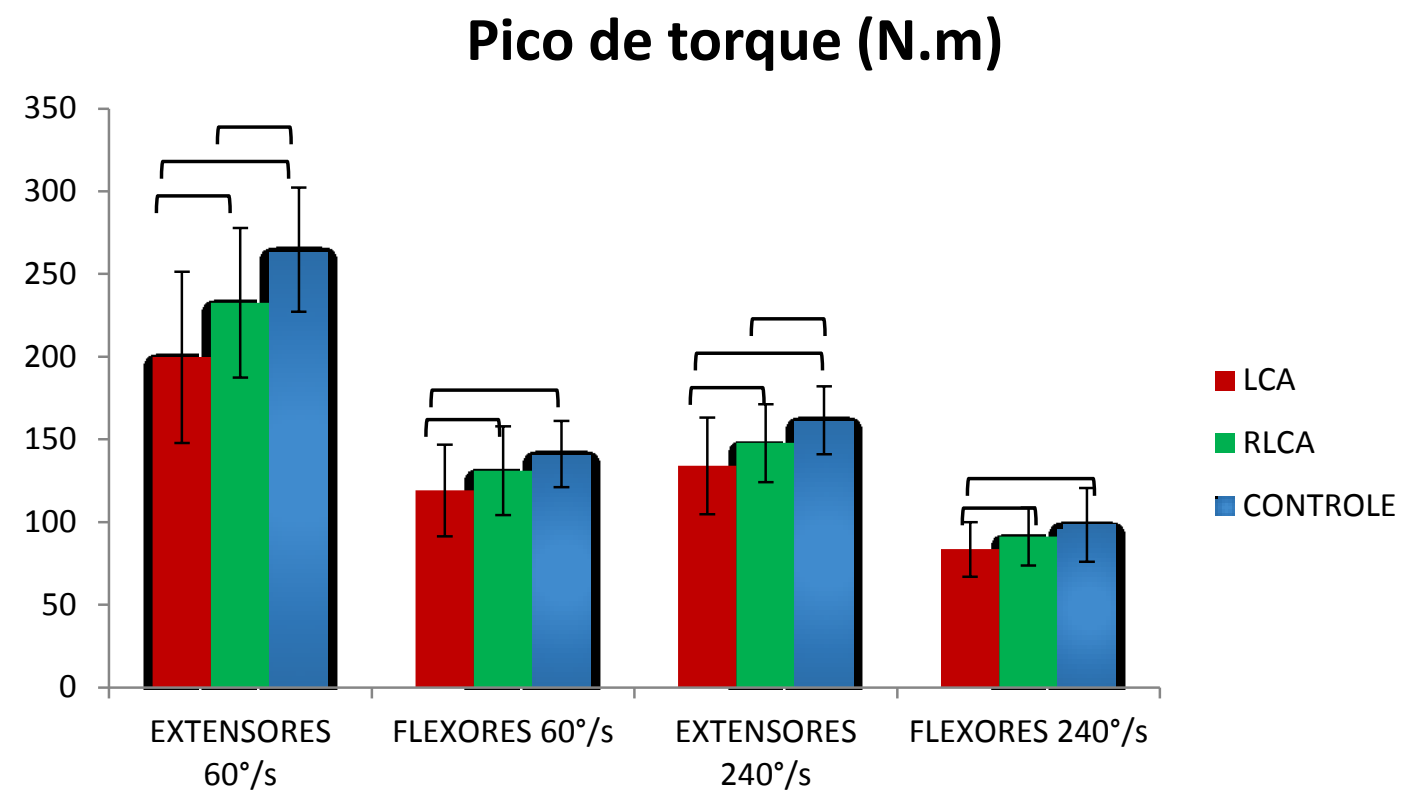

Gráfico 13 - Pico de torque dividido pela massa corpórea dos músculos extensores e flexores do joelho a $60 \%$ e $240 \%$, nos diferentes grupos. Os colchetes indicam diferença estatisticamente significativa $(p<, 05)$

\section{Pico de torque / massa corpórea (\%)}

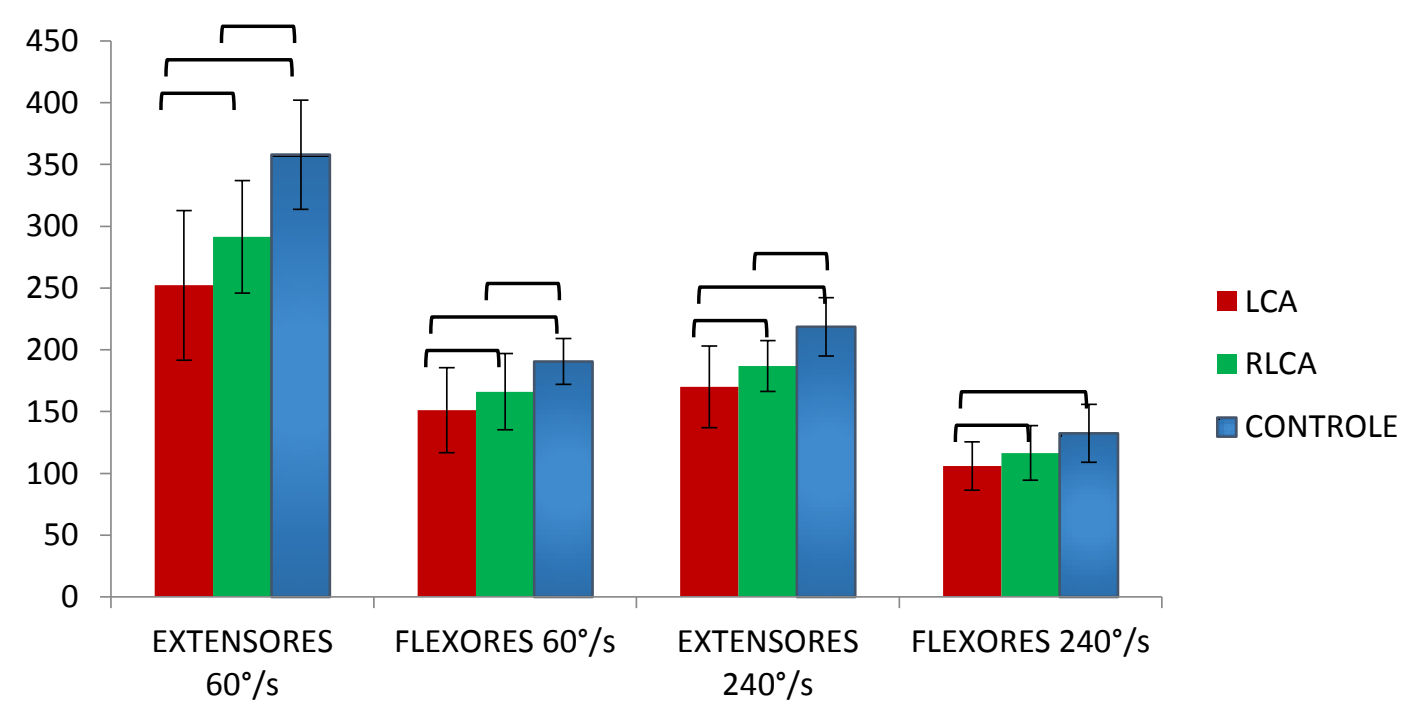

Gráfico 14 - Déficit de pico de torque comparado à perna contralateral dos músculos extensores e flexores do joelho a $60 \%$ e $240 \%$ sos 
diferentes grupos. Os colchetes indicam diferença estatisticamente significativa $(p<, 05)$

\section{Déficit de pico de torque (\%)}

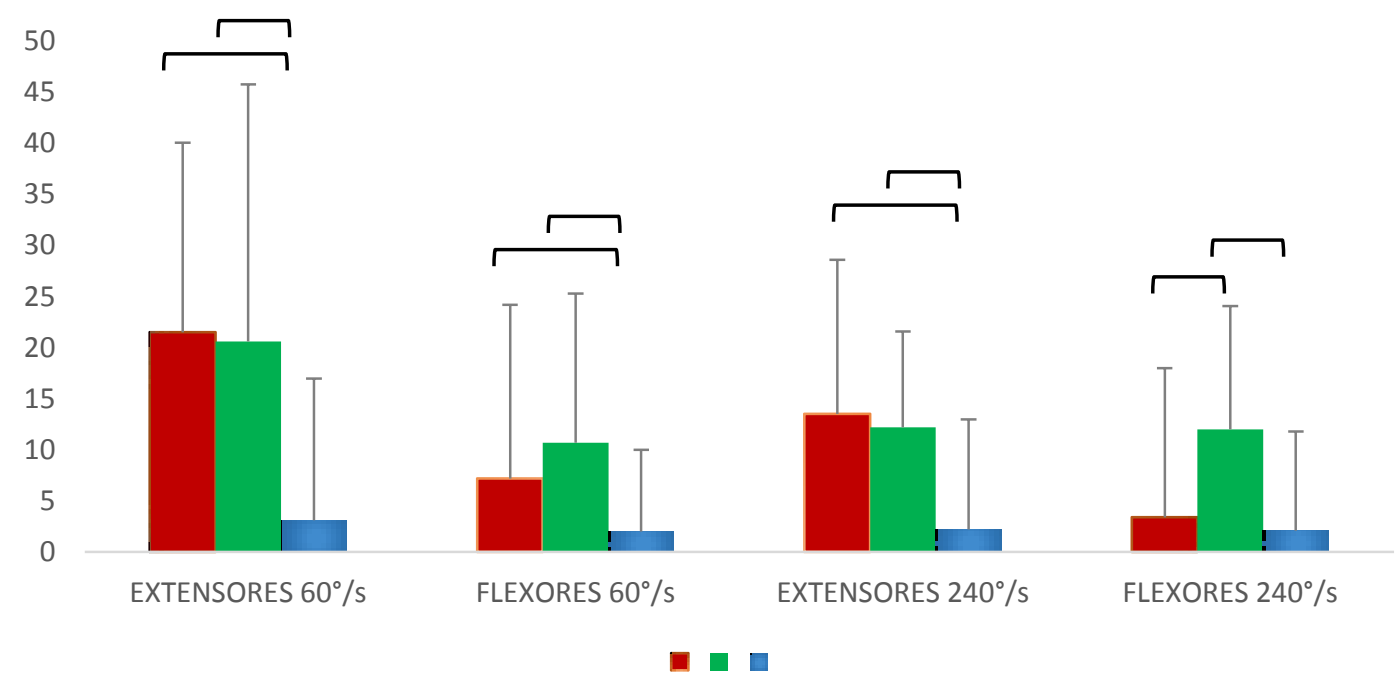

Gráfico 15 - Trabalho total dos músculos extensores e flexores do joelho a $60 \%$ e $240 \%$ nos diferentes grupos. Os colchetes indicam diferença estatisticamente significativa $(p<, 05)$

\section{Trabalho total (J)}

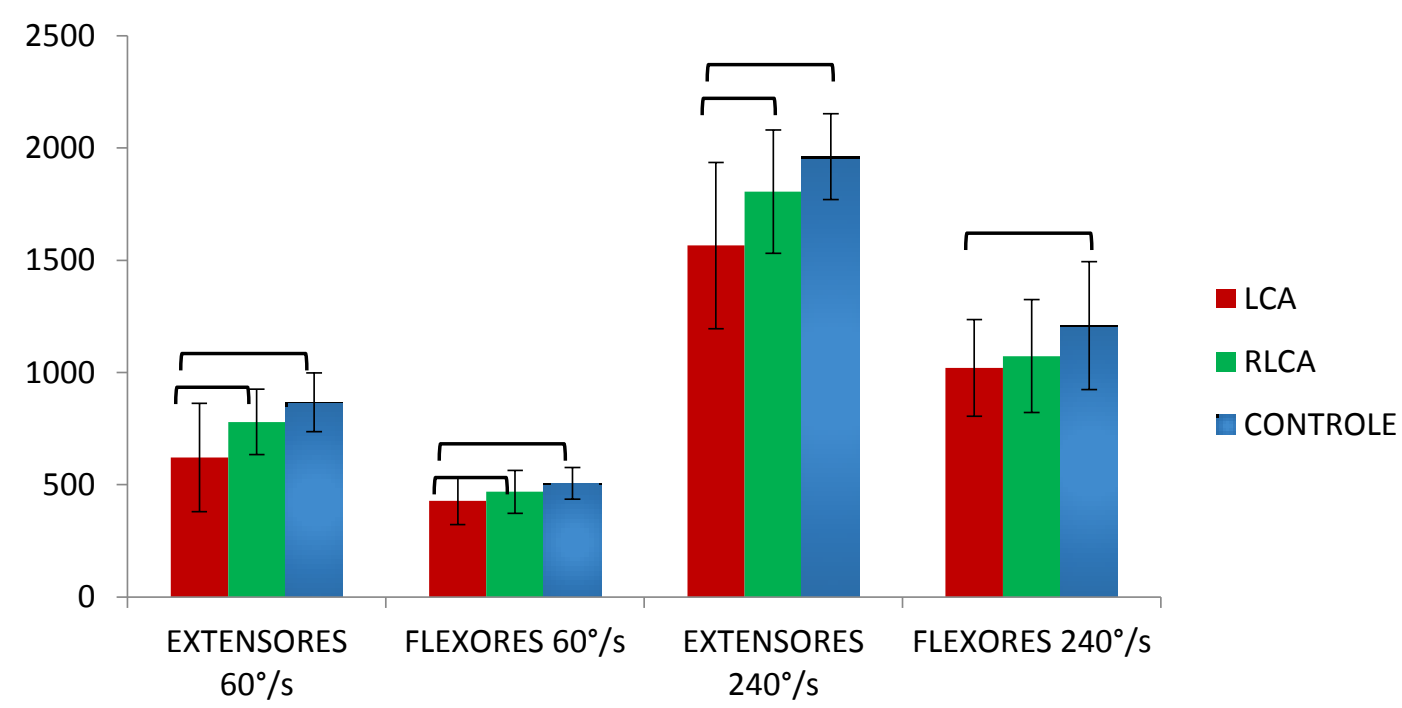


Gráfico 16 - Trabalho total dividido pela massa corpórea dos músculos extensores e flexores do joelho a $60 \%$ s e $240 \%$ s, nos diferentes grupos. Os colchetes indicam diferença estatisticamente significativa $(p<, 05)$

\section{Trabalho / massa corpórea (\%)}

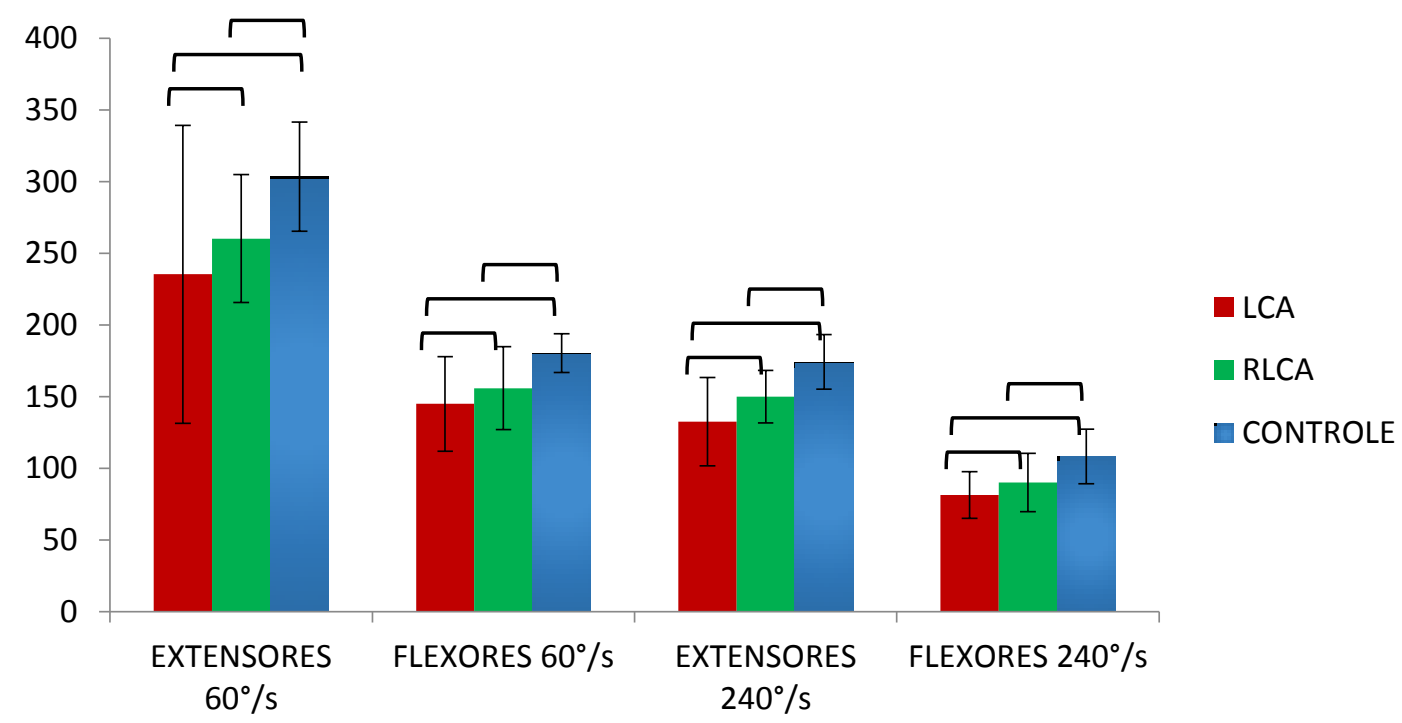

Gráfico 17 - Déficit de trabalho total comparado à perna contralateral dos músculos extensores e flexores do joelho a $60 \%$ s e $240 \%$ s nos diferentes grupos. Os colchetes indicam diferença estatisticamente significativa $(p<, 05)$

\section{Déficit de trabalho total}

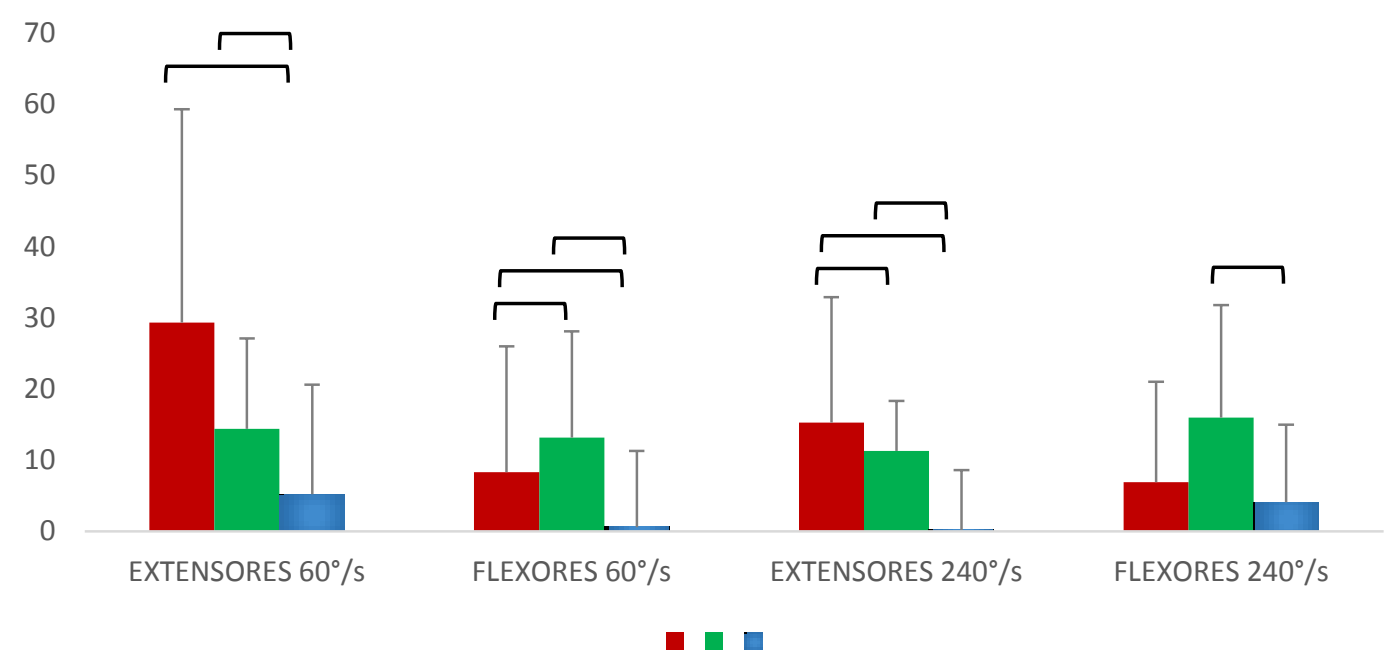


Gráfico 18 - Potência média dos músculos extensores e flexores do joelho a $60 \%$ e $240 \%$ nos diferentes grupos. Os colchetes indicam diferença estatisticamente significativa $(p<, 05)$

\section{Potência média (W)}

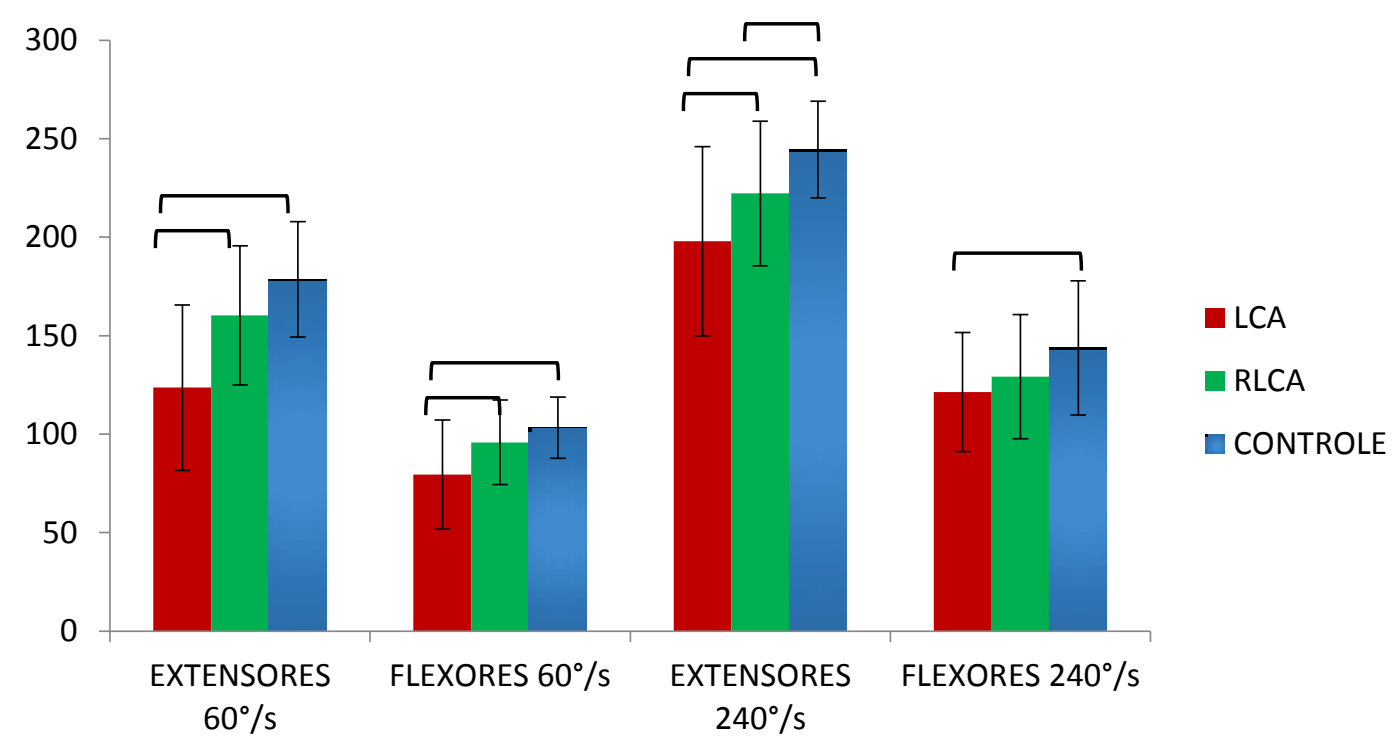

Gráfico 19 - Déficit de potência média comparada à perna contralateral dos músculos extensores e flexores do joelho a $60 \%$ e $240 \%$ s nos diferentes grupos. Os colchetes indicam diferença estatisticamente significativa $(p<, 05)$

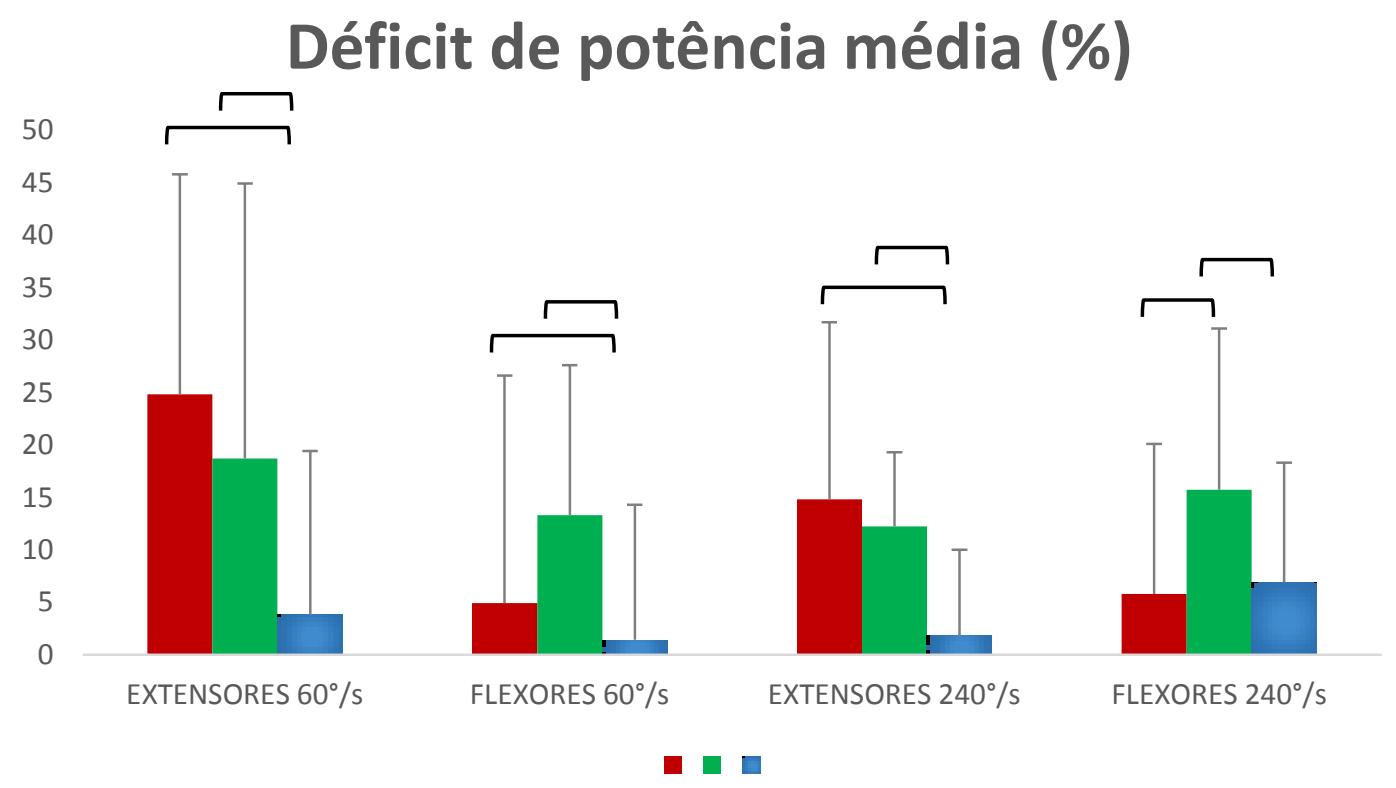


Gráfico 20 - Relação entre os músculos flexores/extensoresbdo joelho a $60 \%$ e $240 \%$ nos diferentes grupos (\%). Os colchetes indicam diferença estatisticamente significativa $(p<, 05)$

\section{Relação flexão / extensão}

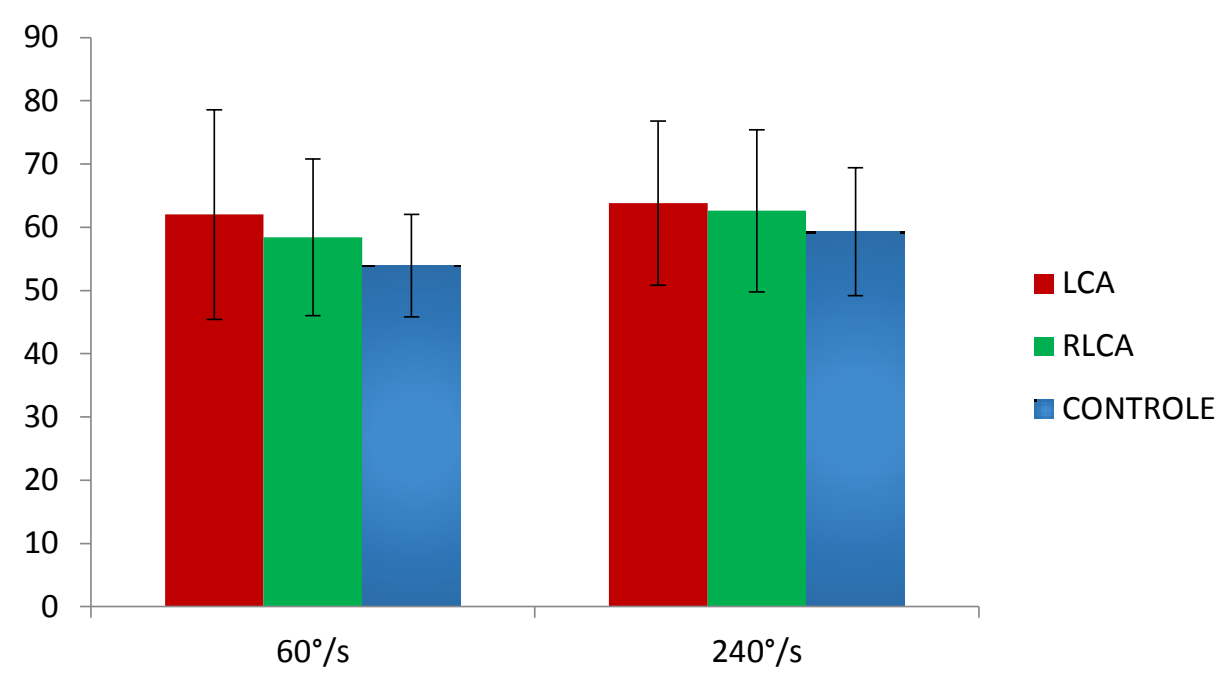

